\title{
5. Große Erwartungen und bittere Enttäuschung: Grimm, Kolbenheyer und Stapel in ihrem Verhältnis zur NSDAP
}

\subsection{Frühe Unterstützung und erste Fühlungnahme 1923-1930/31}

\begin{abstract}
Ich würde es nicht begrüßen, wenn der Radikalismus in unveränderter Form Oberhand auf lange Dauer erhielte, aber wenn der Nationalsozialismus nicht gekommen wäre, man hätte ihn erfinden müssen. ${ }^{1}$
\end{abstract}

Schon sehr früh nach dem Zusammenbruch des „Dritten Reichs“ hat Veit Valentin hellsichtig hervorgehoben, wie weitgehend die Geschichte des Nationalsozialismus und seines Aufstiegs als eine „Geschichte seiner Unterschätzung“2 verstanden werden kann. Speziell zur Erklärung der illusorischen Zähmungskonzeptionen $^{3}$ seitens der Eliten des politischen Konservatismus ist das Interpretament der „Unterschätzung“ fraglos von zentraler Bedeutung. Im Falle von Grimm, Kolbenheyer und Stapel würde hinsichtlich ihres Verhältnisses zur NSDAP vor 1933 ein allein auf „Unterschätzung“ abzielender analytischer Zugriff indes deutlich zu kurz greifen. Gewiss: Auch sie perzipierten die NS-Bewegung mitunter leichtfertig als eine vermeintlich rein episodenhafte Erscheinung, die kurzfristig für eigene Zwecke instrumentalisiert werden könnte und sollte. ${ }^{4}$ Eine erschöpfende Erläuterung ihrer Einstellungen ist damit jedoch keineswegs gewonnen. Ihre Wahrnehmung der NS-Bewegung war weder konstant, noch blieb sie ohne Ambivalenzen, wie ein Blick in die Quellen rasch lehrt. Die Annahme, Grimm, Kolbenheyer und Stapel wären sich in dem hier interessierenden Zeitfenster stets sicher gewesen, wie sie sich zum Nationalsozialismus stellen sollten und wie dieser als politische und soziale Bewegung einzuschätzen sei, wäre irrig und ginge an der empirischen Realität vorbei. Vielmehr lässt sich eine spannungs- und widerspruchsvolle Gleichzeitigkeit von Wohlwollen und Skepsis, Hoffnung und Verunsicherung,

\footnotetext{
KAG, Erwin Guido Kolbenheyer an Jakob Schaffner, 25. Oktober 1930 (Durchschlag).

Valentin, Geschichte, S. 284.

3 Vgl. Jasper, Zähmung.

4 In seiner im Juni 1931 verfassten internen Denkschrift Sechs Sätze zur Entwicklung der Verlagsunternehmungen des D.H.V. vertrat Stapel etwa die Auffassung, dass „der Nationalsozialismus [...] wahrscheinlich nur eine Durchbruchskraft" darstellen, die nach ihrem zu wünschenden und zu erwartenden Erfolg praktisch überflüssig werden und die politische Arena einer "nationalbolschewistische[n] " und einer "national-konservative[n] " Front überlassen würde. Wohl müsse der DHV also schon aus Eigeninteresse „engste Fühlung mit dem Nationalsozialismus halten“, ohne sich aber „an ihn zu binden“. Es gelte, sich „auf die nach dem Nationalsozialismus kommenden Fronten" einzustellen (zitiert aus der Beilage des Briefs von Wilhelm Stapel an Erwin Guido Kolbenheyer vom 19. Juni 1931, in: KAG, Schriftwechsel mit Wilhelm Stapel: 1930-1931, Herv. i. Orig.).
} 
Unterschätzung und Bedeutungszuschreibung beobachten. Im Folgenden soll zunächst der Umgang mit der NS-Bewegung vor der Reichstagswahl vom 14. September 1930 interessieren, die den politischen Durchbruch der NSDAP einläutete ${ }^{5}$, ehe anschließend die Reaktionen auf den spektakulären Wahlerfolg der Nationalsozialisten skizziert werden.

Die Verteidigung des Hitler-Putschs durch StaPel und grimm - In den Jahren 1920-1922 schenkten Grimm, Kolbenheyer und Stapel der NSDAP noch keine nähere Aufmerksamkeit. Dies vermag freilich nicht zu überraschen, blieben die Nationalsozialisten im Vorfeld ihres aufsehenerregenden Debakels vor der Münchner Feldherrnhalle und dem anschließenden, vielbeachteten Hitler-Prozess doch eine Randerscheinung des politischen Lebens, eine völkische Splitterpartei unter vielen, die - zumal außerhalb Bayerns - kaum der Rede wert war. Der Putschversuch ${ }^{6}$ veranlasste Grimm und Stapel dann allerdings, sich öffentlich zu Wort zu melden. Konkret war es die spöttische Presseberichterstattung über den kläglich misslungenen Putschversuch, die Grimm und Stapel als unangemessen kritisch und destruktiv empfanden und die sie zur Widerrede motivierte. Kolbenheyer hielt sich demgegenüber bedeckt. Die für so viele Autoren der Weimarer Republik nachweisbare Sensibilität, keinesfalls in den Ruf zu geraten, einseitig parteipolitisch orientiert oder gar gebunden zu sein, war bei ihm besonders stark ausgeprägt und ein elementarer Bestandteil seines Selbstverständnisses als Künstler. Das immer wache, intrinsische Bedürfnis, die Chimäre präferenzloser Überparteilichkeit aufrechtzuerhalten, prägte das öffentliche und private Auftreten Kolbenheyers noch stärker als jenes von Grimm und Stapel - jedenfalls in den Jahren der Weimarer Republik. 1940 sollte sich Kolbenheyer aus euphorischer Zustimmung zur nationalsozialistischen Außenpolitik dann jedoch zum Parteieintritt in die NSDAP entschließen. ${ }^{7}$

Stapel begann bereits über ein halbes Jahr vor Hitlers Putschversuch damit, in seiner Zeitschrift schützend für die junge NSDAP einzutreten. Im Februar 1923 wies er das „große Geschrei“, das sich schon damals wegen des rabaukenhaften politischen Auftretens der Nationalsozialisten erhob, als unberechtigt zurück. Stapel war hierbei indes weniger darum bemüht, politische Einzelforderungen der NSDAP zu verteidigen, vielmehr versuchte er, seine Leser von dem angeblichen außenpolitischen Wert der Nationalsozialisten für das gesamte Deutsche Reich zu überzeugen: Ohne das von den Nationalsozialisten geschürte und lebendig erhaltene „nationale Feuer in Bayern“, so versuchte er plausibel zu machen, „würde der Damm der Deutschböhmen allein die Tschechen nicht abhalten, den Franzosen

5 Die NSDAP vereinigte bei der Wahl 18,3\% der abgegebenen Stimmen auf sich und wurde mit 107 Mandaten zur zweitstärksten Partei im Reichstag hinter der SPD mit 143 Mandaten.

6 Vgl. Gordon, Hitlerputsch 1923; Kershaw, Hitler, Bd. 1, S. 253-267. Gedankenanstöße zu einer Neubewertung des Putschs in: Dotterweich, „Hitlerputsch“.

7 Vgl. Kap. 5.3.2. 
mainabwärts entgegenzustürmen"8. Auch zum rabiaten Antisemitismus, der gerade in den frühen 1920er Jahren die öffentlichen Auftritte der Nationalsozialisten entscheidend prägte, nahm Stapel Stellung und argumentierte, dass dieser in der republikanischen Öffentlichkeit viel zu kritisch und nervös betrachtet werde. Er forderte stattdessen - hier kommt das Element der Unterschätzung sehr deutlich zum Ausdruck -, der NS-Bewegung mehr guten Willen zuzugestehen: Hatten die Nationalsozialisten nicht „selbst das Wort ausgegeben, Zucht zu halten“? Niemand „außer den Sensationisten [sic!]“, so behauptete Stapel, könne Anlass dazu haben, an dem „guten Willen“ der Nationalsozialisten „zu zweifeln“. Kritikern der NSDAP warf Stapel vor, sich „Gespenster“ vorgemacht, die „Hauptsache“ jedoch aus dem Blick verloren zu haben: Es sei „wichtiger, daß die Tschechen sich nicht an den Main getrauen, als daß etliche empfindliche und ängstliche jüdische Gemüter sich nicht nach München getrauen“9.

Wie nah sich Stapel zum damaligen Zeitpunkt den radikalen politischen Positionen der Nationalsozialisten angenähert hatte und verbunden fühlte, zeigt ein Brief an Kolbenheyer vom 19. Oktober 1923. Der Brief entstand vor dem Hintergrund der am 26. September 1923 getroffenen Entscheidung der Reichsregierung unter Gustav Stresemann, die Politik des „Passiven Widerstands“ gegen die französisch-belgische Ruhrbesetzung zu beenden. Auch wenn diese Entscheidung eindeutig wirtschaftlicher Vernunft und politischem Verantwortungsbewusstsein entsprach ${ }^{10}$, führte sie bei Stapel - wie bei zahlreichen anderen Autoren des rechten Lagers ${ }^{11}$ - zu einer zusätzlichen Verhärtung republikfeindlicher, antidemokratischer Überzeugungen. Stapels Brief an Kolbenheyer geht dabei an Schärfe noch deutlich über seine publizistischen Äußerungen während des Krisenjahrs $1923^{12}$ hinaus. Hitler, so Stapel, habe „ganz recht“ gehabt:

„man hätte sämtliche Zechen und Hochöfen sprengen und verbrennen sollen im Ruhrgebiet. Was liegt uns an der Industrie! Die Söhne können sich eine neue Industrie schaffen, wenn sie noch nicht genug von dem Zeugs haben! Wir müssen erst die Freiheit behaupten und soviel Franzosen zu Tode befördern, als wir irgend können. Aber der träge sozialdemokratische Diätenspeck in Berlin bangt ja für die ,Kultur', d. h. für das, was er dafür hält"13.

8 Deutsches Volkstum. Monatsschrift für das deutsche Geistesleben 5 (1923), S. 82. Die Vorstellung einer „Invasion der verhältnismäßig gutorganisierten tschechischen Armee“ in deutsches Territorium bildete in der Frühphase der Republik ein „permanentes Schreckgespenst“; allerdings „,folgten den immer wiederkehrenden Gerüchten über bevorstehende Großangriffe aus dem Osten zu keiner Zeit reale Taten." (Keller, Wehrmacht, S. 138f.).

${ }^{9}$ Deutsches Volkstum. Monatsschrift für das deutsche Geistesleben 5 (1923), S. 82.

10 Zum französisch-belgischen Ruhrbesetzung und der - aus wirtschaftlicher wie sozialpolitischer Perspektive - notwendigen Beendung der Politik des "Passiven Widerstands" durch die deutsche Reichsregierung vgl. Krüger, Außenpolitik, bes. S. 132-206; Fisher, Crisis, sowie die aufschlussreichen, deutsche und französische Perspektiven vereinigenden Beiträge in: Schwabe (Hg.), Ruhrkrise; Krumeich/Schröder (Hg.), Schatten.

${ }^{11}$ Vgl. Köhler, Nachkrieg.

12 Vgl. hierzu Keßler, Stapel, S. 72-78.

${ }^{13}$ KAG, Wilhelm Stapel an Erwin Guido Kolbenheyer, 19. Oktober 1923 (Herv. i. Orig.). Stapel spielte hier sehr wahrscheinlich auf eine schon zeitgenössisch beachtete, radikale Rede Hitlers vom 21. August 1923 im Münchner Zirkus Krone vor rund 8000 Zuhörern an, in der Hitler unter anderem ausführte: „Was hat es zu sagen, wenn in der Katastrophe unserer Gegenwart 
Als Hitler nur wenige Wochen später mit seinem Putschversuch gescheitert war, setzte Stapel seine öffentliche Verteidigung der Nationalsozialisten im Deutschen Volkstum fort. Dabei argumentierte er, dass am 9. November zwar „offensichtlich verfrüht“ losgeschlagen worden sei, jedoch keinerlei Veranlassung bestehe, den Putschversuch als eine „Riesendummheit“ abzuwerten, wie es „Stammtische“ und „Literaten an ihren Pulten"14 mit Vorliebe täten. Das Scheitern des Putschversuchs sei vor allem mit Blick auf die „moralische[n]“ Folgen für das deutsche Volk zu bedauern. Der Misserfolg müsse sich insbesondere auf die „begeisterte Jugend“ verheerend auswirken: Ludendorff und Hitler seien „die einzigen“ Persönlichkeiten gewesen, die das „nationalen Empfindungen zugänglich[e]“ Volk noch hätten „begeistern können“; „anständige Männer“, die von den „tausend taktischen Kunstgriffen" der Politik unberührt geblieben seien, suche man in Deutschland ansonsten leider vergeblich. Nun, nach dem Scheitern des Putschs, werde das „neue Deutschland [...] nicht aus der jugendlich-schönen Kraft der Begeisterung und des Heroismus erschaffen“, sondern aus „nüchtern-kluge[r] Berechnung“. Damit drohte dem deutschen Volk in den Augen Stapels das Schicksal, „Zu einem bloßen Aktionsfeld für geldmachende Großfinanziers und kluge, undurchsichtige Reichswehrgeneräle“ herabzusinken, „zwischen denen allerlei Parteigrößen hinund herwanken "15 würden.

Mehr noch als jener Hitlers, schmerzte Stapel der Ansehensverlust Ludendorffs, den er aus „persönlicher Unterhaltung " 16 kannte. In einem Brief an Kolbenheyer vom 19. November 1923, in dem seine damalige Ludendorff-Begeisterung ${ }^{17}$ abermals deutlich vorscheint, bezeichnete Stapel das Bild, das von Ludendorff „durch die Zeitungen gerollt“ werde, als „saudumm“18. Die Weimarer „Literaten“ könnten „dieser Art Mensch (ausgesprochen nordisch) nicht gerecht werden“. Ludendorff sei „nicht ,Putschist“ - darüber habe er sich „seinerzeit in München ausführlich mit ihm in seiner Villa unterhalten.“ Ludendorff sei vielmehr „einer der anständigsten, mutigsten Menschen, die je gelebt“ hätten. „Tief ethisch, stark protestantisch. Fähig, abweichende Meinungen sorgfältig anzuhören.“ Durch das

Industrieanlagen zugrunde gehen? Hochöfen können bersten, Kohlengruben ersaufen, Häuser mögen zu Asche verbrennen - wenn nur ein Volk dahinter aufsteht, unerschütterlich, zum Letzten entschlossen. Denn wenn das deutsche Volk wieder aufersteht, dann wird auch das andere alles wieder aufstehen. Wenn aber alles das stünde und ein Volk geht an innerer Fäulnis zugrunde, so sind Kamine, Industriewerke und Häusermeere nichts anderes als die Leichensteine dieses Volkes! [...] Hinter dem brennenden Ruhrgebiet hätte ein solches Volk seinen Widerstand auf Tod und Leben organisiert. [...] So hätte [Wilhelm] Cuno die Ruhrfrage zum Anlaß nehmen müssen, unter entschlossener Nutzung der emporflammenden Stimmung des ganzen Volkes zu zeigen: jetzt bricht eine andere Stunde an. Ofen um Ofen, Brücke um Brücke gesprengt! Deutschland erwacht! Frankreichs Armee hätte sich nicht in das Grauen eines solchen Weltuntergangs peitschen lassen! Bei Gott, wir ständen heute anders da!“" (Kuhn, Programm, S. 79; vgl. auch: Jäckel/Kuhn (Hg.), Hitler, S. 982).

14 Deutsches Volkstum. Monatsschrift für das deutsche Geistesleben 5 (1923), S. 455.

15 Ebd. (Herv. i. Orig.).

${ }^{16}$ KAG, Wilhelm Stapel an Erwin Guido Kolbenheyer, 19. November 1923.

17 Vgl. Kap. 2.2.1.

${ }^{18}$ KAG, Wilhelm Stapel an Erwin Guido Kolbenheyer, 19. November 1923. 
„Münchener Schlamassel“ sei Ludendorff „ganz rein hindurchgegangen“, der „Zeitungspöbel“ aber bewerfe ihn nun „am meisten mit Dreck“"19. Wen Stapel mit dem „Zeitungspöbel“ meinte, stellte er im Deutschen Volkstum unmissverständlich klar: Die Pressekritik an Ludendorff und Hitler führte Stapel auf die „journalistische Technik gewisser jüdischer und jüdisch geschulter Literaten“ zurück, die darauf zielten, die beiden außergewöhnlichen und mutigen Männer „beim Volke durch Lächerlichmachung zu entwerten "20 - ein antisemitischer Topos, den kurze Zeit später auch Hitler in seinen Arbeiten an Mein Kampf aufgreifen sollte. ${ }^{21}$ Allzu leichtfertig, so Stapel, werde vergessen, dass es Ludendorff gewesen sei, der im Ersten Weltkrieg mit noch nicht einmal „dem halbe[n] deutsche[n] Heer [...] Rußland zu Boden“ geschlagen habe. Ein solcher Mann, so folgerte Stapel, könne prinzipiell „nichts Lächerliches“ tun. Niemand solle sich durch die ,jüdische“ Berichterstattung „verwirren lassen“: Hitler und Ludendorff hätten in München mit „leidenschaftlich glühende[n] Seelen und einem lauteren Willen für Deutschlands Ehre und Größe“ gefochten. Darin werde auch Gustav Ritter von Kahr, der aus dem Putschversuch als Sieger hervorgegangen sei, „sie nicht übertreffen“22 können.

Im Januar 1924 war es dann weniger Ludendorff als Hitler, den Stapel im Deutschen Volkstum mit besonderem Nachdruck gegen öffentliche Kritik verteidigte. Nun war es Hitlers Aufbau und Konsolidierung der NSDAP seit 1919/20, die er als eine „Leistung“ bezeichnete, die „Achtung“ abnötige und verdiene. Wer Hitler einmal „selbst reden gehört“ habe, gelange rasch zur Einsicht, dass es sich bei ihm um „einen Menschen [handle], der redlich sein Bestes gab“23 - etwas, das sich von seinen journalistischen Kritikern nicht behaupten lasse. Ludendorff wiederum, so hieß es nun, sei bei dem Putschversuch „nur mitgegangen, als die Vertreter der höchsten bayrischen Gewalt“ ebenfalls mitgegangen seien. Dass Ludendorff - anders als Kahr und Lossow - sein Wort nicht „auf einen halben Wink hin“ zurückgenommen habe, mache ihm „Ehre, nicht Unehre“24. Mit diesem Versuch, zwischen Ludendorff einerseits und dem eigentlichen Putschisten-Kreis andererseits zu unterscheiden, nahm Stapel in gewisser Weise die Begründung vorweg, die bei der Urteilsverkündung des Münchner Hochverratsprozesses am 1.April

19 Ebd. (Herv. i. Orig.).

${ }^{20}$ Deutsches Volkstum. Monatsschrift für das deutsche Geistesleben 5 (1923), S. 455.

${ }^{21}$ Siehe das Kapitel „Persönlichkeit und völkischer Staatsgedanke“, in dem Hitler „die destruktive Wirkung der Tätigkeit des Judentums in anderen Volkskörpern“ auf die „ewigen Versuchen“ der Juden zurückführt, „die Bedeutung der Person bei seinen Gastvölkern zu unterhöhlen und die Masse an ihre Stelle zu setzen“. Auf diese Weise trete "an Stelle des organischen Prinzips der arischen Menschheit das destruktive des Juden“" (Hitler, Kampf, Bd.2, S. 85f.). Auch Theodor Fritsch hatte schon in seinem einflussreichen, vielfach aufgelegten Handbuch der Judenfrage die Juden bezichtigt, demokratisches und kommunistisches Gedankengut nur deshalb zu „predigen“, um auf diesen „Umweg zur Aufrichtung der jüdischen Weltherrschaft mit Hilfe des betörten Proletariats" zu gelangen (Fritsch (Hg.), Handbuch, S. 634).

${ }^{22}$ Deutsches Volkstum. Monatsschrift für das deutsche Geistesleben 5 (1923), S. $455 f$ f.

${ }^{23}$ Deutsches Volkstum. Monatsschrift für das deutsche Geistesleben 6 (1924), S. 45.

${ }^{24}$ Ebd. 
1924 für den Freispruch Ludendorffs aufgeführt wurde: Der Urteilsbegründung zufolge war Ludendorff ,von den Ereignissen so ergriffen gewesen, daß er nichts von dem Hochverrat merkte, der um ihn her vor sich ging " 25 .

Stapels Verbundenheit mit den Putschisten und der nach dem Putschversuch verbotenen NSDAP war zu diesem Zeitpunkt so stark, dass er sich bei den Reichstagswahlen vom 4. Mai 1924 sogar als parteiloser Zweitkandidat hinter Ernst Graf zu Reventlow für die Hamburger Wahlliste der Nationalsozialistischen Freiheitspartei zur Verfügung stellte, die sich aus Mitgliedern der NSDAP und der kurz zuvor ebenfalls verbotenen Deutschvölkischen Freiheitspartei zusammensetzte. ${ }^{26}$ Das Schicksal, sich mit dem ihm so verhassten Parlamentarismus näher auseinandersetzen zu müssen, blieb Stapel indes erspart: Seine Kandidatur blieb erfolglos. ${ }^{27}$

Gänzlich frei von Kritik blieb Stapels Publizistik zur NSDAP in den 1920er Jahren indes nicht. Im Vordergrund standen hier jedoch weder ethische noch weltanschauliche, sondern organisatorische und strategische Fragen. So kritisierte Stapel im April 1925 in der von Hermann Ullmann herausgegebenen Politischen Wochenschrift, dass die NSDAP und ihr „Führer“ nach Neugründung der Partei im Februar 1925 abermals die Stadt München zu ihrer Zentrale erkoren hatten und nicht etwa Berlin. Unter dem Titel Hitlers falscher Ansatz behauptete Stapel, dass jeder Politiker mit ,historisch-politische[m] Gefühl“ intuitiv erfassen müsse, dass vom deutschen Süden her lediglich „Anregungen ausgehen“ könnten, „aber nicht Entscheidungen “28. Hitlers Entscheidung, die nationalsozialistische Bewegung abermals von der bayerischen Landeshauptstadt aus aufbauen und leiten zu wollen, glich nach Stapel dem Versuch, „mit den Karten [eines] zusammengestürzten Kartenhauses zum zweitenmal in derselben Weise" bauen zu wollen: „Wiederholung statt Originalität“. Dass die „nationale Bewegung“ 1919/20 „in München kulminiert“ sei, galt Stapel vor dem Hintergrund der Münchner Räterepublik noch als erklärlich; dass „sie nun abermals in München beginnen" solle, sei hingegen allein "durch die Gewohnheit motiviert" und Zeichen von „Ermattung“29.

Auch im Falle Grimms lässt sich eine frühe publizistische Unterstützung der NSDAP nachweisen. Dass er schon früh zu einem Anhänger der Nationalsozialisten geworden war, hob Grimm sowohl öffentlich als auch privat wiederholt hervor. So bekannte er etwa in einem Wahlaufruf zugunsten Hitlers vor dem zweiten Wahlgang der Reichspräsidentenwahl am 10.April 1932, „erst recht nach dem

${ }^{25}$ Hoegner, Radikalismus, S. 113.

${ }^{26}$ Vgl. Sauer, Freiheitspartei. Dass Hitler sämtliche Parteineugründungen mit dem Begriff „nationalsozialistisch" nach dem Verbot der NSDAP entschieden ablehnte, da er seinen alleinigen Führungsanspruch von ihr gefährdet sah, dürfte Stapel damals unbekannt gewesen sein.

271938 vermerkte Stapel rückblickend, dass er seinen Misserfolg als „Wink des Schicksals“ verstanden habe, „nicht in die praktische Politik zu gehn, sondern meiner 1918 erwählten Aufgabe treu zu bleiben. Ich lehnte es fortan ab, in Parteiversammlungen zu sprechen - auch bei den Deutschnationalen sprach ich nicht." Vgl. Stapel, Jahre [1938], S. 801.

28 Stapel, Ansatz, S. 188 (Herv. i. Orig.).

${ }^{29} \mathrm{Ebd}$. 
9. November 1923“ zum NSDAP-Wähler geworden zu sein: „Ich, der Parteilose, stimmte für die nationalsozialistische Partei trotz vielem, das mich störte, um der Bewegung willen, die um die Partei entstand und durch die Partei gehalten wurde wie der Leib durch die Knochen. “30 Bereits kurz zuvor hatte Grimm seine langjährige Verbundenheit zur NSDAP, ebenso wie seine persönliche Bekanntschaft mit Hitler, auch in einem Brief an den Hamburger Großreeder Kurt Woermann hervorgehoben, mit dem er aus der Deutschen Kolonialgesellschaft bekannt war: „Ich bin ein Freund des Nationalsozialismus nicht seit den letzten zwei Jahren sondern vom Tage seiner Entstehung an.“31 Zwar sei er „der Partei nicht beigetreten“, habe aber, „wo ich konnte, im Stillen für die Bewegung gearbeitet.“ Ein mögliches „Mißlingen des Nationalsozialismus“ galt Grimm als „das Mißlingen unserer Zukunft. Ich kenne Hitler persönlich und schätze ihn“32.

Es wäre zu einfach, hinter diesen Äußerungen lediglich eine bloße Anbiederung an die damals dynamisch aufstrebende NSDAP zu erblicken. Mit Joseph Goebbels hatte Grimm bereits im Frühjahr 1927 den Kontakt gesucht ${ }^{33}-$ zu ei- $^{2}$ nem Zeitpunkt also, an dem der spätere Aufstieg der NSDAP zur erfolgreichen Massenpartei noch keineswegs absehbar war. Auch hatte Grimm, wie gezeigt, seine Sympathien für die Nationalsozialisten schon vor großem Publikum in Volk ohne Raum (1926) kundgetan, indem er am Ende des Romans in einer Passage, die im nationalsozialistischen Lager wohlbekannt war, eine Lanze für die Münchner Putschisten brach: Den Märtyrertod seines Romanhelden Cornelius Friebott datierte Grimm „knapp vor jenem neunten November 1923 in München“, an dem einige „Wagemutige und Sehnsüchtige [...] von anderen Deutschen“ zusammengeschossen worden seien, während „Wortemacher rundum regierten“34.

Diese den dezisionistischen Aktivismus der NS-Bewegung zelebrierende Passage war jedoch nicht die einzige Referenz auf den Hitler-Putsch während der 1920er Jahre. Schon am 22. September 1924 hatte Grimm im Hannoverschen Kurier seinem politischen Frust freien Lauf gelassen, als er mit Entsetzen die Bereitschaft von etwa der halben DNVP-Reichstagsfraktion verfolgte, den Dawes-Plan

${ }^{30}$ Grimm, Antwort [1932], S. 17. Der Artikel erschien ursprünglich im Göttinger Tageblatt am 7. April 1932.

${ }^{31}$ DLA, A:Grimm, Hans Grimm an Kurt Woermann, 9. März 1932.

32 Ebd. Die Bekanntschaft Grimms mit Hitler ging auf ein „Reichskolonialtreffen“ in Stuttgart im Jahr 1928 zurück, bei dem Hitler gegenüber Grimm geäußert haben soll, Volk ohne Raum von mehrfachem Lesen her zu kennen (vgl. Franke, Grimm, S. 25; Gümbel, Volk, S. 73). Eine zweite flüchtige Begegnung mit Hitler ergab sich im Oktober 1931 auf der Tagung in Bad Harzburg. Da die Forderung nach „Lebensraum“ zu den zentralen Kategorien der Weltanschauung Hitlers gehörte, ist ein Interesse an Grimms Roman durchaus plausibel. Indes hatte Hitler seit etwa 1928 infolge der sogenannten Legalitätstaktik „in der öffentlichen Bekundung seiner ,Lebensraum'- und ,Germanisierungs'-Ziele [...] eine Art ,Moratorium' eingelegt" (Wirsching, „Man kann nur Boden germanisieren“, S. 532, Anm.63). Für weiterführende Hinweise zum Stellenwert der „Raumfrage“ in der Weltanschauung Hitlers vgl. Jäckel, Weltanschauung, S. 29-54.

${ }^{33}$ Vgl. Kap. 5.2.4.

${ }^{34}$ Grimm, Volk [1927], Bd. 2, S. 663 f. Für weitere Details zu dem Roman vgl. den Exkurs im Anschluss an Kap. 2.2.1. 
zu unterstützen ${ }^{35}$, der in der rechtsradikalen, nicht zuletzt nationalsozialistischen Agitation heftig und mit zum Teil wüst antisemitischer Rhetorik attackiert wurde. ${ }^{36}$ In diesem Kontext ließ Grimm neben seiner Kritik an der DNVP auch seine Wertschätzung für die Münchner Putschisten durchscheinen. Als, so Grimm, „die agrarischen Deutschnationalen mit den Sozialdemokraten“ zum Dawes-Plan „zusammen ,Ja' sagten“, sei „das westliche Lachen ungeheuer gewesen “37. Durch die Kollaboration mit den Sozialdemokraten sei der gegen die sogenannte Weimarer „Erfüllungspolitik“ gerichtete, unbedingte Oppositionskurs der Deutschnationalen vor den Augen der Alliierten als „Bluff“ enttarnt worden. Angesichts dieser „Blamage“ hätten die Alliierten nun leichtes Spiel, dem deutschen Volk noch umfänglicher ihre Interessen aufzunötigen, zumal die deutsche Öffentlichkeit, so Grimm mit Blick auf den misslungenen Hitler-Putsch des Vorjahres, „von selbst bemüht" sei, „noch den nationalsozialistischen Versuch töricht zu machen und zu überwinden "38. Ebenso wie Stapel wollte Grimm also Hitler und Ludendorff nicht der Lächerlichkeit preisgegeben sehen. Nach seiner Auffassung sollte nicht unentwegt die mangelhafte Vorbereitung und Durchführung des Putschversuchs, sondern der hinter den äußerlichen Ereignissen stehende, bewunderungswürdige und vorbildliche nationale Idealismus der Putschisten erkannt und hervorgehoben werden.

Kolbenheyer Und DER „KAMPFBUnd FÜR DeUTSChe Kultur“ - Öffentliche Äußerungen Kolbenheyers zum Hitler-Putsch sind aus den 1920er Jahren nicht bekannt. Lediglich in seiner Autobiografie betonte Kolbenheyer, dass er als Privatperson den Münchner Putsch als einen Ausdruck der „erwachenden Lebenskräfte" des deutschen Volks wahrgenommen und begrüßt habe. Mit eigenwilliger Logik beschrieb er den Putsch im Rückblick als ein zugleich zeitgemäßes und verfrühtes Unterfangen: Der Putsch habe „Zweifellos der Not der Stunde“ entsprochen, sei „natürlich“ und „zeitgerecht" gewesen, sei zugleich jedoch „zu früh“ gekommen. Noch nach dem Zweiten Weltkrieg rätselte Kolbenheyer, warum das „politische Programm“ Hitlers vor dem Hintergrund des damaligen „verzweifelten Zustand[s] des deutschen Volkes“ nicht jedermann in seiner „Natürlichkeit, ja Selbstverständlichkeit" eingeleuchtet habe. ${ }^{39}$ Dass Kolbenheyer hier tatsächlich sämtliche Punkte des Parteiprogramms der NSDAP vom 24. Februar 1920 vor Augen hatte, ist indes unwahrscheinlich. Seine weiteren Ausführungen lassen

${ }^{35}$ Vgl. Büttner, Weimar, S. 350-353.

${ }^{36}$ In der NS-Zeitschrift Der Weltkampf konstatierte etwa Gregor Straßer: „Der Dawesplan ist nichts anderes als das jüdische Versailles der deutschen Volkswirtschaft" (Der Weltkampf 2 (1925), S. 625-644, hier S. 629). Verwiesen sei auch auf Alfred Rosenbergs Pamphlet Die internationale Hochfinanz als Herrin der Arbeiterbewegung in allen Ländern (1925), in dem behauptet wird, durch den Dawes-Plan habe sich die von ,jüdischem Finanzkapital“ getragene "amerikanische Hochfinanz" zum „eigentliche[n] Regent[en] Deutschlands“ erhoben (Rosenberg, Hochfinanz, S. 26f.).

37 Grimm, Kolonialpläne [1924], S. 37

${ }^{38}$ Ebd.

${ }^{39}$ Kolbenheyer, Sebastian Karst, Bd. 2, S. 415 f. 
vielmehr vermuten, dass er auch hier einer - für seine Autobiografie so typischen wie bezeichnenden - selektiven Wahrnehmung des Nationalsozialismus unterlag. Das Programm der NSDAP reduzierte er im Wesentlichen auf zwei Ziele: Erstens die Revision der Versailler „Friedensdiktate“, zweitens den „Zusammenschluß aller deutschen Stämme“ zu einem von „Stammesdeutschen getragen[en]“, "gleichberechtigte[n] Großdeutschland“40. Ausgespart blieben in dieser nachgerade banalen Verengung freilich insbesondere die offensiven antisemitischen Inhalte des Programms. ${ }^{41}$ Während der Weimarer Republik hielt sich Kolbenheyer demgegenüber mit öffentlichen Sympathiebekundungen für die NS-Bewegung weitgehend zurück. Unter keinen Umständen wollte er vor den Augen der Öffentlichkeit als ein im parteipolitischen Sinne nationalsozialistischer Dichter angesehen werden.

Dieses Kalkül - sowie seine gleichzeitige Solidarisierung mit den Zielen der NS-Bewegung - versuchte Kolbenheyer auch Alfred Rosenberg plausibel zu machen, nachdem ihn dieser im Juni 1929 als Vorsitzender des KfdK $^{42}$ kontaktiert und zur Mitarbeit aufgefordert hatte. ${ }^{43}$ Dass sich Rosenberg bereits wenige Monate nach der Gründung des Kampfbunds um eine Zusammenarbeit mit Kolbenheyer bemühte, kann Kenner von Rosenbergs Der Mythus des 20. Jahrhunderts $(1930)^{44}$ nicht überraschen. So ließ der „Chefideologe“ der NSDAP in seinem weltanschaulichen Hauptwerk keinen Zweifel daran, in welch hohem Ansehen Kolbenheyer bei ihm stand, als er dessen Paracelsus-Trilogie - gemeinsam mit Grimms Volk ohne Raum - als ein Werk mit „Ewigkeitswert“45 zelebrierte. Darüber hinaus musste auch die christentumsfeindliche Tendenz in Kolbenheyers Paracelsus-Trilogie das Gefallen des NS-Ideologen finden. ${ }^{46}$

${ }^{40}$ Ebd. Weitere Informationen zu Kolbenheyers Ausdeutung des Nationalsozialismus nach dem Zweiten Weltkrieg in Kap. 6.2.

${ }^{41}$ Vgl. Mommsen (Hg.), Parteiprogramme, S. 547-552. Siehe darin - ausgehend von Programmpunkt 4 („Staatsbürger kann nur sein, wer Volksgenosse ist. Volksgenosse kann nur sein, wer deutschen Blutes ist, ohne Rücksichtnahme auf Konfession. Kein Jude kann daher Volksgenosse sein") - die Forderung nach einer „Fremdengesetzgebung" für Juden (Punkt 5), nach deren Ausschluss aus allen öffentlichen Ämtern (Punkt 6), nach deren Einwanderungsverbot (Punkt 8) und nach deren Ausweisung bei unzureichender Grundversorgung der Staatsbürger (Punkt 7). Letzterer Programmpunkt ist angesichts der Hungerunruhen und enormen Versorgungsprobleme in der frühen Weimarer Republik als Forderung nach Ausweisung sämtlicher Juden zu verstehen. Vgl. hierzu: Howard, Consequences; Reif, Hunger; Schulte-Varendorff, Hungerunruhen; Büttner, Weimar, S. 133f., 176-179.

${ }^{42} \mathrm{Zu}$ Entstehungshintergründen und Geschichte des Kampfbunds für deutsche Kultur vgl. Gimmel, Organisation; Piper, Rosenberg, S. 259-274.

${ }^{43}$ Vgl. KAG, Inv. Nr. 154: Vereine, 1929: Alfred Rosenberg (Kampfbund für deutsche Kultur) an Erwin Guido Kolbenheyer, 27. Juni 1929.

${ }^{44} \mathrm{Zu}$ den Inhalten des Buchs vgl. Piper, Rosenberg, S. 179-230.

${ }^{45}$ Rosenberg, Mythus, S. 416.

${ }^{46}$ Vgl. ebd., S. 416f.: „,Es ist kein Volk wie dieses, das keine Götter hat und ewig danach verlangt, den Gott zu schauen', läßt Kolbenheyer den ewigen Wanderer [gemeint ist hier die germanische Göttergestalt Odin, d. Verf.] zum Kreuzesgott sagen. Jener nimmt den müden Christus, der bettelnd am Wege liegt, auf seine starken Arme und trägt ihn durch die deutschen Gaue. Und die armselige zerquälte Gestalt Christi saugt den starken Odem dieses deutschen Ingeniums auf und wird stärker und kraftvoller. Bis der große Einäugige spricht über 
Kolbenheyer reagierte auf die Avancen Rosenbergs betont freundlich, lehnte jedoch ein direktes persönliches Engagement im KfdK zunächst ab. Dabei stellte er jedoch unmissverständlich klar, dass Rosenberg bei seinen kulturpolitischen Vorstellungen und „Bestrebungen“ stets seine „aufrichtige Zustimmung“ „erwarten“ dürfe. Er selbst, so Kolbenheyer, habe „längst für das“ gewirkt, wofür nun auch der KfdK einstehe. Dass er sich gleichwohl „von allem parteilich gebundenen abseits“ halte, dürfe Rosenberg nicht als „deutsche Einfalt der Eigenbrötelei“ missverstehen. Ausschlaggebend, so Kolbenheyer, sei es vielmehr, dass er sein Werk „nur vollbringen“ könne, wenn er „es über alle Partei stelle“. Nur auf diese Weise könne er sich „die Freiheit des Schaffens“ erhalten, „die den Abfluß meidet und aus der Quelle unmittelbar schöpft“. Kolbenheyer bat Rosenberg, sein Gesamtwerk „als Bundesgenossen des Kampfbundes für deutsche Kultur“ zu nehmen, denn „es ist sein Bundesgenosse“ 47 .

Rosenberg zeigte sich von Kolbenheyers Schreiben zwar enttäuscht, reagierte aber durchaus verständnisvoll. Kolbenheyers „innere Abwehrinstinkte gegenüber allen Vereinigungen“ hielt er für nachvollziehbar. Gleichwohl unterließ es Rosenberg nicht, nachzufragen, ob Kolbenheyer gegebenenfalls einmal bei einer Veranstaltung des KfdK vorlesen wolle. ${ }^{48}$ Doch ohne Erfolg: Sichtlich um die Vermeidung eines offenen Streits bemüht, rechtfertigte sich Kolbenheyer abermals in aller Ausführlichkeit und unter Wiederholung derselben Argumente für seine Entscheidung, nicht öffentlich im Rahmen des KfdK aufzutreten: „Ich kämpfe besser mit Ihnen, wenn ich allein kämpfe“49.

Als im Juli 1931 in Tübingen mit maßgeblichem Engagement des völkisch orientierten Philosophieprofessors Max Wundt ${ }^{50}$ eine Ortsgruppe des KfdK gegründet wurde ${ }^{51}$, war Kolbenheyer jedoch zu einem Beitritt bereit. Neben Kolbenheyer traten bei der Gründungsveranstaltung noch weitere „namhafte Herren des

die Deutschen: ,Sie bekennen mich nicht mehr, denn sie haben nur mehr Zungenlaut für ihre ewigen Götter, die das Siegel des Todes tragen, alles andere scheint ihnen klein. Aber sie leben mich. Daß dieses Volkes Blut noch soviel Urquell durch die Adern führt! So müssen sie die Sehnsüchtigen sein unter den Menschen.... Aus dieser Weltenvision entsteigt dem Dichter der große Sucher Paracelsus, auf der Schwelle zweier großer Epochen stehend, über beide hinausschauend mit der Sehnsucht nach einer Zeit, da nicht mehr Wort wider Wort, Altar wider Altar stehen, sondern dieses alles eingefügt sein wird in die Urgesetze des Lebens. [...] Glaubt jemand etwa, ein Kolbenheyer hätte sein großes Werk aus artistischem Wohlgefallen heraus geschrieben und nicht, weil er selber ein einsamer Sehnsüchtiger ist? Und glaubt jemand, sein Werk zu verstehen, wenn er nicht die Kraft der Sehnsucht in sich wachsen gefühlt hat? Wer das glaubt, hat nicht nur diesen ,Roman' nicht erfaßt, er hat germanische Kunst in ihrem Wesen überhaupt noch nicht von ferne geahnt".

${ }^{47}$ KAG, Inv. Nr. 154: Vereine, 1929: Erwin Guido Kolbenheyer an Alfred Rosenberg, 4. Juli 1929 (Durchschlag, Herv. i. Orig.).

48 KAG, Inv. Nr. 154: Vereine, 1929: Alfred Rosenberg (Kampfbund für deutsche Kultur) an Erwin Guido Kolbenheyer, 12. Juli 1929.

${ }^{49}$ KAG, Inv. Nr. 154: Vereine, 1929: Erwin Guido Kolbenheyer an Alfred Rosenberg, 13. Juli 1929 (Durchschlag).

${ }^{50}$ Knappe Hinweise zu Person und Wirken von Max Wundt in: Dahms, Philosophen, S. 729738.

${ }^{51}$ Lönnecker, „...Boden für die Idee Adolf Hitlers auf kulturellem Felde gewinnen“, S. 124. 
geistigen nationalen Tübingen“ in die Ortsgruppe ein, darunter „drei Dozenten der Universität“ 52 . In der Folgezeit wurde Kolbenheyer in der laut Harald Lönnecker „besonders erfolgreich“ agierenden Tübinger Ortsgruppe zur „zentrale[n] Figur“. Anfragen um öffentliche Vorträge lehnte der Dichter indes auch weiterhin mit dem Verweis ab, seinen „Förderungsabsichten“ nur „nach eigenem Ermessen“ nachkommen zu wollen; er stehe nicht „zu beliebigem Gebrauch“ zur Verfügung. ${ }^{53}$

Neben seiner Sorge, zu einem „Parteidichter“ gestempelt zu werden, hing dies auch damit zusammen, dass Kolbenheyer ein erst spätberufener Vortragsredner war und nach 1918 zunächst jedwede Anfragen um Vorträge ablehnte, ehe er im März 1932 schließlich an der Universität München sein Debüt als Redner gab. ${ }^{54}$ Entscheidend war jedoch Kolbenheyers genuine Abneigung, sich öffentlich vor den Karren der NSDAP spannen zu lassen. Aufschlussreich ist in diesem Zusammenhang ein Anfang November 1931 verfasster Brief, in dem Kolbenheyer Stapel von Auseinandersetzungen mit dem KfdK berichtete. In dem Brief kommt klar zum Ausdruck, dass Kolbenheyer in seinem Verhältnis zu Rosenbergs Organisation die Rolle des Lehrmeisters in Anspruch nahm, keineswegs aber jene des Lakaien. Der Kampfbund, so Kolbenheyer, habe von München aus versucht, ihn „als Fahne auf[zu]ziehen" 55 , was er jedoch nicht mit sich machen lasse. Stattdessen wollte Kolbenheyer „diese Herren [...] privatim einladen, um ihnen zu sagen, was man kluger Weise tun darf $\mathrm{u}[\mathrm{nd}]$ was nicht." Zugleich bezeugt der Brief jedoch auch Kolbenheyers Freude über das große Gewicht seines Namens im KfdK: „Übrigens scheinen die Leute vom Kampfbund vorläufig auf mich hören zu wollen, also werde ich das Eisen zu schmieden verstehen. Es ist ein Glück, daß wir Deutsche doch zuweilen auch die Wahrheit hören wollen. "56 Kolbenheyers Haltung gegenüber dem KfdK zeigt demnach eine für die Zeit der Weimarer Republik durchaus charakteristische Ambivalenz: Einerseits war Kolbenheyer von der Sorge beseelt, bei einer zu deutlichen Annäherung an Rosenbergs Organisation in den Ruf eines bloßen Parteidichters zu geraten. Andererseits zeigen die Briefe von 1929 eindeutig, dass er bemüht war, den Leiter des KfdK, mit dessen Zielen er

52 Ebd., S. 125.

53 Vgl. ebd, S. 124, 127, 133.

${ }^{54}$ Im überfüllten Auditorium Maximum der Universität München sprach Kolbenheyer zum Thema „Unser Befreiungskampf und die deutsche Dichtkunst“. Ausschlaggebend für Kolbenheyers Entscheidung, als Redner in die Öffentlichkeit zu treten, war ein Brief der Münchner Studentenvertretung gewesen, in welchem er gebeten worden war, zu dem Thema „Ist die deutsche Kultur am Ende?" zu sprechen. Der Sachverhalt, dass es überhaupt zu einer solchen Fragestellung hatte kommen können, zumal von Seiten junger Akademiker, versetzte Kolbenheyer in eine derart "fassungslose Erregung", dass er eine Ablehnung der Bitte mit seinem Gewissen nicht habe vereinbaren können: „Ich wurde aus dem Versteck gejagt. Ich durfte mich nicht verweigern. [...] Das lud eine neue Verantwortung auf mich. Ich sollte fortan meinem Volke nicht mehr nur an meinem Schreibtische dienen. "Vgl. Kolbenheyer, Sebastian Karst, Bd. 3, S. $106 f$.

55 DLA, A:Stapel, Erwin Guido Kolbenheyer an Wilhelm Stapel, [?] November 1931 (der undatierte Brief ist zwischen zwei Briefe vom 28. Oktober und 7. November eingeordnet).

56 Ebd. 
sich offen solidarisierte, nicht durch eine reine Verweigerungshaltung vor den Kopf zu stoßen.

Ein Brief an den Schweizer Schriftsteller Jakob Schaffner, den Kolbenheyer wenige Wochen nach dem spektakulären Erfolg der Nationalsozialisten bei der Reichstagswahl vom 14. September 1930 verfasste, belegt dabei, dass Kolbenheyer hinsichtlich des weltanschaulichen Radikalismus der NS-Bewegung zu großen Konzessionen bereit war. Zwar betonte der Dichter, im Grunde „gegen den absoluten Radikalismus“ eingestellt zu sein; in bestimmten „Krisenzeiten“ stelle sich ein solcher Radikalismus jedoch von selbst und ganz natürlich ein. Nur auf diese Weise könne das „Bestandstaugliche“ eines Volks gefördert und geschützt werden. ${ }^{57}$ Aufgrund der weltanschaulichen Gewissheiten, wie er sie in seiner Bauhütten-Philosophie niedergelegt hatte ${ }^{58}$, glaubte Kolbenheyer, im Nationalsozialismus eine gesunde, biologisch bedingte „Volksreaktion“ erkennen zu können. Wohl sei es zu wünschen, dass der Radikalismus nicht lange vorherrsche, aber, so Kolbenheyer, „wenn der Nationalsozialismus nicht gekommen wäre, man hätte ihn erfinden müssen “59.

Im Deutschen Volkstum sekundierte Stapel - mittlerweile selbst beflissener Bauhütten-Schüler ${ }^{60}$ - dieser biologistischen Perzeption des Wahlerfolgs der NSDAP, indem er ihn zum „Ausdruck eines langen und tiefen volksbiologischen Prozesses“61 verklärte. Wenn man davon absehe, das Ergebnis der Wahlen „auf parlamentarische Schwierigkeiten hin, also nach sekundären Maßstäben zu beurteilen, sondern wenn man es biologisch wertet, so zeigt es eine gesunde Reaktion an. So antwortet der gesunde Volkskörper auf eine jahrelange Vergiftung "62. Privat reagierte Stapel allerdings sehr viel verunsicherter auf die Frage, welche Folgen das Wahlergebnis tatsächlich zeitigen werde: „Daß die Nationalsozialisten über 70 Mandate bekommen würden, habe ich nicht gedacht. [...] Was die 107 Mann für die Zukunft bedeuten, weiß der Himmel. Man ,muss hindurch` - aber wie kommt man am anderen Ende zum Vorschein?" 63

Grimm verstand das Wahlergebnis vom September 1930 wiederum primär als Erfolg jener Partei, die ihm zum damaligen Zeitpunkt auf Seiten der politischen Rechten als die „einzige noch handlungsfähige“64 erschien. Im März 1931 bilanzierte er die politische Lage in Deutschland wie folgt: „Ich sehe übrigens gar keinen Weg mehr, auf dem uns irgendwo wieder Achtung gewonnen werden könnte, als den über den Nationalsozialismus"65. Vor diesem Hintergrund ging Grimm in den Jahren 1931/32 mit Nachdruck dazu über, offensiv für die NSDAP zu werben,

${ }^{57}$ KAG, Erwin Guido Kolbenheyer an Jakob Schaffner, 25. Oktober 1930 (Durchschlag).

${ }^{58}$ Vgl. Kap. 3.3.1.

${ }^{59}$ KAG, Erwin Guido Kolbenheyer an Jakob Schaffner, 25. Oktober 1930 (Durchschlag).

${ }^{60}$ Vgl. Kap. 2.3.2.

61 Stapel, Wahl [1930], S. 796.

62 Ebd.

${ }^{63} \mathrm{KAG}$, Wilhelm Stapel an Erwin Guido Kolbenheyer, 26. September 1930.

${ }^{64}$ Gümbel, Volk, S. 74.

65 DLA, A:Grimm, Hans Grimm an Deutsches Volkstum, 14. März 1931. 
wofür er seine exzellenten Verbindungen zur bürgerlichen Rechtspresse mobilisierte. Hierbei war er stets auch darum bemüht, an jenen Facetten Kritik zu üben, die ihn an der NS-Bewegung störten, um hierdurch - so seine illusorische Hoffnung - Einfluss auf die politische Entwicklung des Nationalsozialismus gewinnen zu können. Grimms, Kolbenheyers und Stapels Versuche der Einflussnahme im Vor- und unmittelbaren Umfeld der NS-,,Machtergreifung“ sowie die Reaktionsformen, die jene Versuche von Seiten der NSDAP evozierten, sind Gegenstand des nachfolgenden Kapitels.

\title{
5.2 Verhinderte Mentoren: Versuche zur Lenkung der NS-Bewegung und ihre Zurückweisung
}

\subsubsection{Versuche der Einflussnahme auf die NS-Bewegung $1932 / 33$}

\begin{abstract}
Ich habe nicht die Absicht, als Gegner des Nationalsozialismus aufzutreten, ich habe wohl die Absicht, kritisch zu sein, wo Kritik nötig ist und durch eine bessere Erfahrung vertreten werden kann. ${ }^{66}$

Ich meinerseits halte dafür: je mächtiger die N.S.D.A.P. an Masse wird, um so eifersüchtiger müssen wir unsere Selbstständigkeit wahren. [...] Mit der Wahrung freier Kritik tut man der nationalen Sache einen höheren Dienst, als wenn man sich mit den Mediokritäten vereinspatriotisch einläßt. In Kunst und Wissenschaft ist persönliche Fühlung wichtig, Freundschaft etwas Großes, aber Organisation eine Art Sündenfall. 67
\end{abstract}

Bekanntlich bemühte sich Hitler in Mein Kampf mit Nachdruck darum, sich und seine Partei von allen etablierten „Größen“ der völkischen Bewegung abzugrenzen. Süffisant karikierte er sie pauschal als „deutschvölkische Wanderscholaren“ und „völkische Komödianten“, deren „positive Leistung“ für das deutsche Volk „immer gleich Null“ gewesen sei, trotz einer mitunter „schon dreißig oder gar vierzig Jahre"68 währenden Arbeit. Diese polemische Distanzierungsgeste war freilich an konkrete politische und propagandistische Wirkungsabsichten geknüpft: Hitler reduzierte die völkische Bewegung bewusst auf ihre bizarren und verstiegenen Züge, um sie als unzeitgemäß und überlebt erscheinen zu lassen, im Kontrast zum Nationalsozialismus als der zukunftsträchtigeren, sehr viel kraftvolleren und damit zur Führung berufenen Bewegung. Es galt, den Nationalsozialis-

${ }^{66}$ DLA, A:Grimm, Hans Grimm an Mündensche Nachrichten, 16. August 1931.

${ }^{67}$ KAG, Wilhelm Stapel an Erwin Guido Kolbenheyer, 11. November 1931.

${ }^{68}$ Hitler, Kampf, Bd. 1, S. $381 \mathrm{f}$. 
mus als etwas vielversprechend Neues und noch nie Dagewesenes in der deutschen Geschichte zu inszenieren. Aus diesem Kalkül heraus war es für Hitler von hoher Bedeutung, die zutiefst epigonalen Wesenszüge der NS-Ideologie sowie seines Denkens zu kaschieren, drohte ihm in den frühen 1920er Jahren doch die Gefahr, zu jenen weltfremden „Inflationsheiligen“ gerechnet zu werden, die damals in missionarischer Absicht durch Deutschland schwadronierten und kleine Bevölkerungskreise mit ihren abseitigen Heilsversprechen zwar zu mobilisieren vermochten ${ }^{69}$, vom Gros der Gesellschaft hingegen abgewiesen und verlacht wurden. Darüber hinaus erkannte Hitler „zu Recht die Gefahr“, bei einer Zusammenarbeit mit anderen völkischen Kleingruppierungen alsbald „in Führungskämpfen und Intrigen aufgerieben zu werden "70. Infolgedessen grenzte er sich ostentativ von jener Bewegung ab, aus der sich die NS-Ideologie und sein eigenes Denken maßgeblich speisten. ${ }^{71}$

Dies machte es auch für außerhalb der NSDAP stehende, völkisch orientierte Intellektuelle wie Grimm, Kolbenheyer und Stapel, die nicht dem Kreis schrulliger „Wanderscholaren“ zuzurechnen waren, ausgesprochen schwierig, bei ihren vielfältigen Versuchen der Einflussnahme auf die NS-Bewegung Erfolge zu verbuchen. Die Schwierigkeiten waren zumal dann eklatant, wenn die Einflussnahme über den Weg offener Briefe, Zeitschriften- und Zeitungsartikel oder Reden unternommen wurde - also vor den Augen der politisch interessierten Öffentlichkeit. Die immer wache Sorge der nationalsozialistischen Führungsriege, nicht in den Ruf bloßer Lehrjungen längst etablierter Figuren im völkischen Lager zu geraten, führte hier unweigerlich zu einer vorauseilend reservierten und argwöhnischen Haltung.

Hans Grimms „Bitte an den Nationalsozialismus“ (1932) - Obgleich Grimm diese Einstellung der Nationalsozialisten zu außerparteilichen Einflussversuchen nicht verborgen geblieben war, beschloss er im September 1932 eine öffentliche Bitte an den Nationalsozialismus auszusprechen. ${ }^{72}$ Ursprünglich hatte Grimm mit dem Gedanken gespielt, mehrere namhafte Autoren des rechten Lagers hinter seiner Bitte zu versammeln, er entschied sich letztendlich jedoch gegen diesen Plan. Als Mitunterzeichner kamen für ihn nur Männer in Betracht, „die dem Nationalsozialismus unbedingt freundlich“ gesinnt waren und von dessen Anhängern mutmaßlich „nicht beargwöhnt werden“73 konnten. Insbesondere das zweite Kriterium machte die Auswahl indes schwierig. Nach der Einschätzung Grimms erfüllte zum damaligen Zeitpunkt lediglich August Winnig diese Voraussetzungen. Gegenüber Winnig, der 1920 wegen seiner Beteiligung am Kapp-Lüttwitz-Putsch

69 Zur Geschichte der „Inflationsheiligen“ vgl. Linse, Propheten.

70 Plöckinger, Geschichte, S. 81.

${ }^{71}$ Das gilt zuvorderst für das am 24. Februar 1920 im Münchner Hofbräuhaus verkündete 25-Punkte-Programm der NSDAP, das inhaltlich „so gut wie nichts Originelles oder Neues mit Blick auf die völkischen Rechte" bot (Kershaw, Hitler, Bd. 1, S. 190).

72 Vgl. Grimm/Winnig, Bitte.

73 DLA, A:Grimm, Hans Grimm an August Winnig, 14. September 1932. 
aus der SPD ausgeschlossen worden war und ein Jahrzehnt später mit der Studie Vom Proletariat zum Arbeitertum ${ }^{74}$ großes Aufsehen erregt hatte, betonte Grimm: „Ich weiß von solchen Leuten im Augenblick nur Sie und mich“75.

Grimm und Winnig hatten bereits 1922 in dem von Arthur Moeller van den Bruck herausgegebenen Sammelband Die neue Front mitgewirkt und dabei verwandte Themen besetzt. ${ }^{76}$ Eine enge persönliche Beziehung entwickelte sich dann seit 1926. Anlass war hier, wie bei vielen anderen Autoren, die Veröffentlichung von Volk ohne Raum. Nach der Lektüre des Romans verfasste Winnig für die Berliner Börsen-Zeitung eine hymnische Rezension, in der er Grimms Werk als "große völkische“ und „große dichterische Tat"77 huldigte. Dass das deutsche Volk Grimm für das „große Erzählwerk“ zu „Dank“ verpflichtet sei, teilte Winnig dem Dichter auch persönlich mit. ${ }^{78}$ Winnig hatte das Buch demnach „mit Bedacht gelesen“, bewunderte Grimms „große Leistung“ und fühlte sich „dem Geiste“ des Romans eng „verbunden“79. Die beiden Autoren blieben bis 1948 in einem regelmäßigen und freundschaftlichen Austausch, ehe eine heftige Auseinandersetzung über das politische Erbe des Nationalsozialismus einen jähen und endgültigen Bruch zwischen ihnen herbeiführte. ${ }^{80}$

Den Text der Bitte an den Nationalsozialismus verfasste Grimm indes weitestgehend allein. Nachdem er einen Entwurf verfasst und im September 1932 an Winnig übermittelt hatte, stimmte dieser Grimms Ausführungen sogleich „mit Freuden“ zu und nahm eilends Kontakt mit Richard Jügler auf, dem ihm wohlbekannten Hauptschriftleiter der Berliner Börsen-Zeitung. ${ }^{81}$ Grundvoraussetzung für die Zusammenarbeit mit Winnig war für Grimm, dass die gemeinsame Bitte an den Nationalsozialismus eine „ungeheure Hochachtung vor Hitler und dem Nationalsozialismus“ und „größte Dankbarkeit für die Leistung der Bewegung zum Ausdruck“82 bringen musste. Ihr Versuch der Einflussnahme auf die Führung der NSDAP war ausdrücklich von der Absicht getragen, zur Stärkung des inneren Zusammenhalts und zur Stabilisierung der politischen Dynamik des Nationalsozialismus beizutragen. Kurzum: Hitler sollte „ein Dienst“ erwiesen

${ }^{74}$ In dieser 1930 erschienenen Schrift, die 1941 das 52. Tausend erreichte, hatte Winnig ein „gegenmarxistisches Begriffsbewußtsein“ zu entwickeln versucht und dabei den „alte[n] Gegensatz zwischen ,Arbeiterstand' und ,Proletariat' aus der Mitte des 19. Jahrhunderts wieder aufgegriffen" (Conze, Proletariat, S. 67).

75 DLA, A:Grimm, Hans Grimm an August Winnig, 14. September 1932.

76 Während Grimm einen Aufsatz über Übervölkerung und Kolonialproblem schrieb, steuerte Winnig einen Beitrag über Die neue Weltlage bei. Nähere Informationen zu dem Sammelband in: Schlüter, Moeller van den Bruck, S. 314-317.

77 Zitiert nach: Lennartz, Schriftsteller, S. 612.

${ }^{78}$ Vgl. DLA, A:Grimm, August Winnig an Hans Grimm, 31. August 1926.

79 Ebd.

${ }^{80}$ Grimm führte den Bruch herbei, nachdem ihm Winnigs 1946 veröffentlichte Erinnerungen Rund um Hitler bekannt wurden, die ihn aufgrund ihrer Kritik am Nationalsozialismus zutiefst empörten. Vgl. Kap. 6.2.

${ }^{81}$ DLA, A:Grimm, August Winnig an Hans Grimm, 15. September 1932. Winnig fügte dem Wortlaut der Bitte an den Nationalsozialismus lediglich einen kurzen zusätzlichen Absatz zu.

82 DLA, A:Grimm, Hans Grimm an August Winnig, 14. September 1932. 
werden. Zugleich ging es Grimm und Winnig darum, dem Nationalsozialismus eine Hilfestellung zu bieten, damit „er sich nicht selbst zerstör[e]“. Konkret sollten durch die Bitte jene von der NS-Bewegung „schwer erschreckte[n]“ Menschen „wieder Mut fassen“, die ,augenblicklich ganz hülflos [sic!] "83 seien. Dieses Motiv speist sich aus einer Flut von Briefen und Anfragen "gequälte[r] Menschen "84, die Grimm im Lauf des Jahres 1932 erreicht hatte. Sie alle hatten vom Schöpfer von Volk ohne Raum Orientierung darüber erhofft, wie sie sich in der diffizilen und unübersichtlichen politischen Lage Deutschlands zur NSDAP stellen sollten. Grimm konzipierte die Bitte an den Nationalsozialismus als Kollektivantwort auf all diese Anfragen. Sie sollte der NSDAP Wähler sichern, das war die Hauptsache, zugleich aber auch eine vorsichtige Mahnung sein.

In welcher Weise aber versuchte Grimm, durch seinen Text auf die Entwicklung der NS-Bewegung einzuwirken? Grimm und Winnig legten zu Beginn ihrer Bitte „dankbares Zeugnis“ dafür ab, dass „die Hitler-Bewegung“ Deutschland „vor der kommunistischen Auflösung und damit vor der völligen Abtötung der besonderen deutschen Kräfte des Geistes und der Seele" 85 errettet habe - insbesondere aufgrund ihres vermeintlich heilsamen Einflusses auf die deutsche Jugend. „Nach vierzehn Jahren unseligen Lavierens“ sei erst aufgrund des „unbeugsamen Willens, des rastlosen Kampfes und der Wahl- und Massensiege" der NS-Bewegung wieder die Möglichkeit eines gemeinsamen nationalen Handelns in greifbare Nähe gerückt. Vor diesem konstruierten Hintergrund rechneten es Grimm und Winnig gar zu den Verdiensten der Nationalsozialisten, das „durch feindliche Bedrückung, durch Raumenge, durch Verhemmung seiner besten Kräfte [...] verzweifelte" deutsche Volk „vor dem Bürgerkriege bewahrt" 86 zu haben. Die von der SA gewollte, provozierte und getragene Brutalisierung der innenpolitischen Auseinandersetzung während der Weimarer Republik ${ }^{87}$ klammerten Grimm und Winnig dabei nicht etwa stillschweigend aus, sondern billigten ihr in verklausulierter Form Indemnität zu: Die politische Aggression der Nationalsozialisten rechtfertigten sie durch den Hinweis, dass die NS-Bewegung auf ihrem Weg, die „entnationalisierte[n] Massen“ - gemeint waren hier pauschal die Anhänger der Republik ebenso wie die Anhänger der KPD - wieder „für den nationalen Staat“ zu gewinnen, weder zimperlich noch "wählerisch" sein durfte und weiterhin sein dürfe. Neben diesem bezeichnenden Euphemismus führten Grimm und Winnig zur Verteidigung der Nationalsozialisten weiterhin ins Feld, dass die NSDAP seit ihrer Gründung unter einem Trommelfeuer „schamlos und hemmungslos gewordene[r] Agitation der inneren und äußeren Reichsfeinde "88 gestanden habe. Unter diesen Voraussetzungen sollte das Mittel politischer Gewalt und brachial hasserfüllter Propaganda seitens der Nationalsozialisten als ein von außen aufge-

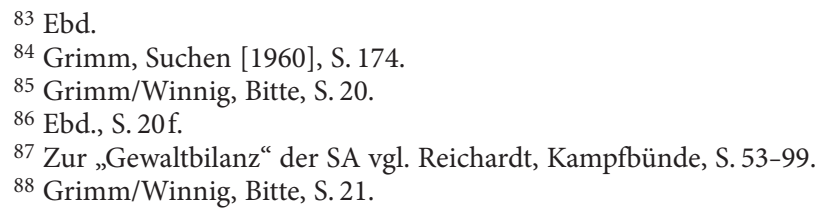


nötigtes, bloß reaktives Verhalten erscheinen, das, wenn schon nicht grundsätzlich zu befürworten, so doch verständlich und entschuldbar war.

Nach diesem einleitenden Blankoscheck „wag[t]en“ es Grimm und Winnig anschließend, „eine offene Bitte auszusprechen“. In einem zugleich mahnenden und wohlwollend väterlichen Tonfall riefen sie die Nationalsozialisten dazu auf, es mit den sozialistischen Elementen in ihrer Politik und Ideologie nicht zu weit zu treiben: „Ganz kurz formulier[t]" lief ihre Bitte darauf hinaus, die NS-Bewegung möge sich in keine Front „treiben lassen“, von welcher aus „,nur mehr Arbeitnehmer-Politik alten und das heißt marxistischen Stils getrieben werden" könne; „weder „Deutschland noch der deutsche Arbeiter“ könnten auf dieser Basis „gerettet werden“89. Wohl, so gestanden Grimm und Winnig zu, könne „ArbeiterPolitik eine gute deutsche Politik sein“, jedoch nur wenn es ihr gelinge, den Arbeiter als „Kern“ der „leiblichen Volkskraft zu bewahren“ und ihn zum „willentlichen Mit-Träger der gesamten deutschen Aufgabe zu erheben“. Eine solche „ArbeiterPolitik“ müsse sich jedoch „durch ihre Zielsetzung wie durch die Überlegenheit ihrer Sicht“ von einer klassenkämpferischen „Arbeitnehmer-Politik“90 sozialistischen Stils völlig abgrenzen. Die NS-Bewegung habe das Verdienst, von allen politischen Parteien „das Reich am stärksten und wirklichsten gewollt" und damit „das deutsche Volk dem einigen Reiche näher gebracht“ zu haben als „jemals“ zuvor. Durch die gegenwärtige „Taktik der Partei“ einer „klassenkämpferischen Arbeitnehmer-Front“ stehe dieses Verdienst jedoch wieder „auf dem Spiele“. Werde sie aufrechterhalten, müsse die NS-Bewegung „zu Grunde“ gehen und mit ihr der gesamte „nationale Staat“91.

Grimms und Winnigs Bitte an den Nationalsozialismus lief also darauf hinaus, die NS-Bewegung möge in ihrem als existenziell bedeutsam perzipierten Kampf gegen den Marxismus selbst nicht zu sehr auf marxistische Methoden verfallen. Sehr wahrscheinlich stand ihnen bei dieser Ermahnung insbesondere die damalige Bereitschaft der Berliner Nationalsozialisten vor Augen, sich in ihrem Protest gegen das Weimarer "System“ mit Kommunisten zusammenzuschließen. Den Höhepunkt dieses kurzfristigen Trends bildete der von NSDAP und KPD getragene Streik bei der Berliner Verkehrsgesellschaft Anfang November 1932. ${ }^{92}$ Zugleich knüpften Grimm und Winnig - bewusst oder unbewusst - mit dem Vorwurf einer zu starken Nähe der Nationalsozialisten an den Marxismus und seine politischen Techniken an eine Kritik an, mit der sich die NSDAP schon früh konfrontiert sah. ${ }^{93}$ Entsprechend hat Hitler schon in Mein Kampf zu dem Vorwurf,

89 Ebd., S. 22.

90 Ebd.

91 Ebd., S. 23.

92 Vgl. Röhl, Gegner.

93 Erinnert sei an den bayrischen Pfarrer und BVP-Politiker Wilhelm Vielberth, der im Mai 1923 in der Zeitschrift Politische Zeitfragen mit Blick auf das Wirtschaftsprogramm der Nationalsozialisten sowie ihre Religionsfeindlichkeit schrieb: „Die großen Irrtümer, die nun seit dem Humanismus in der Kulturwelt fortgewirkt, sich entfaltet und ausgebaut haben, erreichen den Zenith im Schlußsatz des Marxismus, in der bolschewistischen, zentralistisch- 
seine Partei sei „nur eine Spielart des Marxismus“, Stellung bezogen und ihn zurückgewiesen. ${ }^{94}$

Von der Wirkung der Bitte an den Nationalsozialismus wurden Grimm und Winnig alsbald enttäuscht. „In bester Wohlmeinung“, so Winnig rund zwei Wochen nach der Veröffentlichung, habe man den Nationalsozialisten „eine Gelegenheit“ geboten, „in anständiger Form von begangenen Fehlern abzurücken und berechtigte Zweifel aufzulösen"95. Diese Gelegenheit sei jedoch nicht nur ausgeschlagen, sondern geradezu brüsk zurückgewiesen worden. Prominent hatte sich diese Zurückweisung in einer Stellungnahme Joseph Goebbels artikuliert, die am 24. September 1932 in der Berliner NS-Gauzeitung Der Angrifferschien. Mit kühl reserviertem Ton, in dem seine damals beginnende Entfremdung zu Grimm deutlich anklingt ${ }^{96}$, wies Goebbels darauf hin, Grimm habe sich mit seiner „Bitte an die falsche Adresse" gewendet. Wenn die Bitte

„schon einmal von Ihrer Seite ausgesprochen werden sollte, dann an diese sogenannte Staatsautorität selbst, und zwar so, daß sie die unabweisbare Pflicht habe, augenblicklich das Feld zu räumen und nicht länger der Nation und der Welt das schmähliche Schauspiel zu bieten, dass Hitler und seine Bewegung mit List und falscher Klugheit in einer historischen Stunde von einer historischen Aufgabe ferngehalten werden ${ }^{\text {"97 }}$.

Zugleich forderte Goebbels Grimm dazu auf, nicht „den Schein von heute für das Sein von morgen zu nehmen“ und damit den „untrüglichen Blick zu verlieren für das, was kommen wird, weil es kommen muß "98. Auf eine Auseinandersetzung mit den konkreten Inhalten der Bitte an den Nationalsozialismus verzichtete Goebbels vollständig. Stattdessen nahm er die Veröffentlichung zum Anlass für weitere Wahlkampfpropaganda für die Reichstagswahl vom 6. November 1932.

Die öffentliche Stellungnahme Goebbels' wurde im Lager der NSDAP von einem deutlich vernehmbaren Murren über das Auftreten Grimms und Winnigs flankiert. Inmitten des Wahlkampfs für die Reichstagswahl war den Nationalsozialisten die Bitte doppelt unwillkommen. Noch nach dem Zweiten Weltkrieg erstaunte Grimm die Größenordnung des „Geheul[s]“ und der „Verdrehung[en] und Anwürfe", mit der die NSDAP auf die Veröffentlichung der Bitte an den Nationalsozialismus reagiert habe. ${ }^{99}$ Aufschlussreich ist in diesem Zusammenhang ein Brief Walter Franks vom 3. November 1932, dem späteren Direktor des Reichsinstituts für Geschichte des Neuen Deutschlands, der mit Grimm seit 1930

unitaristischen Weltrepublik, die keinen Gott mehr kennt [...] und die rein diesseitige Weltregierung nach kommunistischen Rezepten bedeutet. Der nationale Sozialismus ist ein Abbild davon, angewendet auf eine einzelne Nation, die deutsche. [...] [S] ein politisches Ziel ist die zentralistisch-unitarische Diktatur und sein Wirtschaftsgedanke vorläufig der Staatssozialismus!“ (Vielberth, Nationalsozialismus, S. 102f.).

${ }^{94}$ Vgl. Hitler, Kampf, Bd. 2, S. $126 f$.

95 DLA, A:Grimm, August Winnig an Hans Grimm, 10. Oktober 1932.

96 Zum Verhältnis zwischen Grimm und Goebbels vgl. Kap. 5.2.4.

97 Hier zitiert aus: Gümbel, Volk, S. 79.

${ }^{98}$ Hier zitiert aus: Franke, Grimm, S. 42.

${ }^{99}$ Grimm, Warum [1954], S. 125. 
befreundet war. ${ }^{100}$ Frank erkannte zwar an, dass Grimm die „Absicht der Versöhnung" geleitet habe, warf dem Dichter jedoch eine verzerrte politische Perspektive vor: Anstatt die entscheidende Frage behandelt zu haben, „ob Hitler das Recht hatte, die Kanzlerschaft zu verlangen und die Vizekanzlerschaft abzulehnen", habe es Grimm bevorzugt, das abseitige und nebensächliche Thema einer vermeintlich zu „einseitigen Arbeitnehmerpolitik“101 aufzugreifen. Schlimmer noch: Die notwendige Kritik an der zu „einseitigen Arbeitgeberpolitik“ des regierenden „konservative[n] Klassenkabinett[s]“ unter Franz von Papen sei dabei völlig ausgespart geblieben. Grimm habe die „Parität“ vermissen lassen. Zu allem Überfluss habe er seine Kritik ausgerechnet in der Berliner Börsen-Zeitung publiziert, dem „Blatt des industriellen Scharfmachertums"102.

Frank drängte sich zudem der Eindruck auf, dass die Bitte an den Nationalsozialismus mit Grimms literarischem Hauptwerk Volk ohne Raum inhaltlich unvereinbar sei: Wohl „ohne es zu wollen“, gerate Grimm in eine Gesellschaft, „in der man den armen Cornelius Friebott mit Nasenrümpfen hinausgeworfen hätte“, bzw. in die dieser „erst gar nicht gegangen wäre“. Friebott, der Hauptprotagonist von Volk ohne Raum, wäre stattdessen „geraden Weges zu Adolf Hitler gegangen“. Dabei, so Franks Lamento, gehöre doch auch Grimm in jenen „großen geistigen Zusammenhang“, dessen Ausdruck der „politische Kampf de[s] Nationalsozialismus“ sei. Für geradezu „undenkbar" hielt es Frank, würde sich Grimm in dem „große[n] Kampf“ zwischen Hindenburg und Hitler auf die Seite „eines altersblödsinnigen Feldwebels"103 stellen. Es spricht Bände über die suggestive Wirkmächtigkeit von Grimms Volk ohne Raum, dass Frank an dieser Stelle die Auffassung vertrat, aus dem Jahre zuvor verfassten fiktiven Roman spreche eine authentischere und relevantere Botschaft als aus der Bitte an den Nationalsozialismus, die unmittelbar aus dem politischen Zeitgeschehen heraus verfasst worden war.

Grimm und Winnig verzichteten darauf, die seitens der NSDAP an ihnen geübte Kritik öffentlich weiter zu kommentieren. Vor allem Winnig drängte darauf, eine Replik zu unterlassen. Nach seiner Überzeugung hätte eine Widerlegung der Kritikpunkte lediglich eine „noch mehr kompromittieren[de]“104 Gegenantwort der Nationalsozialisten provoziert, was ausdrücklich nicht in ihrem Interesse lag - zumal so kurz vor der Reichstagswahl vom 6. November 1932. Angesichts der hohen Wahrscheinlichkeit, so Winnig, dass die NSDAP bei der anstehenden Wahl einen „Millionenverlust“ erleiden werde, sei es gegenwärtig das Wichtigste, nichts zu unternehmen, das die Nationalsozialisten „stören, beirren oder schwächen könnte“. Auf diese Weise könne man hinterher für eine mögliche Wahlniederlage der Partei auch nicht verantwortlich gemacht werden. ${ }^{105}$

100 Zum Verhältnis zwischen Grimm und Frank vgl. Kap. 2.3.3.

101 DLA, A:Grimm, Walter Frank an Hans Grimm, 3. November 1932.

102 Ebd. (Herv. i. Orig.).

103 Ebd.

104 DLA, A:Grimm, August Winnig an Hans Grimm, 10. Oktober 1932.

105 Ebd. 
Diese Befürchtung erwies sich indes als unbegründet. Nachdem die Reichstagswahl vom 6. November 1932 der NSDAP in der Tat erhebliche Stimmverluste einbrachte ${ }^{106}$, behandelte die Parteileitung Grimm und Winnig nicht als Sündenböcke, vielmehr überwog das Kalkül, das Verhältnis zu den beiden berühmten Autoren nicht gänzlich abkühlen zu lassen. Grimm und Winnig sollten als künftig potenziell zugkräftige Werbefiguren nicht verloren werden. Mitte November erreichte Winnig ein Schreiben von Rudolf Heß, in dem dieser im Namen der Parteileitung die massive Kritik, die an der Bitte an den Nationalsozialismus geübt worden war, mit der Ausnahmesituation des Wahlkampfs erklärte und entschuldigte. Nur vor dem Hintergrund der "gereizte[n] Stimmung“ des Wahlkampfes habe es zu den scharfen Reaktionen kommen können. ${ }^{107}$ Durch dieses Schreiben zeigte sich Winnig, den keine Überlegungen einer möglicherweise manipulativen Absicht der Parteileitung plagten, wieder deutlich hoffnungsvoller: „Hitlers jetzige Haltung“ zeige, „daß unser Schritt nicht ohne Wirkung geblieben ist“108.

Wilhelm Stapels „Forderungen Der KulturPolitik“ - Im April 1932 veröffentlichte der Mitherausgeber des Deutschen Volkstums, Albrecht Erich Günther, den Sammelband Was wir vom Nationalsozialismus erwarten. Der Band darf als wahre Goldgrube an Informationen darüber gelten, mit welchen Hoffnungen, Erwartungen, aber auch Forderungen völkische und nationalkonservative Autoren am Vorabend des „Dritten Reichs“ der Machtübernahme der NSDAP entgegensahen, die ihnen bereits zum damaligen Zeitpunkt als sicher galt. Angesichts dessen, dass die NS-Führung nach 1933 primär auf junges, als ideologisch besonders verlässlich geltendes Personal setzte, anstatt die selbsterklärten Wegbereiter des „Dritten Reichs“ in bedeutende Ämter zu hieven, bietet der Sammelband zugleich anschauliches Informationsmaterial dafür, völkische und nationalkonservative Enttäuschungserfahrungen im späteren NS-Staat zu konkretisieren. Neben Wilhelm Stapel und August Winnig meldeten sich in dem Sammelband unter anderem der Schriftsteller und spätere Präsident der NS-Reichsschrifttumskammer Hanns Johst, der Marburger Soziologieprofessor Johann Wilhelm Mannhardt sowie Wilhelm Grewe zu Wort, der spätere Botschafter der Bundesrepublik Deutschland in Washington. ${ }^{109}$

Die erhoffte pädagogische Wirkung des Sammelbands richtete sich dabei nicht allein auf die Führung der NSDAP. Günther konzipierte das Buch als eine „Art Umfrage“, in der die Mitarbeiter „Vorschläge und Forderungen entwickeln“ soll-

106 Gegenüber der Reichstagswahl vom 31. Juli 1932 sank der Stimmenanteil der NSDAP von 37,4\% (230 Mandate) auf 33,1\% (196 Mandate). Die NSDAP verlor dabei etwas mehr als zwei Millionen Wählerstimmen. Vgl. Büttner, Weimar, S. 803.

107 Vgl. Mitteilung Winnigs in DLA, A:Grimm, August Winnig an Hans Grimm, 20. November 1932. Informationen zu dem Schreiben von Heß auch in: Grimm, Warum [1954], S. 128.

108 DLA, A:Grimm, August Winnig an Hans Grimm, 20. November 1932.

109 Winnig lieferte einen Beitrag zum Thema Der Weg zur nationalen Arbeiterbewegung, Johst referierte über Kunst unter dem Nationalsozialismus, Mannhardt thematisierte die Erwartungen des „Auslandsdeutschtums“ an den Nationalsozialismus, während Grewe über Verfassungspolitische Aufgaben eines nationalsozialistischen Staates schrieb. 
ten, mit denen die „noch formlose aber auch noch formbare Volksbewegung“ als Ganzes beraten und beeinflusst werden sollte. „Vorschläge, Mahnungen und Forderungen“ sollten in die große „erregte und drängende aber unberatene Volksmasse hineingetragen werden", die sich um die NSDAP „gesammelt"110 hatte. Gegenüber Kolbenheyer kündigte Günther im September 1931 an, dass das Buch „keine nationalsozialistische Schrift werden“ solle, sondern dass es darum gehe, „positive Vorschläge" ${ }^{\text {"111 }} \mathrm{zu}$ entwickeln und zur Diskussion zu stellen. Nach der Veröffentlichung stellte Günther dann allerdings unmissverständlich klar, dass der Sammelband auf „Anregungen zur Weiterbildung und Konsolidierung der nationalsozialistischen Bewegung“ abgezielt habe. Die „Gesamtabsicht" der Schrift liege darin, „der Bewegung einen Dienst zu leisten“112. Günthers Aussage, dass „Hitler gerade jetzt das Bedürfnis“ fühle, „eine solche Hilfe zu erhalten“ - er habe sich „darüber auch mit der Parteileitung in Verbindung gesetzt"113 - kann in diesem Kontext freilich nur bedingt ernst genommen werden. Hitlers Ungeduld, von den Mitarbeitern des Bands politisch beraten zu werden, dürfte sich, falls überhaupt vorhanden, in sehr engen Grenzen gehalten haben. Aus dem Kreis der Nationalsozialisten störte sich Walter Frank bereits im Vorfeld der Veröffentlichung an der grundsätzlichen Konzeption des Sammelbands, über die er von Grimm in Kenntnis gesetzt worden war. Frank lehnte den Anspruch auf eine geistige Belehrung der NS-Bewegung rundweg ab; es sei „der bekannte gönnerhafte Ton der ,Turmschädel` gegen die ,geistig Armen “"114. Stapel hielt Günthers Auffassung hingegen für plausibel und betonte auch gegenüber Kolbenheyer, Hitler erwarte „das Buch mit Interesse“115. Entsprechend sagte Stapel seine Mitarbeit zu und verfasste zwei Aufsätze für den Band. Von den beiden Beiträgen werden hier nur die Forderungen zur Kulturpolitik behandelt, da die Inhalte des zweiten Artikels, Versuch einer praktischen Lösung der Judenfrage, bereits an anderer Stelle der Arbeit eingeflossen sind. ${ }^{116}$

Stapel gliederte seine kulturpolitischen Forderungen in zwölf programmatische Punkte. Schon Punkt 1 behandelt dabei exakt jenes Szenario, das nach 1933 den Kern aller Kritik und Enttäuschung bilden sollte: Stapel ermahnte die Nationalsozialisten, in künftiger Regierungsverantwortung die Ambitionen aller op-

110 DLA, A:Grimm, Deutsches Volkstum an Hans Grimm, 15. Juli 1931.

111 KAG, Albrecht Erich Günther an Erwin Guido Kolbenheyer, 21. September 1931 (Herv. i. Orig.).

112 KAG, Albrecht Erich Günther an Erwin Guido Kolbenheyer, 15. April 1932. Identisch formuliert in: DLA, A:Grimm, Deutsches Volkstum an Hans Grimm, 15. April 1932.

113 DLA, A:Grimm, Deutsches Volkstum an Hans Grimm, 21. Juli 1931. Zwar dürfte Günther ein Schreiben solchen Inhalts erhalten haben, es gab jedoch viele Gründe, es in seiner inhaltlichen Verbindlichkeit infrage zu stellen und kritisch-distanziert zu betrachten. Für die Parteileitung der NSDAP machte es keinen Sinn, Günther als den Mitherausgeber einer Zeitschrift, in der die NS-Bewegung seit fast zehn Jahren mit wohlwollender Aufmerksamkeit verfolgt und kommentiert wurde (vgl. Kap. 5.1), durch eine Bekundung von Desinteresse vor den Kopf zu stoßen.

114 DLA, A:Grimm, Walter Frank an Hans Grimm, 11. November 1931.

115 KAG, Wilhelm Stapel an Erwin Guido Kolbenheyer, 2. Oktober 1931.

116 Vgl. Kap. 3.2.1. 
portunistischer „zudringlicher“ und „mittelmäßiger“ Emporkömmlinge „grundsätzlich" zurückzuweisen und in der Kulturpolitik stattdessen ganz auf die Empfehlungen der Schöpfer bedeutender nationaler Werke zu bauen. Jene Autoren freilich seien „zu vornehm“, um „sich an Mächtige heranzudrängen“, sondern wollten vielmehr „gesucht sein“117. Dass sie nach 1933 eben nicht gesucht, sondern weitgehend ignoriert wurden, sollte im „Dritten Reich“ dann auch zur zentralen Enttäuschungserfahrung Stapels, Grimms und Kolbenheyers werden. ${ }^{118}$ Punkt 2 des kulturpolitischen Forderungskatalogs war nach 1933 hingegen weit größere Erfolge beschieden: Stapels „Gerechtigkeitsgefühl“ verlangte, dass man „alle Professoren, Ministerialbeamte, Schulräte, Direktoren usw.“, die nach 1918 aufgrund ihrer Bindung zur SPD zu ihren Stellungen gelangt seien, „kurzerhand entlassen" müsse. Einer solchen Forderung sollten die Nationalsozialisten durch ihre umfassenden Gleichschaltungsmaßnahmen mehr als gerecht werden. Stapels Erwartung, dass „der Nationalsozialismus nicht seinerseits Ämter nach Parteizugehörigkeit", sondern nach „wirkliche[r] Leistung" ${ }^{119}$ vergeben solle, blieb hingegen illusorisch und zeugt abermals von der elementaren Unterschätzung des totalitären Anspruchs der NSDAP und deren zynischer Bereitschaft, ab 1933 die eigenen wirtschafts- und arbeitspolitischen Versprechungen aus der „Kampfzeit“ mit Füßen zu treten.

Die Punkte 3 und 4, in denen Stapel auf eine Aufhebung der „Pädagogik als besondere Disziplin "120 und die Beschränkung des schulischen Geschichtsunterrichts auf die Zeit „bis zum Jahre 1871"121 abzielte, liefen dem Propagandakalkül der Nationalsozialisten hingegen diametral entgegen. Die heroisierende und selbstinszenierende Verklärung der eigenen Parteigeschichte gehörte bekanntlich zu den Kernelementen der NS-Propaganda. ${ }^{122}$ Stapels Forderung nach einem Verbot jeglicher pazifistischer Agitation (Punkt 5) lag demgegenüber wieder ganz auf Höhe nationalsozialistischer Grundüberzeugungen. Dass auch Stapel vom Pazifismus eine Gefahr insbesondere für die Persönlichkeitsentwicklung von Jugendlichen ausgehen sah, zeigt sich daran, dass er das Verbot „pazifistische[r] Jugendvereinigungen " und die Entlassung pazifistisch eingestellter Lehrer forderte. Mit seiner damit zusammenhängenden Forderung, dass „defaitistische und paneuropäische Literatur" restlos „zu vernichten“123 sei, konnte Stapel im Lager der Nationalsozialisten ebenfalls mit Zustimmung rechnen, nahm sie doch gleich-

117 Stapel, Forderungen [1932], S. 154.

118 Vgl. Kap. 5.3.1.

119 Stapel, Forderungen [1932], S. 154.

120 Ebd. Gerade die Verfasser theoretischer pädagogischer Aufsätze und Bücher hätten sich „in der Praxis oft" als „die unfähigsten Lehrer“ erwiesen. „Wer nicht von Natur die Jugend führen“ könne, lerne es auch nicht „unter dem papiernen Wust von pädagogischer Wichtigtuerei“. Die „massenhafte pädagogische Federfuchserei“ müsse „aufhören“ (ebd., S. 155).

121 Ebd., S. 155: Die „spätere Geschichte“ sollte „dem Elternhaus und den nationalen Schülervereinigungen vorbehalten" bleiben.

122 Vgl. exempl.: Behrenbeck, Kult.

123 Stapel, Forderungen [1932], S. 155. 
sam die knapp ein Jahr später inszenierten Bücherverbrennungen vorweg. ${ }^{124}$ Die Größenordnung und brutale Radikalität der Verfolgung politischer Gegner im NS-Staat sah Stapel zwar nicht voraus, der Ausgrenzung „Andersdenkender“ aus der Öffentlichkeit sprach er aber dennoch das Wort: Da der „Pazifismus volksund staatsgefährlich“ sei, müsse es als „schimpflich“ erachtet werden, „diese Gesinnung zu haben. Menschen von schimpflicher Gesinnung mögen in schimpflichen Winkeln des Privatlebens ihr unvermeidliches Dasein hinbringen, für die Öffentlichkeit sind sie nicht vorhanden"125. Ob Stapel bereits zum damaligen Zeitpunkt ahnte, wie wenig die Nationalsozialisten das „Dasein“ ihrer politischen und weltanschaulichen Gegner als „unvermeidbar“ erachteten, muss dabei offenbleiben. Verfechter einer exterminatorischen Xenophobie war er indes zu keinem Zeitpunkt.

Stapels sechste kulturpolitische Forderung gründete zunächst auf der Annahme, dass der Pazifismus für das „internationale Volk“ der Juden „natürlich“ und ein „Bestandteil seiner nationalen Gesinnung“ sei. In ihrem Fall hielt er daher einen besonderen Rechtsstatus für notwendig: Solange jüdische Pazifisten sich auf „ausdrücklich [...] jüdische Zeitungen“ beschränkten und „die deutsche nationale Gesinnung" nicht diffamierten, sollte es ihnen erlaubt bleiben, sich weiterhin zu Wort zu melden. Nichtjüdische Pazifisten, so Stapels perfides „Zugeständnis“, könnten sich „öffentliche Wirksamkeit“ jederzeit durch einen „Übertritt zum Judentum ermöglichen" 126 .

Die anschließende Forderung nach einem nationalen Mahn- und Gedenktag „des verfluchten Friedensschlusses von Versailles“127 (Punkt 7) bediente lediglich einen rechtspopulistisches Klischee der Weimarer Republik. Die Punkte 8 und 9 zielten hingegen auf die Aufhebung der „bunte[n] Vielfältigkeit“ des „höhere[n] Schulwesens“ durch eine Fixierung auf „Germanentum, Christentum, Antike“ eine Trias, die Stapel zu den drei Säulen des „Deutschtums“ erklärte: Im Deutschen Reich vereinige sich erstens ,germanischer Geist und germanische Tugend“, zweitens „der Glaube an die Erlösung der gefallenen Welt durch den Herrn Jesus Christus“ und drittens „der geistige Adel des Griechentums und der Stolz des Römertums“. Egal welches Spezialfach auch studiert werde, zunächst müssten gleichsam als Studium generale - ,jene drei Elemente des Deutschtums“ von allen Hochschülern erlernt und „erfahren“128 werden.

Stapels zehnte Forderung der Kulturpolitik lief schließlich auf die strikte Trennung von Wissenschaft und anwendungsorientierten technischen Studiengängen hinaus. Nachdrücklich verwarf er in diesem Kontext die Tendenz, wissenschaftliche „Studien nach schulmäßig festen Lehrplänen zu regeln und ein chinesisches Labyrinth von Prüfungen einzuführen“. Stattdessen solle der gemäß Punkt 8 und 9

\footnotetext{
124 Über die Dimension und Hintergründe der Bücherverbrennungen informieren die Beiträge in: Schoeps/Treß (Hg.), Vorgeschichte.

125 Stapel, Forderungen [1932], S. 155.

126 Ebd., S. 155f. (Herv. i. Orig.).

127 Ebd., S. 156.

128 Ebd.
} 
„deutschgebildete Knabe“ - vom deutschen „Mädel“ ist bei Stapel keine Rede - in die Lage versetzt werden, sich „frei und selbstständig in die Wissenschaften hinein[zu]arbeiten"129. Anschließend forderte Stapel eine hier im Detail nicht interessierende organisatorische Neuausrichtung der Preußischen Akademie der Künste (Punkt 11) sowie ein Verdrängung der „Libertinage“ aus „den öffentlichen Auslagen“ (Punkt 12): Dem „Handel mit Sexualien“ dürfe „,nicht die Würde der Zulässigkeit" verliehen werden; das „Aussehen der Öffentlichkeit" solle ausschließlich „durch die christliche Familie bestimmt" werden. Die durch das sogenannte Lex Heinze seit 1900 im Reichsstrafgesetzbuch geregelten Sanktionen gegen die Ausstellung und Verbreitung „unzüchtiger“ Schriften, Abbildungen und Darstellungen ${ }^{130}$ wollte Stapel deutlich verschärft sehen. Bereits eine öffentliche Verhöhnung des Ideals der christlichen Familie sollte demnach „mit Ausweisung aus dem Deutschen Reiche beantwortet"131 werden.

Schon ein Blick auf die Punkte 1-5 dieses kulturpolitischen Programms offenbart die Gleichzeitigkeit von Forderungen, die mit der NS-Ideologie und der späteren nationalsozialistischen Herrschaftspraxis in klarem Widerspruch standen $(1,3$ und 4$)$, und Forderungen, die mit ihr gut in Einklang zu bringen waren (2 und 5). Die spannungsreiche Parallelität von Zufriedenheit und Enttäuschung über die politische Entwicklung des NS-Staats, die sich nach 1933 erweisen sollte, ist im Kleinen in Stapels Forderungen der Kulturpolitik bereits exemplarisch angelegt. Darüber, dass sich die NS-Kulturpolitik freilich unabhängig von seinem 1932 aufgestellten Forderungskatalog entfaltete, machte sich Stapel im „Dritten Reich“ keine Illusionen. ${ }^{132}$

Kolbenheyer Und Die ANSPRÜCHe Des „LebensSTANDS Der Geistig SCHAFFenden“ - Anders als Grimm und Stapel hielt sich Kolbenheyer vor 1933 mit öffentlichen Adressierungen an den Nationalsozialismus zurück. Als er im Herbst 1931 zur Mitarbeit an dem Sammelband Was wir vom Nationalsozialismus erwarten aufgefordert wurde, lehnte er dies mit der Begründung ab, dass es zunächst notwendig sei, sich gemeinschaftlich, etwa auf „eine[r] kl[einen] Konferenz [...] über den Stand des Nationalsozialismus [zu] orientieren". Erst dann lasse sich entscheiden, „wo man einen Rat u[nd] eine Form anlegen soll“. Ohne eine solche gemeinsame Orientierung, so glaubte Kolbenheyer, schreibe „sonst jeder ins Blaue hinein" 133 .

Schon bald nach der NS-,,Machtergreifung" trat Kolbenheyer hingegen mit einigen Veröffentlichungen hervor, in denen er die NS-Bewegung nicht nur zu unterstützen und - entsprechend seiner Bauhütten-Philosophie ${ }^{134}$ - (volks-)bio-

129 Ebd.

130 Zum Entstehungskontext des Gesetzes vgl. Stolleis, „Mordfall Heinze“.

131 Stapel, Forderungen, S. 157.

132 Vgl. Kap. 5.3.1.

133 DLA, A:Stapel, Erwin Guido Kolbenheyer an Wilhelm Stapel, 29. September 1931 (Herv. i. Orig.).

134 Vgl. Kap. 3.3.1. 
logisch herzuleiten ${ }^{135}$, sondern auch in ihrer Entwicklung zu beeinflussen versuchte. Die stärkste Resonanz, sowohl in negativer wie positiver Hinsicht, evozierte er dabei mit der im Winter 1933/34 in zahlreichen deutschen Städten gehaltenen Rede Der Lebensstand der geistig Schaffenden und das neue Deutschland. ${ }^{136}$ In ihr wies Kolbenheyer mahnend auf eine in seinen Augen unzulängliche Personalpolitik des „Dritten Reichs“ und einen nach seinem Geschmack zu weit getriebenen Anti-Intellektualismus hin. Die Rede lief auf die Forderung hinaus, jenen Vertretern des geistigen Deutschlands, die sich vor 1933 als Vorkämpfer des „Dritten Reich“ Verdienste erworben hätten, größtmögliche Freiheiten in ihren jeweiligen Arbeitsgebieten einzuräumen. Da dieser Personenkreis sowohl seine Leistungsfähigkeit als auch seine weltanschauliche Zuverlässigkeit im Kampf gegen die Weimarer Republik bereits unter Beweis gestellt habe, sah Kolbenheyer keine Notwendigkeit für einen kontrollierenden staatlichen Einfluss auf dessen Arbeiten.

Den Begriff „Lebensstand“ grenzte Kolbenheyer mit Nachdruck von jenem des „Berufsstandes“ ab. Die Gliederung des deutschen „Volkswesens“ erschöpfte sich nach seiner Vorstellung nicht im bloß Ökonomischen. Vielmehr ging er von der Existenz einer biologisch bedingten, „natürliche[n] Gliederung“ des Volks aus, die nicht von Menschenhand „organisiert“ werden musste, nicht wirtschaftlich bedingt war, sondern eine „lebensständische, wesentlich erbbedingte und erbentwickelte [...] Artung"137 aufwies. Als theoretische Unterfütterung seiner Differenzierung zwischen „Lebensstand“ und „Berufsstand“ schlug Kolbenheyer das Modell eines „biologischen Sozialismus“138 vor, den er diametral von einem „demagogisch-rationalistischen Sozialismus“ abgrenzte. Letzterem warf er vor, in „naturwidrig[er]“ Weise für „alle Volksgenossen“ die „gleichen Funktionsrechte und die beliebige Funktionswahl“ eingefordert zu haben. Der „biologische Sozialismus“ sollte demgegenüber auf die unterschiedlichen, naturbedingten „Funktionsgruppen im Volke“ hinweisen, darunter eben, unter anderem, auf jene der "geistig Schaffenden“. Auch persönlich glaubte Kolbenheyer, nur deshalb den Beruf des Schriftstellers eingeschlagen zu haben, weil eine spezifische „auslesende Gattenwahl“ seiner „Eltern und Voreltern“139 den hierfür notwendigen biologischen „Wachstumsboden"140 geschaffen habe. Hinauslaufen sollte das Gesell-

135 Vgl. Kolbenheyer, Grundlagen [1933].

136 Vgl. Kolbenheyer, Lebensstand [1934]. Kolbenheyer hielt den Vortrag in Aachen, Dresden, Düsseldorf, Erlangen, Freiburg, Halle, Jena, Köln, München, Stuttgart, Tübingen und Würzburg, vgl. Kolbenheyer, Sebastian Karst, Bd. 3, S. 181-188. In Leipzig und bei einem zweiten Termin in Dresden kam es aufgrund lokaler Animositäten zu zwei im „Dritten Reich“ singulären Vortragsverboten Kolbenheyers, vgl. Kap. 5.2.2.

137 Kolbenheyer, Lebensstand [1934], S. 6 (Herv. i. Orig.).

138 Ebd., S. 11.

139 Ebd.

140 Ders., Sebastian Karst, Bd. 2, S. 72 . Bereits 1920 hatte Kolbenheyer hervorgehoben, dass die „schöpferische Persönlichkeit“ nicht aus einem „bloßen Vererbungsglück“ heraus entstehen könne. „Sie kann allein als Kulmination von eigengearteten Triebreihen erfaßt werden, die sich auf breiter Basis über zahlreiche Geschlechter hin zu ihr nicht nur ausgebaut haben, sondern haben ausbauen müssen“ (Kolbenheyer, Irrationales [1920], S. 5 f.). 
schaftsmodell des „biologischen Sozialismus“ auf ein „organisches Zusammenwirken eigengearteter, also funktionell und biologisch verschiedener Lebensbestände" 141 . Welchem „Lebensstand“ der einzelne Mensch angehörte, entschied sich nach diesem Denken qua Geburt - durch eine dem Willen des Individuums entzogene bzw. vorgeschaltete, vererbungsbedingte Prädisposition.

Insgesamt unterschied Kolbenheyer vier Lebensstände: Erstens das „Bauerntum“, das zugleich „Nährstand“ und „tiefste[r] Quellboden einer Blutzufuhr und -erneuerung“ der anderen Lebensstände sei. Zweitens den „Arbeiterstand“, der durch seine Produktivität den anderen Lebensständen „Zeit und Mühe" abnehme und dadurch den notwendigen Freiraum verschaffe, „der eigengearteten Werktätigkeit“ nachgehen zu können. Drittens den „Verwaltungs- und Verkehrsstand“, unter den Kolbenheyer alles dem Handel und der Wirtschaft sowie dem „Ordnungs- und Kommunikationswesen “ Zugehörige subsummierte. Viertens schließlich den „Lebensstand der beobachtenden, erkennenden, wegweisenden und entwickelnden Kräfte, de[n] Stand der geistig Schaffenden" ${ }^{142}$. Innerhalb dieses biologisch vorgeformten Modells einer Volksgemeinschaft galt es Kolbenheyer als die „Pflicht“ der „geistig Schaffenden“, „volksverantwortlich“ dafür zu sein, „die Ereignisse des überindividuellen, des völkischen Daseins in ihrer Entwicklung zu erkennen“ sowie „ihre Entstehung, ihren $[\ldots]$ naturbedingten Lauf und ihre künftige Wirklichkeit innerlich zu erschauen" ${ }^{143}$.

Diese dem „Lebensstand der geistig Schaffenden“ anheimgestellte Aufgabe, die „deutsche Kulturkraft und -leistung [...] aufrecht zu erhalten“, um dadurch die „Fähigkeit zu kultureller Führung“ innerhalb der „weißen Rasse“ zu bewahren, sah Kolbenheyer im „Dritten Reich“ durch eine zu weit getriebene staatliche Steuerung des „Geistesleben[s] “144 gefährdet. Hatte Kolbenheyer vor 1933 noch mit Nachdruck die Notwendigkeit eines kulturpolitischen Interventionismus zugunsten der völkischen, ,artgemäßen“ Kunst betont ${ }^{145}$, waren ihm nun, nach dem Exodus und der gewaltsamen Ausschaltung seiner literarischen Konkurrenz, die staatlichen Eingriffe zunehmend ein Dorn im Auge. Dies war auch deshalb der Fall, da jene organisatorischen Eingriffe in das Geistesleben von einer Generation jüngerer Nationalsozialisten ausgingen, der Kolbenheyer zwar vielfach guten Willen attestierte, nicht jedoch die Befähigung, die ihrem Ressort zufallenden Angelegenheiten angemessen beurteilen zu können. Entsprechend forderte er, einflussreiche kulturpolitische Ämter künftig nur noch durch ausgewiesene geistige „Führer“ zu besetzen, die eine eigenständige schöpferische Lebensleistung nachweisen könnten. Die nach der „Machtergreifung“ in zentrale kulturpolitische Positionen gelangten NS-Führungseliten betrachtete Kolbenheyer nicht als solche

141 Kolbenheyer, Lebensstand [1934], S. 11.

142 Ebd., S. 15 (Herv. i. Orig.).

143 Ebd., S. 7.

144 Ebd., S. 18, 20.

145 Zum völkischen Kunstverständnis Kolbenheyers vgl. Kap. 2.2.1. 
berufene „Führer“, sondern lediglich als „beauftragte“ „Kommandant[en]“. Der „Lebensstand der geistig Schaffenden“ dulde jedoch

„kein Kommando, er kann nur Führung dulden. Durch seine schöpferische Leistung unterscheidet sich der Führer vom Kommandanten. Wer das geistige Leben eines Volkes ordnen und gestalten will, der erweise sein Führertum durch schöpferische Leistung, die jedem Willen und Anspruch auf gestalterischen Einfluß vorausgegangen sein muß“146.

Die Forderung an den NS-Staat, der invasiven und überheblichen Organisationswut jener „Kommandanten“ künftig Einhalt zu gebieten und die „geistig Schaffenden“ in ihren Rechten zu stärken, verstand Kolbenheyer - einem „Wort des Führers"147 folgend - als Beitrag zur Transformation der nationalen „Revolution“ in die nationale „Evolution“. Er griff damit einen Ausspruch Hitlers vom 6. Juli 1933 auf, demzufolge sich die „Revolution [...] nicht zu einem Dauerzustand ausbilden“ dürfe, sondern „in das sichere Bett der Evolution“148 hinüberzuleiten sei. Während des revolutionären Umbruchs, so Kolbenheyer, hätten die geistig Schaffenden zunächst zu Recht hintangestanden, hätten sie doch in jener Phase forscher Dynamik unweigerlich ein retardierendes Moment dargestellt. Im Winter 1933/34 sah Kolbenheyer jedoch die Stunde gekommen, in der „deutsche Geistesmenschen“ wieder „die völkische Verpflichtung ihrer eigengearteten Funktion innerhalb des Gemeinschaftslebens erkennen, betätigen und behaupten“ müssten. Die „deutsche Revolution“, so Kolbenheyer, könne erst dann auch zur „deutsche[n] Evolution“ werden, wenn den einzelnen Lebensständen der nötige Entfaltungsraum geschaffen würde, sich „frei im Sinne der Gesamtleistung eines Volkes [zu] betätigen"149.

Dieses kämpferische Plädoyer für die Übertragung kulturpolitischer Macht an verdiente völkische Autoren seiner Generation ergänzte Kolbenheyer um die Warnung vor einer übersteigerten Geistesfeindlichkeit im „Dritten Reich“. Der NSKulturpolitik warf er vor, nicht ausreichend zwischen echter "Geistigkeit“ und bloßem „Intellektualismus“ zu differenzieren. Sein Unterscheidungskriterium ließ hier jedoch viel an Tiefenschärfe zu wünschen übrig: Zeitgemäße Geistigkeit unterschied sich für ihn von „einem überspitzten Intellektualismus“ lediglich dadurch, dass sie "den Volksboden nie“ verliere. Ein philosophischer Text, so Kolbenheyer, dürfe nicht automatisch als eine „faule Angelegenheit“ zurückgewiesen werden, nur weil er „nicht ohne weiteres jeder Durchschnittsintelligenz verständlich" 150 sei - hier kamen leidvolle Erfahrungen aus der Rezeption seiner Bauhütten-Philosophie zum Tragen. ${ }^{151}$ Zum Abschluss seiner Rede rief Kolbenheyer zur Sammlung und Zusammenarbeit jenes Personenkreises auf, den er sich selbst eingeschlossen - zu den „geistigen Führer[n]“ zählte, „die mit dem neuen Deutschland gehen, weil sie das neue Deutschland vorgebaut haben, ehe es

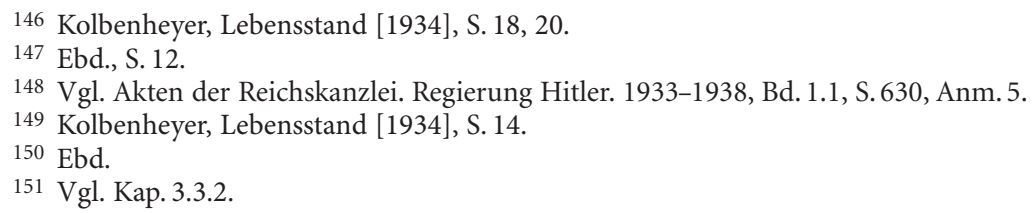


gewesen ist“152. Ihnen, den „wirklich Geistigen“ und wahren Vorkämpfern des „Dritten Reiches“, wollte Kolbenheyer „ihr lebensständisches Wesen“ vor Augen führen, das hieß ihr biologisches Erbe, welches sie gleichsam „zum Geistigen“153 zwang. Nur durch eine solche Solidarisierung der "geistig Schaffenden“ werde „die deutsche Lebenswelt wachse[n] und ihren Führerrang in der Welt der weißen Rasse behaupte[n] "154 können.

Wie schon das Befremden zeigt, mit dem Gottfried Benn auf Kolbenheyers Rede reagierte, fühlte sich beileibe nicht das ganze im „Dritten Reich“ verbliebene und nicht verfolgte "geistige Deutschland“ von dem Plädoyer des Dichters angesprochen. Benn fand Kolbenheyers Ausführungen gleichermaßen „langweilig“ und „konfus“; es sei „weder Biologie noch Philosophie noch Soziologie noch Politik. Von allem etwas und das Ganze hat man schon ein dutzend Mal gehört. Ich finde es auch sehr oberflächlich." 155 Bei vielen anderen namhaften Autoren und Wissenschaftlern fand Kolbenheyers Rede indes eine sehr positive Aufnahme. Mit der Argumentation, dass die lebenserfahrenen "geistig Schaffenden“ im NS-Staat eine exklusive kulturpolitische und wissenschaftliche Funktion erfüllen müssten, rannte Kolbenheyer bei ihnen offene Türen ein. Auch für seine Kritik an nazistischer Geistesfeindlichkeit erntete er viel Applaus. Ein kleines Panorama einschlägiger Schreiben mag dies illustrieren:

Der Leipziger Bibliothekar und Leiter des Instituts für Leser- und Schrifttumskunde Walter Hofmann ${ }^{156}$ begrüßte Kolbenheyers Ausführungen vorbehaltlos und verstand sie als notwendigen Beitrag im Kampf zwischen einem wahren und lebendigen Nationalsozialismus auf der einen und einem Nationalsozialismus der "Vermassung" und Uniformierung auf der anderen Seite. ${ }^{157}$ Otto Höfler, kurz vor seiner Berufung zum Professor für germanische Altertumskunde und Philologie an der Universität Kiel stehend, konnte im März 1934 „kaum“ zum Ausdruck bringen, wie gut ihm die „klare, feste, ernste Art“ tat, mit der Kolbenheyer gesagt habe, „was nottut“ 158 . Huldigende Worte fand auch der Professor für allgemeine Geschichte an der Universität Wien, Heinrich von Srbik ${ }^{159}$, dessen freundschaft-

152 Kolbenheyer, Lebensstand [1934], S. 20.

153 DLA, A:Stapel, Erwin Guido Kolbenheyer an Wilhelm Stapel, [?] Dezember 1933 (der undatierte Brief ist chronologisch zwischen zwei Briefen vom 14. und 24. Dezember eingeordnet).

154 Kolbenheyer, Lebensstand [1934], S.20f. In der Gesamtausgabe letzter Hand änderte Kolbenheyer die Formulierung „...Führerrang in der Welt der weißen Rasse“ zu dem unverfänglichen „...Rang in der Welt“. Vgl. zu dieser Problematik die Ausführungen in Kap. 1.5.

155 Zitiert nach der Abschrift des Briefs in: Scheufele, Dokumentation, S. 94.

$156 \mathrm{Zu}$ Person und dem im ersten Drittel des 20. Jahrhunderts einflussreichen Wirken Hofmanns (1879-1952) vgl. Marwinski, Bibliothek.

157 Vgl. KAG, Walter Hofmann an Erwin Guido Kolbenheyer, 26. Februar 1934.

158 KAG, Otto Höfler an Erwin Guido Kolbenheyer, 1. März 1934.

$159 \mathrm{Zu}$ Werk und Person Heinrich von Srbiks (1878-1951) vgl. Schönwälder, Srbik. Für völkische Ideologeme im Werk von Srbiks vgl. ebd., S. 533-540. Ebenso wie Kolbenheyer verstand und konzipierte auch von Srbik sein Schaffen explizit als „Dienst am Volk“ (zitiert nach ebd., S. 533). 
liche Beziehung zu Kolbenheyer auf das Jahr 1927 zurückging. ${ }^{160}$ Nach Übersendung der „Lebensstand“-Rede dankte Srbik für den hellsichtigen Mut, mit dem Kolbenheyer - in den Augen des berühmten Wiener Historikers die herausragende intellektuelle Führergestalt des „Dritten Reichs“ - vor einer Geringschätzung des Geistigen gewarnt habe. ${ }^{161}$ Auch der an der Medizinischen Akademie Düsseldorf lehrende Chirurgie-Professor Emil Karl Frey teilte Kolbenheyer nach wiederholter Lektüre der Rede seine völlige Zustimmung mit und klagte über die bedauerliche geistige Lage im NS-Staat. Frey konnte sich des Eindrucks nicht erwehren, dass „wohl nicht vom Führer selbst, aber von Vielen, die heute Rang und Stellung haben, [...] der Wert des freien geistigen Schaffens, das doch eine der besten deutschen Eigenschaften darstellt, unterschätzt, und zwar bewusst unterschätzt" werde. Ganz im Sinne Kolbenheyers betonte der Chirurg die Wichtigkeit, dass „diejenigen, die in der Lage sind, den Wert geistigen Schaffens für Deutschland zu beurteilen, sich aus dem Gefühl der Verantwortung heraus sammeln "162 würden. Dieser Idee habe Kolbenheyer mit seiner Rede die notwendige intellektuelle Substanz verliehen und sie erheblich vorangetrieben.

Belege der Zustimmung für die „Lebensstand“-Rede haben sich indes nicht nur in privaten Zuschriften an Kolbenheyer erhalten. So lehnte sich der Ordinarius für Mittlere und Neuere Geschichte an der Universität Halle, Siegfried A. Kaehler, im Mai 1934 in einem Brief an seinen Schüler Hermann Körner direkt an Kolbenheyers Ausführungen an, als er den damaligen Stand der NS-Bewegung kommentierte. Auch Kaehler orientierte sich hierbei an der oben zitierten Aussage Hitlers; es schien ihm „immer deutlicher“ zu werden, dass „gerade auf weltanschaulichem Gebiet“ die „Evolution noch längst nicht die [nationalsozialistische] Revolution abgelöst“ hatte. Stattdessen sei nach wie vor alles „im Fluß“. Kaehlers Hoffnung ging in dieser Situation dahin, dass „die jüngere Generation der sogenannten akademischen Schicht recht bald in die Lage " komme und sich als fähig erweise, jene „Aufgaben zu übernehmen und durchzusetzen“, die „Kolbenheyer in seinem Programm des ,Lebensstandes der geistig Schaffenden“ angezeigt" $" 163$ habe.

Nach eingespieltem Muster trug auch Will Vesper zur Verbreitung und Popularisierung der Rede bei, indem er sie den Lesern seiner Zeitschrift Die neue Literatur als „dringend[e]“ Lektüreempfehlung gab. Kolbenheyers „Kritik aus liebendem Herzen“ sei für die Gegenwart von eminenter Bedeutung, da sie „Dunst und Missverständnisse“ vertreibe. Die Rede umfasse keine Zeile, die „selbst das unsicherste Gemüt als schädlich für die [NS-]Bewegung empfinden könnte“. Wer

160 Srbik ging damals ein Exemplar des Romans Das Lächeln der Penaten zu, worauf er sich als ein Bewunderer und Anhänger von Kolbenheyers literarischem und philosophischem Werk zu erkennen gab. Vgl. KAG, Heinrich von Srbik an Erwin Guido Kolbenheyer, 12. Juni 1927. Knappe Hinweise zu Kolbenheyers Das Lächeln der Penaten in: Jäger, Literatur, S. $162 \mathrm{f}$.

161 Vgl. KAG, Heinrich von Srbik an Erwin Guido Kolbenheyer, 18. März 1934.

162 KAG, Karl Emil Frey an Erwin Guido Kolbenheyer, 28. Februar 1934.

163 Brief Siegfried Kaehlers an Hermann Körner vom 14. Mai 1934, abgedruckt in: Bußmann/ Grünthal (Hg.), Kaehler, S. 247f. (für den Hinweis auf diesen Brief danke ich Peter Keller). 
Gegenteiliges behaupte, mache sich einer „plumpe[n] Beleidigung des echten Nationalsozialismus"164 schuldig.

Dieser Optimismus erwies sich indes als unzutreffend. Zwar erfuhr Kolbenheyer, wie seit Anbeginn seiner Vortragstätigkeit, einen erheblichen Zuspruch und Publikumszulauf, wo immer er seine „Lebensstand“-Rede hielt, von einigen Exponenten der NSDAP wurde seine „Kritik aus liebendem Herzen“ jedoch sehr wohl als feindseliger Akt wahrgenommen. Die Versuche Grimms, Kolbenheyers und Stapels, nach 1933 Einfluss auf die NS-Bewegung auszuüben, stießen angesichts des rigorosen Alleingültigkeitsanspruchs des Nationalsozialismus auf eine demonstrative und mitunter überaus scharfe Ablehnung. Die Zurückweisungen der Lenkungsversuche und die Vorbehalte gegen die drei Autoren von Seite der NSDAP sind Gegenstand der nachfolgenden Überlegungen.

\subsubsection{Vorbehalte und Kritik gegen Grimm, Kolbenheyer und Stapel im „Dritten Reich"}

Seht, meine Freunde, so etwas gibt es heute. Man erhebt den Anspruch einer der größten deutschen Schaffenden der Gegenwart zu sein, man fordert, daß die Nation in schweigender Ehrfurcht vor seinem Werke steht, - aber man singt das Horst-Wessel-Lied nicht, man demonstriert seine selbstständige Mannhaftigkeit gegen diesen, nationalsozialistischen Unfug. Kleines Bild eines großen Dichters! ${ }^{165}$

KritiK an Grimms ÖfFentlichen Stellungnahmen Im Jahr 1932 - Die zwar im Kern eindeutig befürwortenden, zugleich aber vorsichtig mahnenden Äußerungen zur NSDAP, die Grimm im Jahr 1932 in die Öffentlichkeit getragen hatte, gerieten im „Dritten Reich“ nicht in Vergessenheit. Vielmehr spitzte sich die Kritik an Grimm im Vergleich zur späten Weimarer Republik zunächst weiter zu, sodass mitunter gar die ganz und gar verfälschende Behauptung kolportiert wurde, Grimm habe sich 1932 in eine offene Gegnerschaft zum Nationalsozialismus begeben. Nationalsozialistische Kritiker machten Grimm nicht nur seine gemeinsam mit August Winnig veröffentlichte Bitte an den Nationalsozialismus zum Vorwurf. ${ }^{166}$ Scharfe Kritik entzündete sich auch an der Rede Von der bürgerlichen Ehre und bürgerlichen Notwendigkeit, die Grimm in den letzten anderthalb Jahren der Republik in mehreren deutschen Städten gehalten hatte. ${ }^{167}$ Auch in ihr hatte Grimm zwar unmissverständlich zugunsten Hitlers und der NSDAP Stellung

164 Die neue Literatur 35 (1934), S. 245.

165 Der Angriff, 3. Juli 1935. Zitiert nach: Gümbel, Volk, S. $195 f$.

166 Vgl. Kap. 5.2.1.

167 Erstmals hatte Grimm die Rede am 28. November 1931 in Berlin gehalten. Als Organisator fungierte damals die Fichte-Gesellschaft. Grimm konnte das Manuskript seines Vortrags durch die exzellente Beziehung zu Paul Fechter (vgl. Kap. 3.1.3) sogleich in der Berliner DAZ veröffentlichen. 
bezogen ${ }^{168}$, es zugleich jedoch nicht unterlassen, auf die seiner Meinung nach vorhandenen Unvollkommenheiten der Hitler-Partei hinzuweisen. Neben der Warnung vor einer zu starken Annäherung der NS-Bewegung an marxistische Techniken und Positionen, die bereits im Zentrum der Bitte an den Nationalsozialismus gestanden hatte, kritisierte Grimm in seiner Rede vor allem die starken antibürgerlichen Ressentiments in der NSDAP und zielte somit auf ein „Erstarken des nationalen Besitz- und Bildungsbürgertums"169 im Gefüge der NS-Ideologie ab. Sein Plädoyer für eine größere Hochachtung des Bürgertums versuchte er dabei merklich in eine der nationalsozialistischen Zielgruppe einleuchtende Rhetorik zu kleiden:

„Ich glaube an Blut, ich glaube an die Kraft des Erbes, aber ich weiß, daß Blut und Erbe sich erschöpfen können. Ich vertrete hier nicht ein ererbtes Recht bestimmter Geschlechter zur Oberschicht, aber ich [...] vertrete freilich den Gedanken der Oberschicht [...] und ich vertrete den Willen und die Fähigkeit und Voraussetzungen zur Oberschicht, die das Pariaideal nicht kennt, während deutscher Bürgersinn sie kennt. [...] wenn man Abstand und Form und Andacht und Tradition und Persönlichkeit und das Streben nach materieller Unabhängigkeit angreift, greift man die Notwendigkeit jeder künftigen Oberschicht an, wenn man den Bürgersinn ausrottet, rottet man den Willen zur Oberschicht aus, und mit diesem Willen geht der Wille zum Herrenvolke ebenfalls verloren." 170

Jedoch umsonst: Da Grimms öffentliche Stellungnahmen des Jahres 1932 von kritischen Tönen nicht völlig frei geblieben waren, wurden sie im „Dritten Reich“ pauschal als eine Versündigung an der NS-Bewegung gewertet und gegen den Dichter gekehrt.

Dies war nicht etwa nur bei führenden NS-Funktionären wie Joseph Goebbels der Fall. ${ }^{171}$ Auch von gewöhnlichen „Märzgefallenen“172 wurden scharfe Vorwürfe laut, wie das Beispiel des Herausgebers der Zeitschrift für Deutschkunde Walther Linden illustriert. Im Sommer 1933 veröffentlichte Linden, der am 1.April 1933 Mitglied der NSDAP geworden war ${ }^{173}$, in seiner Zeitschrift einen Aufsatz, der die Entwicklung des politischen Denkens von Thomas Mann und Hans Grimm thematisierte und negativ als „Entwicklungsstufen scheidender Bürgerlichkeit“174 deutete. Zwar griff Linden zunächst den altbekannten, anerkennenden Topos auf, Grimm habe sich durch Volk ohne Raum einen „ungeheuren Verdienst in der

168 „Der Führer“, so Grimm mit Blick auf Hitler, habe sich „in acht Jahren gesteigert [...] wie wenige Deutsche vor ihm [...]. Ich sehe bewundernd, daß er fast als Erster in der Welt Menschenmasse ohne Zwang und auch ohne irgendeinen nahen Nutzen aus ihrem völlig freien Willen in seine Gefolgschaft gebracht hat" (ebd., S. 17, Herv. i. Orig.). Der Nationalsozialismus erschien Grimm vor diesem Hintergrund freiwilliger Gefolgschaft als „die erste und bisher einzige echte demokratische Bewegung des deutschen Volkes. Ich höre die Nationalsozialisten als erste Volkskreise sich nicht zur Gleichheit sondern zur Gemäßheit, und das heißt, sich zur Führerschaft der jeweils Besten bekennen, wodurch eben sie ganze Deutschheit dartun" (ebd., S. 15, Herv. i. Orig.).

169 Gümbel, Volk, S. 150.

170 Grimm, Ehre, S. 32 (Herv. i. Orig.).

171 Vgl. Kap. 5.2.4.

172 Vgl. Falter, „Märzgefallenen“; Weigel, „Märzgefallene“.

173 Vgl. Kaiser, Grenzverwirrungen, S. 135, Anm. 18.

174 Vgl. Linden, Entwicklungsstufen. 
neueren deutschen Dichtungsgeschichte" erworben, da er als erster Dichter ein „bis in den Kern politische[s] Romanwerk der Gegenwart geschaffen "175 habe. Für alles über den Roman hinausgehende hatte Linden aber nur Kritik übrig. Gegen Ende der Weimarer Republik, so sein hauptsächlicher Vorwurf, sei im politischen Denken Grimms ein fundamentaler und unseliger Wandel eingetreten: Ausgerechnet während der „großen Entscheidungskämpfe des Jahres 1932“ habe sich Grimm bewusst in einen offenen „Gegensatz“ zu dem „steil emporwachsenden [...] Nationalsozialismus" gesetzt und sich auf die „Seite der konservativen Reaktion" geschlagen. Anstatt dem Nationalsozialismus mit aller Kraft beizustehen, habe es Grimm vorgezogen, der Bewegung in aller Öffentlichkeit vorzuwerfen, „den Proletarier zu begünstigen und zu bolschewistisch zu werden" ${ }^{176}$. In dieser Kritik, so die in diesem Fall durchaus zutreffende Diagnose Lindens, sei die „,bürgerliche Angst" des Dichters vor den „erwachten und empordrängenden Massen" zum Tragen gekommen. Zu dem nationalsozialistischen Glauben einer „Umschmelzung zum neuen Menschen“ habe Grimm „trotz seiner tiefen und lebendigen Einsichten in die wahren deutschen Volksnöte" nicht finden können; ein „breite[r] Graben des Generationsunterschiedes" habe ihn vielmehr von diesem Glauben „getrennt “177. Anstatt also das „aufbrechende Massengefühl“ als einen „Durchbruch deutschen organischen Geistes“ zu begrüßen, sei Grimms Denken ganz „im Wirtschaftlichen“ befangen und infolgedessen von einem „eigenbrötlerische[n] Zug “178 nicht frei geblieben.

Dieser Kritik schloss sich ein hektischer, emotionsgeladener Briefwechsel zwischen Linden und Grimm an, der rasch zu einem schroffen Bruch zwischen den beiden zuvor konstruktiv miteinander verkehrenden Männern führte. ${ }^{179}$ Tief empört beschwerte sich Grimm unmittelbar nach der Veröffentlichung des Artikels bei Linden darüber, dass es „ganz unmöglich“ sei, wenn „in der gegenwärtigen Zeit" behauptet werde, er habe 1932 gegen den Nationalsozialismus agitiert.

175 Ebd., S. 356. In Volk ohne Raum habe der deutsche Leser erstmalig die Möglichkeit gehabt, die Handlung einer epischen Dichtung vollständig „auf die großen deutschen Volksschicksale bezogen" zu sehen. Insbesondere aus diesem Grund sei der Roman nach seinem Erscheinen „,on der deutschen Jugend und weit ins Auslanddeutschtum hinein jubelnd begrüßt" worden.

176 Ebd., S. 358.

177 Ebd. (Herv. i. Orig.). Näheres zu dem Aspekt des Generationsunterschiedes im nachfolgenden Kapitel.

178 Ebd., S. 359f. (Herv. i. Orig.).

179 Es entbehrt nicht der Ironie, dass Linden just zu jenem Zeitpunkt, als Grimm mit seiner später so stark bekrittelten Bitte an den Nationalsozialismus an die Öffentlichkeit trat, in einem Vortrag über die Deutsche Dichtung der Gegenwart, den er in zahlreichen deutschsprachigen Gemeinden in Rumänien, Jugoslawien, Bulgarien und Polen hielt, für Grimms Werk geworben hatte: „Ich habe meinen Vortrag ,Deutsche Dichtung der Gegenwart', der Ihr Werk und dasjenige Kolbenheyers und Carossas als Lebensdeutung des modernen Deutschland behandelt, in Neusatz [...] und Groß-Betschkerek [...], in Belgrad in der Jugoslaw[isch]$\mathrm{d}[\mathrm{eu}] \mathrm{t}[\mathrm{schen}]$ Gesellschaft [...], in Sofia (Universität), Philippopel, Stara Zagora, Burgas und Varna [...] gehalten und immer wieder die Erfahrung gemacht, daß eine ruhige und besonnene Hervorhebung des nationalen deutschen Standpunktes die entschiedenste Wirkung ausübt" (DLA, A:Grimm, Walther Linden an Hans Grimm, 21. Oktober 1932). 
Grimm warf Linden vor, in gewissenloser Weise verleugnet zu haben, dass all seine Veröffentlichungen des Vorjahrs „in sehr wesentlichen Augenblicken die Nationalsozialistische Bewegung zu unterstützen versucht" hätten. Wer die Texte Grimms liest, wird dem Dichter hier zustimmen müssen. Entsprechend forderte Grimm von Linden, seine falschen Behauptungen in der nächsten Ausgabe der Zeitschrift für Deutschkunde „unter allen Umständen“ vor den Augen der Öffentlichkeit richtigzustellen. ${ }^{180}$

In einer ausführlichen Replik „bedauer[t]e“ Linden, Grimms „Forderung ablehnen zu müssen“. Linden hielt stattdessen an seiner Interpretation fest, dass Grimm zwar zu Beginn des Jahres 1932 die NS-Bewegung „durch eine Sympathieerklärung unterstützt“, anschließend sein Verhältnis zu ihr jedoch „entscheidend“181 geändert habe. Mit der „Sympathieerklärung“ spielte Linden auf Grimms Antwort und Aufruf an Deutsche an, die vor dem zweiten Wahlgang der Reichspräsidentenwahl im April 1932 erschienen war. In ihr hatte Grimm öffentlich bekundet, Hitler wählen zu werden, und ,jede[n] Deutsche[n]“ aufgefordert, „wenigstens um seiner Kinder willen [...] dasselbe [zu] tun“182. Mit seiner anschließend „durch alle deutschen Zeitungen“ hallenden Bitte an den Nationalsozialismus habe sich der Dichter jedoch „gegen die Bewegung gewandt“ und an ihrer statt den „versinkenden bürgerlichen Kräfte[n]“ den Vorzug gegeben. Möge Grimm seinen Text auch „in bester Absicht“ verfasst oder „sogar geglaubt haben, den richtigeren und besseren Nationalsozialismus zu vertreten“: Innerhalb der Bewegung sei sein Schritt als „Verrat im entscheidenden Augenblick“183 aufgefasst worden. Dasselbe galt in den Augen Lindens für die Rede Von der bürgerlichen Ehre und bürgerlichen Notwendigkeit; sie habe „in gleicher Richtung“ gewirkt. Am „aufreizendsten“ sei Grimms „Behauptungsversuch der bürgerlichen Kräfte“ jedoch bei einer Teilnahme an einem Berliner „Herrenklubessen“ im Jahr 1932 zum Ausdruck gekommen. Hier habe sich Grimm „unter die Namen der reaktionären Schildhalter des versinkenden Bürgertums“ gemischt sowie jene „der mit diesen verbündeten jüdischen Finanzleute"184. Vor diesem Hintergrund war es Linden „unerfindlich“, wie Grimm behaupten konnte, die Vorwürfe seien „aus der Luft gegriffen“. Seine Darstellung könne er nur dann „berichtigen“, wenn Grimm einen „sachlichen Anlass“ hierfür liefern könne. Angesichts der Inhalte der ihm vorliegenden Texte meinte Linden jedoch keine andere Ansicht vertreten zu können als jene, dass Grimm sich 1932 mit der NS-Bewegung „nicht nur in einem

180 DLA, A:Grimm, Hans Grimm an Walther Linden, 30. Oktober 1933.

181 DLA, A:Grimm, Walther Linden an Hans Grimm, 6. November 1933.

182 Grimm, Antwort [1932], S. 15.

183 DLA, A:Grimm, Walther Linden an Hans Grimm, 6. November 1933. Mit „im entscheidenden Augenblick" spielte Linden auf den Wahlkampf für die exakt ein Jahr vor der Entstehung des Briefs stattgefundene Reichstagswahl an.

184 Ebd. Zur Geschichte des Deutschen Herrenklubs (ab 1933: Deutscher Klub), der 1924 von Heinrich von Gleichen-Rußwurm, einem Vertrauten Grimms, gegründet worden war und stark unter dem Einfluss der Schriften Arthur Moeller van den Brucks stand, vgl. Schoeps, Herrenklub; Malinowski, „Führertum“. 
Zustand höchster Gespanntheit, sondern auch im offenen Kampfe befunden“185 habe. Die diametrale Gegensätzlichkeit der Auffassungen über die den fraglichen Texten innewohnende politische Tendenz und Aussageabsicht ließ sich letzten Endes nicht auflösen. Was Grimm als eine für die langfristige Prosperität des Nationalsozialismus notwendige Hilfestellung erachtete, deutete Linden als reaktionären Versuch, die NS-Bewegung zu einer grundsätzlichen Kursumkehr zu bewegen, welche sich nur zu ihrem Nachteil hätte auswirken können.

Sehr zum Leidwesen Grimms erwies sich der Vorwurf, er sei 1932 öffentlich als Gegner des Nationalsozialismus aufgetreten, im „Dritten Reich“ als ausgesprochen zählebig. Spöttisch vermerkte im Juli 1935 etwa ein Artikel des NS-Blatts Der Angriff, Grimm habe noch 1932 als „Wanderprediger die deutsche Bürgerlichkeit“ gepriesen, als „über die Feigheit und Verlogenheit des deutschen ,Bürgers“ schon die Hühner lachten“. Der von Grimm erhobene „Anspruch[,] einer der größten deutschen Schaffenden der Gegenwart“ zu sein, vor dessen Werk „die Nation in schweigender Ehrfurcht" 186 zu stehen habe, sei so in sich zusammengebrochen. Angesichts solcher Vorwürfe echauffierte sich auch der Leiter des LMV, Gustav Pezold, im September 1935 gegenüber Wilhelm Stapel darüber, wie „verlogen“ die Unterstellung sei, Grimm habe „in den Jahren vor dem Umsturz Hitler bekämpft“. In Wahrheit, so der sichtlich um die Absatzchancen des bis dahin erfolgreichsten Hausautors besorgte Verleger, sei Grimm während der Präsidialkabinette „mit dem ganzen Gewicht seiner Persönlichkeit für Hitler und öffentlich ja auch mehrmals für Goebbels eingetreten"187.

Diese Deutung ist prinzipiell korrekt, klammert jedoch aus, dass Grimms Plädoyers zugunsten der NSDAP stets mit dem pädagogischen Anspruch auf politische Belehrung verbunden waren, der in einer totalitären Bewegung, die vorbehaltlose Gefolgschaft und Einordnung einforderte, unweigerlich Friktionen hervorrufen musste. Dadurch geriet die eigentliche Intention Grimms, zur Stabilisierung und zum Erfolg der NS-Bewegung beizutragen, aus dem Blickfeld. Anspielend auf die Auseinandersetzung mit Linden klagte Grimm im November 1933 gegenüber seinem langjährigen Vertrauten Alfred Hugenberg, ununterbrochen „kleine[n] Schweinereien“188 ausgesetzt zu sein. Eine wirkungsvolle argumentative Strategie gegen die Vorwürfe gelang dem Dichter zu keinem Zeitpunkt.

KonflikTe um Kolbenheyers „LebensSTAnd“-Rede - Mit ablehnenden Reaktionen auf seine Rede Der Lebensstand der geistig Schaffenden und das neue Deutschland sah sich Kolbenheyer erstmals im Januar 1934 konfrontiert, nach einer Veranstaltung im Auditorium Maximum der Universität München. Der Vortrag war im Rahmen des Winterhilfswerks organisiert worden und hatte prominente Zuhörer

185 DLA, A:Grimm, Walther Linden an Hans Grimm, 6. November 1933.

186 „Kleines Bild eines großen Dichters“, in: Der Angriff vom 3. Juli 1935, zitiert nach: Gümbel, Volk, S. $195 \mathrm{f}$.

187 DLA, A:Stapel, Gustav Pezold an Wilhelm Stapel, 23. September 1935.

188 DLA, A:Grimm, Hans Grimm an Alfred Hugenberg, 1. November 1933. 
angelockt. Unter den Anwesenden befand sich etwa der bayerische Kultusminister und Gründer des Nationalsozialistischen Lehrerbunds Hans Schemm. ${ }^{189}$ Im Anschluss an den Vortrag kam es - der Autobiografie Kolbenheyers zufolge - im „Studentenhaus“ zu einer „sehr heftigen Diskussion“ mit einigen in der SA organisierten Studenten. Schon während der Rede wollte Kolbenheyer die Anwesenheit einer „Gruppe des Widerstandes“ unter seinen Zuhörern verspürt haben, von welcher er dann im Studentenhaus stark angegriffen worden sei. Zugleich habe er unter den Studenten jedoch auch „gewichtige Sekundanten“190 gefunden.

Kolbenheyers Andeutungen können durch Äußerungen des in der Bundesrepublik bekannt gewordenen rechtsextremen Publizisten Kurt Ziesel ergänzt werden. ${ }^{191}$ Ziesel hatte als damaliger Mitarbeiter des Völkischen Beobachters dem Vortrag Kolbenheyers beigewohnt und war auch bei der anschließenden Diskussion zugegen. Aufgrund seiner engen persönlicher Verbindung mit Kolbenheyer muss seine Schilderung indes mit großer Vorsicht behandelt werden. ${ }^{192}$ Nach Ziesels Darstellung spitzte Kolbenheyer in der Diskussion seine Warnung vor „drohenden Gefahren eines kulturellen Niedergangs im neuen Staat“ noch einmal zu und machte sie nun speziell der SA zum Vorwurf. Kulminiert sei Kolbenheyers Kritik in der Aussage, das „Maulheldentum“ der „ungeistige[n] Radaubrüder“ der SA, wie überhaupt ihr gesamtes Auftreten, stelle eine „Kulturschande“ für Deutschland dar. Über diese Äußerung sei es „beinahe zu einer Schlägerei“193 gekommen. Ziesel berichtet überdies, dass er am Tag nach dem „Skandal“ von Reinhard Heydrich, damals Leiter der Politischen Abteilung der Polizeidirektion München, zum Rapport über die Ereignisse einbestellt und dabei mit einem Haftbefehl gegen den Dichter konfrontiert worden sei. Mit seinem Verweis auf die angebliche „Weltgeltung“ Kolbenheyers habe er jedoch dessen Verhaftung verhindern können. ${ }^{194}$

Fraglos spitzte Ziesel die Ereignisse einseitig zu. Sein Versuch, Kolbenheyer heroisierend als angeblich „anständig gebliebenen“195, vom NS-Staat schwer bedrängten Exponent des geistigen Deutschland darzustellen, ist evident. Ziesel gehörte nach $1945 \mathrm{zu}$ den fleißigsten Apologeten Kolbenheyers und forderte „auf öffentlichen Veranstaltungen [...] wiederholt“ dazu auf, „endlich auch Kolben-

189 Vgl. Kolbenheyer, Sebastian Karst, Bd. 3, S. $184 \mathrm{f}$.

190 Ebd., S. 185.

191 Zur schillernden, von skandalträchtigen Prozessen insbesondere gegen Günter Grass begleiteten und hoher Publizität gekennzeichneten „Zweiten Karriere“ Ziesels (1911-2001) nach 1945 vgl. Busch, NS-Autoren, S. 219-286.

192 Ziesel zeigte sich in seiner Arbeit davon überzeugt, dass er es ,ausschließlich dem Mut, der Kameradschaft und der menschlichen Anständigkeit" Kolbenheyers zu verdanken hatte, „nicht ein paar Jahre lang in den Kerkern und Lagern Hitlers verbracht“ zu haben. Aus diesem „Blickwinkel“ erschienen Ziesel nach dem Zweiten Weltkrieg alle „Verdammungen und Verurteilungen“ Kolbenheyers und anderer Autoren „als besonders fragwürdig, niederträchtig und absurd“" (Ziesel, Gewissen, S. 20).

193 Ziesel, Gewissen, S. 21.

194 Ebd., S. $21 \mathrm{f}$.

195 Zum Topos des „anständig geblieben“-Seins in der bundesrepublikanischen Erinnerungskultur vgl. die Beiträge in Gross (Hg.), Moral. 
heyer in Deutschland [wieder] gebührend zu ehren.“"196 In den zeitgenössischen Briefen Kolbenheyers an Stapel im Frühjahr 1934, die von detailreichen larmoyanten Selbstdarstellungen des Dichters ansonsten schier überquellen, ist von einer quasi in letzter Sekunde verhinderten Inhaftierung jedenfalls keine Rede. Als das Winterhilfswerk nach einem Jahr abermals Veranstaltungen in München organisierte, wurde Kolbenheyer erneut eingeladen, wobei er unter abermals „sehr groß $[\mathrm{em}]$ “ Zustrom eine Lesung aus seinen Werken geben konnte. ${ }^{197}$ Muss also Ziesels Behauptung einer nur um ein Haar vermiedenen Inhaftierung auch stark relativiert werden, so ist damit nicht gesagt, dass Kolbenheyer während der Diskussion im Münchner Studentenhaus nicht in der Tat scharfe Kritik gegen die SA geäußert hat. Kolbenheyer litt zeit seines Lebens nicht unter mangelndem Selbstbewusstsein; außerdem steht außer Frage, dass er zum damaligen Zeitpunkt eine starke persönliche Abneigung gegen die SA empfand. Dies zeigt nicht zuletzt seine Erleichterung, als er von der Liquidierung der SA-Führung im Rahmen des sogenannten Röhm-Putschs erfuhr. Die „Reinigung des SA-Kommandos“ ließ Kolbenheyer „aufatmen. Solche Kerle gehören weg.“ Hitler habe „sehr tapfer gehandelt" 198 .

Innerhalb der Führungsriege der NSDAP war es insbesondere der „Beauftragte des Führers für die Überwachung der gesamten geistigen und weltanschaulichen Schulung und Erziehung der NSDAP“ und frühere Kolbenheyer-Bewunderer ${ }^{199}$ Alfred Rosenberg, der aufgrund der „Lebensstand“-Rede eine deutliche Aversion gegen den Dichter entwickelte. Zufolge einer persönlichen Unterredung zwischen Stapel und Rosenberg im September 1934, war der "Chefideologe“ der NSDAP überzeugt, dass Kolbenheyer die Rede spezifisch als Kritik gegen ihn und sein Amt konzipiert hatte. Folgt man Stapels vertraulicher Paraphrasierung der unter vier Augen gemachten Äußerungen Rosenbergs, fühlte sich dieser ,gekränkt", dass sich Kolbenheyer "gegen ihn und überhaupt gegen den Nationalsozialismus gestellt" habe. Kolbenheyers Vortrag legte Rosenberg „als Angriff gegen sich aus“200 - eine

196 Brüdigam, Schoß, S. 260

197 KAG, Wilhelm Stapel an Erwin Guido Kolbenheyer, 5. April 1935 (Herv. i. Orig.).

198 DLA, A:Stapel, Erwin Guido Kolbenheyer an Wilhelm Stapel, 2. Juli 1934. Stapel sekundierte Kolbenheyer in dieser Ansicht: Seine „erste Empfindung“ war demnach: „Gott sei Dank, die Säuberung beginnt!“ Anschließend habe er sich jedoch an „der unnötig moralisierenden, unsachlichen Ansprache Goebbels“ gestört, insbesondere daran, dass Röhms Homosexualität nun als allgemein bekannt bezeichnet werde, während man zuvor für eine entsprechende Äußerung „ins Konzentrationslager“ gesteckt worden sei. Stapel ließ sich dabei von der propagandistischen Hochverratsbehauptung hinters Licht führen: „Ich kann mir das bei Röhm gut vorstellen“. Zugleich reagierte er mit makabren Zynismus, als er die Auffassung vertrat, dass es für Röhm, der „abgesehen vom Moralischen, ein Mordskerl, ein geborener Revolutionär“ gewesen sei, den „stilvolle[n] Abschluß seines Lebens“ bedeute, dass er nun „sozusagen von seinen eigenen Leuten abgeknallt“ worden sei (KAG, Wilhelm Stapel an Erwin Guido Kolbenheyer, 5. Juli 1934). Zur propagandistischen Funktionalisierung der sexuellen Orientierung Röhms im „Dritten Reich“ vgl. Nieden/Reichardt, Skandale.

199 Zur Würdigung Kolbenheyers in Rosenbergs Mythus des 20. Jahrhunderts vgl. Kap. 5.1.

200 KAG, Wilhelm Stapel an Erwin Guido Kolbenheyer, 27. September 1934 (Herv. i. Orig.). 
unzutreffende Annahme, die Kolbenheyer noch in seiner Autobiografie zurückgewiesen hat. ${ }^{201}$

Rosenbergs Abneigung gegen den Dichter entlud sich im März 1934, als er während einer „Kulturwoche“ des Gaus Thüringen in Weimar einen Vortrag über „Die Weltanschauung des Nationalsozialismus“ hielt, in den er eine abschätzige Anspielung auf Kolbenheyer einfließen ließ. Auf eine namentliche Nennung des Dichters verzichtete Rosenberg zwar, sodass gewiss nicht alle Hörer (und Leser) der Rede die Anspielung verstanden, für Kenner der „Lebensstand“-Rede war sie jedoch evident. Konkret nahm Rosenberg jene „Kreise“ ins Visier, die der Meinung seien, den Nationalsozialismus über die Themen „Autorität“ und „Führerschaft" aufklären zu müssen und belehren zu können; „ganz weise“ werde etwa behauptet, dass man „zwischen Führern und Kommandanten“ unterscheiden müsse. Zur Erziehung jener „Kommandanten“ werde die Notwendigkeit „geistige[r] Führer“ postuliert, die sich als eigener „Lebensstand des deutschen Volkes [...] zu einem sozusagen abstrakten Führertum“ zusammenfinden müssten. Laut Rosenberg kam in dieser Forderung "gelinde gesagt, eine geistige Arroganz" zum Ausdruck, gegen die der Nationalsozialismus seit jeher gekämpft habe. Zugleich spiegle sich in ihr der „Verzweiflungskampf gewisser, geistiger Schichten“ wider, denen Rosenberg unterstellte, in der Überzeugung zu leben, die nationale Revolution sei deshalb zustande gekommen, damit sie sich „bequem“ einem "Philisterdasein“ hingeben könnten. Jegliche Trennung zwischen „einen Handwerker- und einen geistigen Lebensstand“" werde von der nationalsozialistischen Weltanschauung jedoch abgelehnt: „Wenn wir das zugestehen würden, hätten wir 14 Jahre umsonst gekämpft“202.

Dieses publizistische Scharmützel war freilich Ausdruck eines übergreifenden, allgemeineren Konflikts. So war, wie Rosenberg in seiner Unterredung mit Stapel betonte, innerhalb der NSDAP großer Unmut entstanden, als nach der Berufung Hitlers zum Reichskanzler in Teilen der Presse „eine Anzahl Schriftsteller [...] als die eigentlichen Erfinder des Nationalsozialismus gefeiert worden“ seien. Dabei sei so getan worden, als habe „der Nationalsozialismus seine Gedanken woanders her“, auch Hitler sei in den Artikeln „nur nebenbei, wie aus Höflichkeit, erwähnt worden“. Eine solche „Legende“ habe sich „der Nationalsozialismus nicht gefallen lassen“ können und sei deshalb in einen „Kampf gegen die Ansprüche von Literaten“ getreten, „die sich an die Stelle der eigentlichen Träger der Bewegung setzen wollten" 203 . Auch Rosenberg trieb also das Interesse an, den - ideengeschichtlich betrachtet - zutiefst epigonalen Charakter der NS-Ideologie zu kaschieren, wie es schon in Hitlers Mein Kampf zum Ausdruck gekommen war. ${ }^{204}$ Den Nationalso-

201 Vgl. Kolbenheyer, Sebastian Karst, Bd. 3, S. 237.

202 Thüringische Staatszeitung. Amtliches Nachrichtenorgan der Thüringischen Staatsregierung und der Gauleitung Thüringen der N.S.D.A.P., 3. März 1934, Nr. 53 (Herv. i. Orig.).

203 KAG, Wilhelm Stapel an Erwin Guido Kolbenheyer, 27. September 1934.

204 Vgl. Kap. 5.2.1. 
zialisten, so Stapels treffende Formulierung, ging es also auch um einen „Kampf ums Urheberrecht ${ }^{\text {“205. }}$.

Rosenbergs Rede in Weimar und der Vorfall in München blieben nicht die einzigen Episoden in einem für Kolbenheyer konfliktreichen Frühjahr 1934. Inmitten einer großen Vortragsreise, die sich an den Münchner Vortrag anschloss, erhielt Kolbenheyer am 23. Januar einen Brief der Universität Leipzig, in welchem er im Namen des damaligen Rektors Arthur Golf gebeten wurde, von dem geplanten Vortrag seiner „Lebensstand“-Rede „Abstand zu nehmen“. Andernfalls stünden „Unruhen zu befürchten“206. Kurz darauf erfuhr Kolbenheyer, dass auch ein für Dresden geplanter Vortrag mit derselben Begründung abgesagt wurde. Zugleich informierte ihn ein "Gewährsmann" in Leipzig - es handelte sich sehr wahrscheinlich um Erich Kröning 207 -, dass die Leipziger Presse angewiesen worden sei, jegliches Wirken für Kolbenheyer zu „unterbrechen“. Weder „Voranzeigen, noch Berichte, noch Hinweise auf das Werk, noch Besprechungen" seien zu veröffentlichen. Als wichtigste Drahtzieher der Anweisungen vermutete Kolbenheyer „Kreishauptmann Dönnike [sic!] und Gauschulungsleiter Studentkowsky [sic! ]" 208 .

Diese Informationen wirkten auf Kolbenheyer zunächst wie ein Schock, schien sich in ihnen doch die Möglichkeit einer staatlich koordinierten Aktion zur Unterbindung weiterer Veranstaltungen seiner Rede anzudeuten. Solche Befürchtungen stellten sich jedoch bald als unbegründet heraus. Die beiden Verbote in Leipzig und Dresden blieben Einzelfälle, die durch lokale Animositäten bedingt waren. Ihre Bedeutung für Kolbenheyers Stellung in der Frühphase des „Dritten Reiches" wird daher leicht überschätzt. Bereits die unlängst geäußerte Behauptung, Kolbenheyer sei infolge seiner „Lebensstand“-Rede „zeitweilig die Vortragstätigkeit untersagt" 209 worden, führte in die Irre, da sie ein wenn auch kurzfristiges, so doch reichsweites Vorgehen gegen den Dichter impliziert, welches so nie stattgefunden hat.

Vor den Ereignissen in Leipzig hatte Kolbenheyer seine Rede unter anderem „in Halle $[\ldots]$ unter großem Zulauf $\mathrm{u}[\mathrm{nd}]$ stürmischem Beifall halten“210 können. Auch in Dresden hatte er vor dem dortigen Verbot bereits gastiert und zwar, wie er im Dezember 1933 nicht ohne Stolz an Stapel berichtete, mit einem

205 KAG, Wilhelm Stapel an Erwin Guido Kolbenheyer, 27. September 1934.

206 Zitiert aus den maschinenschriftlichen Aufzeichnungen Kolbenheyers zum Vortragsverbot in: DLA, A:Stapel, Erwin Guido Kolbenheyer an Wilhelm Stapel, 25. Januar 1934 (Beilage).

207 Vgl. Kap. 3.5.2.

208 DLA, A:Stapel, Erwin Guido Kolbenheyer an Wilhelm Stapel, 25. Januar 1934 (Beilage). Beide Namen der NS-Funktionäre schrieb Kolbenheyer falsch. Es handelte sich um Walter Dönicke (1899-1945) und Werner Studentkowski (1903-1951). Das Amt des „Kreishauptmanns" in Leipzig hatte Dönicke von 1933 bis 1937 inne. Anschließend fungierte er bis zu seinem Selbstmord im April 1945 als Oberbürgermeister der Stadt Leipzig. Studentkowski arbeitete von 1934 bis 1941 im Rang eines Oberregierungsrats im Sächsischen Volksbildungsministerium. Anschließend war er im Propagandaministerium tätig.

209 Scheufele, Dokumentation, S. $92 \mathrm{f}$.

210 DLA, A:Stapel, Erwin Guido Kolbenheyer an Wilhelm Stapel, 25. Januar 1934. 
„geradezu stürmischen Erfolg“. „Viele Leute konnten nicht mehr zugelassen werden. Man stand im Stiegenhaus"211. Und auch nach den Verboten in Sachsen konnte Kolbenheyer seine Vortragsreise ohne Störungen weiterführen: Als die Deutsche Akademie in Würzburg im Februar 1934 auf Veranlassung Kolbenheyers bei den Behörden offiziell anfragen ließ, ob ein Einverständnis mit einer Veranstaltung der Rede vorliege, wurde sogleich grünes Licht gegeben. ${ }^{212} \mathrm{Im}$ November 1934 schrieb Kolbenheyer an August Winnig, dass er seinen Vortrag „nun schon 4mal [...] nach dem damaligen Verbot öffentlich wiederholt“ habe und zwar jeweils „nach ausdrücklicher Forderung der Veranstalter“213. Anfragen bei den „entsprechende[n] N.S.-Führungsstelle[n]“ hätten stets ergeben, dass dem Vortrag nichts im Wege stehe. Die Verbote in Leipzig und Dresden, so schlussfolgerte Kolbenheyer mit guten Gründen, gingen auf das „Betreiben irgend welcher untergeordneter Personen“ zurück. Die eigentlich „betreffenden Führer“ seien hingegen mit zu vielen „andern Angelegenheiten überhäuft“214, um sich selbst einzuschalten.

Angriffe Gegen Stapel und Gegen DAS „Deutsche Volkstum“ - Eine ähnliche Erfahrung wie Kolbenheyer in Leipzig und Dresden machte Stapel in Kiel. Dort wurde bereits im November 1933 ein von dem studentischen Kampfbund deutscher Christen veranstalteter Vortrag zum Thema „Deutschtum und Christentum" auf polizeiliche Weisung kurzfristig abgesagt. ${ }^{215}$ Wie Stapel mitgeteilt wurde, ging das Verbot auf eine Beschwerde des „aus 14 Studenten“ bestehenden „Kieler Heiden-Verein[s] - kein Witz, sondern Tatsache -“ zurück. Dieser habe im Vorfeld der Veranstaltung „mit Störung gedroht“ und sei von dem „atheistische[n] Rektor" der Universität unterstützt worden. Der Kieler Polizeipräsident, „ein Graf zu Rantzau“, sei „vor dieser ,Macht“ zusammen[geknickt]“216. Die selbsterklärten Heiden hatten zuvor in der Kieler Zeitung verlautbaren lassen, Stapels Auffassung „über Religion und Rasse“, insbesondere aber die von ihm „behauptete Vereinbarkeit von Deutschtum und Christentum“, sei „für die junge nationalsozialistische Generation untragbar"217. Das Verbot kam für Stapel umso überraschender, als er die Kerninhalte des geplanten Vortrags kurz zuvor ohne jede Widerstände in der Broschüre Die Kirche Christi und der Staat Hitlers hatte

211 DLA, A:Stapel, Erwin Guido Kolbenheyer an Wilhelm Stapel, 14. Dezember 1933.

212 Vgl. DLA, A:Stapel, Erwin Guido Kolbenheyer an Wilhelm Stapel, 21. Februar 1934.

213 KAG, Erwin Guido Kolbenheyer an August Winnig, 30. November 1934 (Durchschlag, Herv. i. Orig.).

214 Ebd.

215 Eine Schilderung der Stellungnahmen zahlreicher Beteiligter in: Schmalz, Kirchenpolitik, S. 100-103.

216 KAG, Wilhelm Stapel an Erwin Guido Kolbenheyer, 18. November 1933. Das Rektorenamt hatte damals der Professor für Physikalische Chemie, Karl Lothar Wolf (1901-1969), inne. Den Vorwurf gegen Wolf nahm Stapel später zurück, vgl. Schmalz, Kirchenpolitik, S. 101.

217 DLA, A:Stapel, Manuskripte: Bericht über das Verbot von Stapels Vortrag an der Universität Kiel, S. 3. 
publiziert können. ${ }^{218}$ Zudem hatte Stapel noch am Vortag des Verbots auf Einladung „an der Eröffnung der Reichskulturkammer in Berlin teilgenommen“219. Entsprechend groß war zunächst seine Empörung über das Vortragverbot in Kiel. Über dessen Ungeheuerlichkeit schien ihm „die Weimarer Republik [...] noch im Grabe“ zu lachen. Gerade „vor den Augen der Juden“, so Stapel, sei das Verbot tief „beschämend“, zumal die von ihm entwickelten Thesen im Einklang mit dem „klaren Wortlaut des Parteiprogramms“ und „viele[n] Äußerungen des Führers“220 stünden.

Stapel verfasste nach Verlautbarung des Verbots einen Beschwerdebrief an $\mathrm{Ru}-$ dolf Heß, der ihm als Leser des Deutschen Volkstums persönlich bekannt war. ${ }^{221}$ Dessen damaliger Sekretär Martin Bormann setzte sich daraufhin mit der schleswig-holsteinischen Gauleitung in Verbindung, welche die Mitteilung gab, der Vortrag sei verboten worden, da der veranstaltende Kampfbund deutscher Christen „seit längerer Zeit gegen die Politik der örtlichen Kieler Studentenschaft und der des nationalsozialistischen Studentenbundes Opposition getrieben “ habe. Das Verbot, so versicherte Bormann, habe sich „keinesfalls“ gegen Stapel „persönlich gerichtet“222. Wie schon bei den Verboten von Kolbenheyers „Lebensstand“-Rede in Leipzig und Dresden der Fall, gründeten demnach auch die Ereignisse in Kiel auf spezifischen lokalen Begebenheiten. Spürbar befriedigt stellte Stapel dann auch Ende Januar 1934 fest, dass die gesamte „Gesellschaft von studentisch-heidnischen Wichtigtuern“, von denen das Verbot angestoßen worden war, mittlerweile „davongejagt“ worden sei. „Gott schütze Hitler vor solchen Urgermanen!"223

Stapels Freude und Beruhigung über das Verschwinden des Kieler Heiden-Vereins hielt indes nicht lange an. Sein anfängliches kämpferisches Selbstbewusstsein

218 Die Broschüre, durch die Stapel „bewußt auf die Deutschen Christen als Bündnispartner“ seiner kirchenpolitischen Bemühungen setzte (Schmalz, Kirchenpolitik, S. 252), wurde 1933 drei Mal neu aufgelegt.

219 DLA, A:Stapel, Manuskripte: Bericht über das Verbot von Stapels Vortrag an der Universität Kiel, S. 2.

220 Ebd., S. 2f. Stapel bezog sich hier auf Punkt 24 des Parteiprogramms der NSDAP vom 24. Februar 1920, der vorsah, dass „die Partei als solche [...] den Standpunkt eines positiven Christentums“ vertrete. Stapel überschätzte nicht nur in der Öffentlichkeit die Verbindlichkeit des Parteiprogramms für die NS-Herrschaftspraxis bei Weitem. Auch privat hielt Stapel eine Argumentation mit den Inhalten des Parteiprogramms für stichhaltig: Als ihm über seinen Mitarbeiter A. E. Günther zu Ohren kam, dass ihm von Seiten der NSDAP sein vermeintliches Eintreten „für das Alte Testament“ zum Vorwurf gemacht wurde, kommentierte Stapel dies wie folgt: „Abgesehen davon, daß ich die Autorität des A.T. im dauernden Kampf mit den Theologen bestreite - welch eine kümmerliche politische und kulturelle Sektiererei, einen Menschen, dessen Hilfe man vierzehn Jahre lang gern hinnahm, zu verfemen, weil er im Sinne des Punktes 24 des nat.soz. Parteiprogramms Christ ist!“ (KAG, Wilhelm Stapel an Erwin Guido Kolbenheyer, 26. März 1934, Herv. i. Orig.).

221 Vgl. Literaturarchiv der Monacensia, NL Kalkschmidt, B 98: Wilhelm Stapel an Eugen Kalkschmidt, 5. Dezember 1941.

222 DLA, A:Stapel, Nationalsozialistische Deutsche Arbeiterpartei an Wilhelm Stapel, 22. Dezember 1933.

223 KAG, Wilhelm Stapel an Erwin Guido Kolbenheyer, 26. Januar 1934. 
unter der Parole „Los auf die Minderwertigen! Los auf das Neidgesindel!“ 224 wich rasch einer spürbaren Resignation. Im Gegensatz zu Kolbenheyer, der das Tal öffentlicher Kritik Mitte 1934 bereits durchschritten hatte, traten bei Stapel erst ab 1935 die schwerwiegendsten und langfristigsten Konfliktfelder zutage. Ebenso wie Grimm und Kolbenheyer wäre zwar auch er bereit gewesen, als kulturelles Aushängeschild des NS-Regimes zu fungieren, anders als die Dichter besaß Stapel als politischer Publizist in den Augen der NS-Kulturpolitiker jedoch nicht das hierfür gewünschte Profil und notwendige Renommee.

$\mathrm{Zu}$ Recht hat Oliver Schmalz darauf verwiesen, dass „Stapels Verbindung von Volksgedanken und Christentum“225 häufig Hintergrund der nach 1933 an ihm geäußerten Kritik war. Man muss sich hier jedoch von der Vorstellung lösen, Stapel sei bei den entsprechenden Konflikten stets unbedarftes Opfer perfider „deutschgläubiger“ Aggressoren gewesen. Als Stapel etwa im Frühjahr 1936 in der Zeitschrift Durchbruch, dem Organ der christentumsfeindlichen Deutschen Glaubensbewegung ${ }^{226}$, attackiert wurde, war dies eine Reaktion auf eine zuvor im Deutschen Volkstum veröffentlichte Polemik Stapels. Entsprechend beschwerte sich Hans Kurth, damals Schriftleiter des Durchbruch, in seinem Artikel darüber, dass Stapel die Mitglieder der Deutschen Glaubensbewegung „in einem Atemzuge mit dem Bolschewismus“ genannt und in „eine innere Verwandtschaft“227 mit ihm gestellt habe. Für diesen Angriff revanchierte sich Kurth, indem er Stapel eine "Kampfweise“ vorwarf, die ansonsten nur „bei Rabbinern und Jesuiten“ zu beobachten sei. Darüber hinaus führte er Stapels Kritik auf ein gleichsam naturgesetzmäßiges Unverständnis zurück: Wer, so wie Stapel, „das Christentum als ,geoffenbarte Wahrheit“" betrachte und „sich zur Erbsündenlehre“ bekenne, könne den „Deutschen Glauben“ schlechterdings nicht verstehen, sondern müsse ihn „ablehnen und [...] bekämpfen“228.

224 Aus etwa dreimonatiger Distanz zu dem Vortragsverbot in Kiel sprach Stapel davon, dass den Attacken der "Minderwertigen“, welche "gelten wollen, aber nicht durch Leistung gelten können“, offensiv begegnet werden müsse. Den Kieler Heiden-Verein habe weniger seine christliche Gesinnung als seine „überlegene [...] Logik“ gereizt: „Damit werden sie nicht fertig, darum nehmen sie das Mittel der Diffamierung. Los auf die Minderwertigen! Los auf das Neidgesindel! Damit das Dritte Reich nicht den Spartakisten in die Hände fällt! Mitten zwischen Reaktion und Spartakismus geht der Weg hindurch“ (KAG, Wilhelm Stapel an Erwin Guido Kolbenheyer, 2. Februar 1934, Herv. i. Orig.).

225 Schmalz, Kirchenpolitik, S. 99.

226 Vgl. Junginger, Glaubensbewegung; Nanko, Sammlung.

227 Durchbruch. Kampfblatt für deutschen Glauben, Rasse und Volkstum, 14. Mai 1936.

228 Ebd. (Herv. i. Orig.). Der Konflikt hatte insofern eine Vorgeschichte, als Kurth Mitte der 1920er Jahre von Stapel angezeigt worden war, nachdem dieser die Behauptung aufgestellt hatte, das Deutsche Volkstum sei ein Organ der Freimaurer. Bei dem anschließenden Verfahren stellte sich freilich heraus, dass Kurths Vorwürfe frei erfunden waren. Stapel betont, dass Kurth vor seiner Arbeit in der Deutschen Glaubensbewegung „Frau Ludendorffs Redakteur“ gewesen sei, was eine Erklärung für Kurths erfundene Freimaurerverdächtigung wäre, welche sich im Hause Ludendorff hoher Beliebtheit erfreuten. Zur Aussage Stapels vgl. KAG, Inv. Nr. 169: Hilfen 1933-1945: Wilhelm Stapel an Erwin Guido Kolbenheyer, 31. Januar 1936. 
Wie zwei Aufsätze der von Alfred Rosenberg herausgegebenen Nationalsozialistischen Monatshefte ${ }^{229}$ illustrieren, erschöpfte sich die Kritik am Deutschen Volkstum indes nicht allein in Angriffen gegen das christliche Bekenntnis ihres Herausgebers. Stapels Zeitschrift wurde im Amt Rosenberg grundsätzlich als unwillkommene Konkurrenz genuin nationalsozialistischer Organe betrachtet. Die Kritiker Stapels waren dabei oft auffallend jung. Im Januar 1936 sah etwa der gerade erst 26-jährige, stellvertretende Schriftleiter der Nationalsozialistischen Monatshefte und spätere Leiter der Abteilung für „Juden- und Freimaurerfragen“ im Amt Rosenberg ${ }^{230}$, Eberhard Achterberg (1910-1983), einen Anlass zur pauschalen Abrechnung mit dem Deutschen Volkstum gekommen. Als Aufhänger diente ihm der kurz zuvor in Stapels Zeitschrift erschienene Aufsatz Religiöse Volkskunde ${ }^{231}$ des späteren Würzburger Professors für Volkskunde Josef Dünninger. In dessen „Geschreibsel“ erkannte Achterberg eine grundsätzliche „Absage an unsere Weltanschauung“232 - eine Absage, in der sich zugleich der allgemeine Charakter von Stapels Zeitschrift spiegele. Der Aufsatz, so Achterberg, zeige, „wie es mit der oft betonten nationalsozialistischen Einstellung dieser Zeitschrift“ in Wirklichkeit bestellt sei. Gerade ,in den Fragen, die am tiefsten in die Auseinandersetzung der Gegenwart“ eindrängen, sei „eine innere Haltlosigkeit und Zwiespältigkeit“ zu spüren, „die aber wohl mehr ein Stehen zwischen den Fronten“ sei. Stapels Deutsches Volkstum sei „jedenfalls nur sehr bedingt auch unser Volkstum“233.

Noch deutlich schärfer wurde Stapel im Mai 1937 für seine Publikationen zur "Judenfrage“ von dem damaligen Hauptschriftleiter der Nationalsozialistischen Monatshefte, Matthes Ziegler (1911-1992)234, attackiert. Anlass des Angriffs war in diesem Fall die kurz zuvor veröffentlichte Schrift Die literarische Vorherrschaft der Juden in Deutschland 1918-1933. Stapel hatte sie im Auftrag des Reichsinstituts für Geschichte des neuen Deutschlands verfasst, in dessen Sachverständigenbeirat er seit 1935 tätig war. ${ }^{235}$ Sehr zu seinem Verdruss (und nicht ganz zu Unrecht) vermutete Stapel nach der Veröffentlichung von Zieglers Aufsatz, Opfer des Kompetenzgerangels und der persönlichen Animositäten zwischen Alfred Rosenberg und Walter Frank, dem Leiter des Reichsinstituts, geworden zu sein: Der "große Angriff“ in den Nationalsozialistischen Monatsheften, so Stapel, sei ein

„Akt vor allem gegen Prof. Frank. Auf diese Weise tragen die Herren heute ihre Feindschaften aus. Was soll unsereiner dabei tun? Man leistet ehrliche Arbeit - nicht um sich einzudrängen, sondern auf Anforderung - und dann wird man von der Kreatur[?] eines Machthabers öffentlich bespuckt, ohne die Möglichkeit zu haben, sich wehren zu können. “236

229 Zur Geschichte dieser Zeitschrift vgl. Rusinek, Monatshefte.

230 Vgl. Gossman, Brownshirt, S. 108.

231 Vgl. Deutsches Volkstum. Monatsschrift für das deutsche Geistesleben 17 (1935), S. 898903.

232 Achterberg, Zeitschriftenschau, S. 200.

233 Ebd. (Herv. i. Orig.).

234 Zur Biografie Zieglers vgl. Gailus, Kirchenkämpfer.

235 Wulf, Literatur, S. 446.

236 KAG, Wilhelm Stapel an Erwin Guido Kolbenheyer, 17. Mai 1937 (Herv. i. Orig.). Ausführliche Informationen zum Verhältnis zwischen Rosenberg und Frank in: Heiber, Frank. 
Matthes Ziegler - oder wie er in den Briefen Stapels fortan in Erscheinung trat: „Matjes Ziegler“237 - griff in seinem Aufsatz die Inhalte und Ausrichtung des vorgeblich „sachlichen“ Antisemitismus an, durch die Stapel in den Diskussionen zur "Judenfrage“ während der Weimarer Republik eine erhebliche Diskursmacht zuteil geworden war. ${ }^{238}$ Nun aber wurden Stapel die Abwendung „von dem RadauAntisemitismus der Straße“ und seine auf Wahrung des rechten „Taktes“ ausgerichteten Ansichten zum Vorwurf gemacht. Ziegler stieß sich vor allem an dem Aufsatz Versuch einer praktischen Lösung der Judenfrage, den Stapel 1932 in dem Sammelband Was wir vom Nationalsozialismus erwarten veröffentlicht hatte. Man wisse nicht, so Ziegler, „worüber man sich mehr wundern“ solle: Die „Unbekümmertheit“, mit der Stapel „der praktischen Politik des Nationalsozialismus Vorschriften zu machen“ wage, oder aber „die Undiskutierbarkeit dieser Vorschläge selbst“239. Dass Stapel seine während der „Systemzeit“ vertretenen Ansichten in seiner Studie des Reichsinstituts wiederaufgewärmt habe, trug in den Augen Zieglers „den Charakter der Unentschuldbarkeit“240. Abschließend anerkannte Ziegler zwar gönnerhaft „gewisse Verdienste“, die sich Stapel vor 1933 durch das Deutsche Volkstum erworben habe, legte diesem jedoch nicht ohne drohenden Unterton „dringend nahe“, künftig „auf den Ruhm eines Wissenschaftlers im Staate Adolf Hitlers zu verzichten!“241

Im Falle der Attacke Zieglers sah Stapel von einer öffentlichen Reaktion ab. Gegenüber Kolbenheyer begründete er dies damit, der HVA „keine Schwierigkeiten [...] bereiten" $242 \mathrm{zu}$ wollen. Die hauptsächliche Ursache seines Verzichts auf eine Gegendarstellung war indes, dass er sich zwei Jahre zuvor in einer Auseinandersetzung mit der der SS-Zeitung Das schwarze Korps ${ }^{243}$ schwer die Finger verbrannt hatte. Da dieser Konflikt bereits in gebührender Detaildichte von Oliver Schmalz beschrieben worden ist ${ }^{244}$, kann hier auf eine ausführliche Zusammenfassung verzichtet werden. Zum Verständnis der Ablehnung Stapels, sich zu den Vorwürfen Zieglers öffentlich zu äußern, ist jedoch das Wissen notwendig, dass Stapel 1935 mit der Taktik gescheitert war, seine Zeitschrift zu Gegenangriffen auf herablassende Artikel des Schwarzen Korps zu nutzen. Nach einer Reihe von Artikeln, in denen er als Gegner des Nationalsozialismus porträtiert worden war ${ }^{245}$ und auf die er polemisch geantwortet hatte, beantragte Stapel am 28. August 1935

237 Vgl. bspw. KAG, Wilhelm Stapel an Erwin Guido Kolbenheyer, 31. Mai 1937.

238 Vgl. Kap. 3.2.2.

239 Ziegler, Stapel, S. 412.

240 Ebd., S. 414. Insbesondere kritisierte Ziegler, dass Stapel den nationalsozialistischen Anteil an dem „Kampf gegen die literarische Vorherrschaft der Juden“ viel zu gering geachtet, jenen der „deutschen Geistigkeit“ hingegen viel zu hoch gestellt habe (ebd., S. 415).

241 Ebd., S. 417.

242 KAG, Wilhelm Stapel an Erwin Guido Kolbenheyer, 31. Mai 1937.

243 Zum Programm des Schwarzen Korps und seiner Bedeutung für die SS vgl. Zeck, Korps, bes. S. 89-117, 283-304.

244 Vgl. Schmalz, Kirchenpolitik, S. 103-108.

245 Vgl. bes. Otto Hildebrand, Hinter der freundlichen Maske, in: Das schwarze Korps. Zeitung der Schutzstaffeln der NSDAP. Organ der Reichsführung der SS, 10. Juni 1935. 
gegen Gunter d'Alquen, den Schriftleiter des Schwarzen Korps ${ }^{246}$, ein ehrengerichtliches Verfahren beim Reichsverband der Deutschen Presse. Dabei musste er letztlich die frustrierende Erfahrung machen, dass sein aufwendiger, mit ausführlichem Beweismaterial seiner pronazistischen Gesinnung versehener Antrag ohne jegliche Begründung abgeschmettert wurde. Die „Abschaffung des angeblich überholten ,bürgerlich-liberalen Rechtstaats “ machte sich auf diese Weise ,auch für Stapel empfindlich bemerkbar" ${ }^{\text {"247. }}$.

Neben den Angriffen in einschlägigen NS-Blättern erreichte Stapel am 11. Dezember 1936 für seine Arbeit im Deutschen Volkstum auch eine Rüge durch Alfred-Ingemar Berndt, den damals „stellvertretende[n] Pressechef der Reichsregierung in der Presseabteilung "248 im Reichsministerium für Volksaufklärung und Propaganda. Nach Berndts Auffassung hatte Stapel zuvor in einem Aufsatz zum Thema Der preußische Staat erkennen lassen, „noch nicht die für den deutschen Schriftleiter notwendige innere Einstellung zum nationalsozialistischen Staat hergestellt ${ }^{\text {“249 }} \mathrm{zu}$ haben. Stapel hatte in dem Artikel das Verschwinden eines preußischen Geistes im NS-Staat bedauert und im Wesentlichen eine "Grabrede auf Preußen" ${ }^{250}$ gehalten - eine Auffassung, die Berndt angesichts des „Staatsakts in der Garnisonskirche in Potsdam“ als „äußerst bedenklich“ schien. Für „ganz unmöglich“ hielt er indes Stapels „zweifelnde Beantwortung“ der Frage, ob „die deutsche Volksgemeinschaft ein Gesetz" 251 besitze. Überhaupt würdige Stapel in seiner Zeitschrift „die Geschehnisse der neuen Zeit“ viel zu wenig; die im Deutschen Volkstum „zu Tage tretende Einstellung zum neuen Staat" bilde "durchaus keine günstige Voraussetzung für die Erfüllung" der Stapel „durch das Schriftleitergesetz auferlegten Berufspflichten“. Ebenso wie Matthes Ziegler verzichtete auch Berndt nicht darauf, seine Ausführungen mit einer Drohung zu beenden: Sollte Stapel in Zukunft seine Einstellung nicht

246 Zur Biografie Gunter d’Alquens (1910-1998) vgl. Zeck, Korps, S. 10-68.

247 Keßler, Stapel, S. 208. Die emotionalen und psychologischen Folgewirkungen der Ablehnung des Ehrengerichtsverfahrens werden in Kap. 5.3.1 thematisiert.

248 Vgl. Barbian, Literaturpolitik, S. 93.

249 Zitiert nach Keßler, Stapel, S. 252.

250 Ebd., S. 204.

251 Stapel hatte in dem entsprechenden Artikel argumentiert, dass der preußische Staat seit dem 10. November 1918 aufgehört habe zu existieren, namentlich „in dem Augenblick, als der preußische König und die preußische Armee sich voneinander lösten“. Berndts Kritik zielte jedoch hauptsächlich auf den letzten, ausklingenden Absatz des Artikels, in dem Stapel einen Blick auf die Zeit nach 1933 warf. Zum Verständnis der Kritik Berndts sei der Absatz hier vollständig wiedergegeben: „Eine neue Welt ist auf aufgestiegen aus anderen Gründen der Seele. Seit 1933 gibt es ein ,Deutsches Volk'. Die Preußen waren kein,Volk', sie waren ein ,Staat'. Der Staat war des Preußen strenges Gesetz. Hat auch die deutsche Volksgemeinschaft ein Gesetz? Was ist ihr Nomos? Preußisch war es, ,durch manchen sauren Tritt hindurch ins Alter dringen', auf daß ich tragen mag in Ehren graues Haar'. Preußisch war König Friedrich Wilhelm, als er sich den Holzsarg ins Zimmer tragen ließ und genaue Anweisungen gab. Preußisch war König Friedrich im sorgenvollen Lehnstuhl zu Sanssouci. Deutsche Volksgemeinschaft aber - was ist ihr Nomos und ihr Ethos? Vielleicht ist es die Lebensfreude" (Stapel, Staat [1936], Zitate S. 753f., Herv. i. Orig.). 
korrigieren, würden die „notwendigen Folgerungen“ gezogen. ${ }^{252}$ In der Tat behielt das Ministerium Stapels Zeitschrift weiterhin im Auge. Mit welch perfider Kleinkariertheit es dabei vorging, zeigte sich am 6. Mai 1938, als es Stapel schriftlich dafür tadelte, Heinrich Mann in seiner Zeitschrift namentlich erwähnt zu haben. Konkret hatte Stapel im Deutschen Volkstum die harmlose Feststellung gemacht, dass die Werke des kurz zuvor verstorbenen italienischen Schriftstellers Gabriele D'Annunzio in Deutschland kaum Wirkung entfaltet hätten, der Einfluss jedoch am ehesten in Werken Heinrich Mann zu spüren sei. Durch diese Bemerkung habe Stapel den fatalen Eindruck erweckt, Heinrich Mann könne „noch als deutscher Dichter betrachtet“ werden. In Zukunft, so die ministerielle Anweisung, seien „Emigranten überhaupt nicht mehr, es sei denn in eindeutig negativem Sinne, zu erwähnen“253.

Die von Grimm, Kolbenheyer und Stapel gehegten Hoffnungen, auf die politische Entwicklung des Nationalsozialismus Einfluss gewinnen zu können, wurden von Vertretern der NSDAP im „Dritten Reich“ letztlich mit denkbar einfachen Methoden zurückgewiesen. Die vor 1933 veröffentlichten, klar zugunsten der NSBewegung argumentierenden Texte Grimms und Stapels wurden schlicht auf ihre vereinzelt kritischen Passagen reduziert und so verfälschend zu angeblichen Dokumenten anti-nationalsozialistischen Denkens erklärt. Derselbe Befund gilt für Kolbenheyers Rede Der Lebensstand der geistig Schaffenden und das neue Deutschland aus dem Jahr 1933. Kolbenheyers Plädoyer, eine Stabilisierung des „Dritten Reichs“ könne nur durch einen stärkeren Einbezug der seit 1918 für den völkischen Gedanken wirkenden Intellektuellen seiner Generation gelingen, verhallte innerhalb der NSDAP und blieb wirkungslos. Dass seine Rede außerhalb der Partei demgegenüber starken Zuspruch erfuhr, konnte für den Dichter nur ein schwacher Trost sein. Hatten es Grimm, Kolbenheyer und Stapel nach 1918 unternommen, sich demonstrativ von der älteren Riege der völkischen Bewegung des wilhelminischen Kaiserreichs abzugrenzen ${ }^{254}$, so wurde ihnen nun ein ähnliches Schicksal von Seiten junger Nationalsozialisten zuteil. Ein Unterschied bestand freilich darin, dass die Kritik und Abgrenzung nun sehr viel respektloser, persönlich verletzender und auch unversöhnlicher ausfiel. Dies zeigt sich vor allem bei Stapel, der sich gemessen an Grimm und Kolbenheyer im ersten Jahrfünft des „Dritten Reichs“ mit den deutlich schärfsten Angriffen konfrontiert sah. An den Lebensdaten der in diesem Kapitel berücksichtigten nationalsozialistischen Kritiker hat sich dabei bereits ein signifikanter Anteil von Vertretern der im ersten Jahrzehnt des 20. Jahrhunderts geborenen „Kriegsjugendgeneration“ angedeutet. Das Verhältnis zu dieser Alterskohorte während der Weimarer Republik und im „Dritten Reich“ soll im Folgenden anhand des Beispiels von Hans Grimm detaillierter in den Blick genommen werden.

252 Zitiert nach Keßler, Stapel, S. 252f.; Zum "Staatsakts in der Garnisonskirche in Potsdam“ vgl. Müller, Tag.

253 Zitiert nach Keßler, Stapel, S. 254.

254 Vgl. Kap. 2.2.2. 


\title{
5.2.3 Verschleppter Generationenkonflikt - Zum Verhältnis Hans Grimms zur "Kriegsjugendgeneration"
}

\begin{abstract}
Die Sprache, die Sie in "Volk ohne Raum" reden, verstehen wir alle, aber diese Sprache verstehen wir nicht. Mag das nun an uns liegen oder an Ihnen, die Frage, wer denn schuld sei an dem Missverstehen, scheint mir völlig gleichgültig. Gar nicht gleichgültig aber ist es, daß zwischen Ihnen und den besten deutschen Jungen eine Kluft entsteht. Deshalb habe ich Ihnen das alles schreiben müssen, und ich habe meinen ganzen Zorn in diesen Brief hineingelegt, damit Sie auch genau verstehen, was Sie sich und uns angetan haben. ${ }^{255}$
\end{abstract}

Grimms schier märchenhafter Aufstieg von einer unbedeutenden Randfigur des literarischen Lebens zu schlechterdings dem Autor der Weimarer Rechten infolge der Publikation seines Romans Volk ohne Raum (1926) wurde auch von jener Alterskohorte mitgetragen, die in der Forschung als „Kriegsjugendgeneration“ (Ulrich Herbert), „Überflüssige Generation“ (Detlev Peukert) oder „Generation des Unbedingten“ (Michael Wildt) bezeichnet und herausgearbeitet worden ist. ${ }^{256}$ Die Jahrgänge 1902-1912, die sich nach dem Ersten Weltkrieg „als besonders anfällig für die totalitären Deutungsmuster und Ideologieangebote“ erwiesen und „weitaus mehr als etwa die Frontkämpfergeneration zum gewaltsamen Konfliktaustrag“ 257 neigten, sind im Nachlass Grimms zahlreich vertreten. Die Intensität der ehrfurchtsvollen Begeisterung, mit der sie in der zweiten Hälfte der Weimarer Republik - und insbesondere in den Jahren 1931/32 258 - Grimm und seinem Hauptwerk begegneten, legt es zuweilen nahe, von Grimm als von einem Vaterersatz zu sprechen. ${ }^{259}$

Die enorme Wirkung und Ausstrahlung des Autors schlug sich auch darin nieder, dass Grimms einstmals verschlafenes Domizil Lippoldsberg nach der Veröffentlichung von Volk ohne Raum schier zu einem Pilgerort orientierungssuchender Bewunderer, insbesondere jüngeren Alters, wurde. In welcher Größenordnung Grimm von ehrfurchtsvollen Ratsuchenden auf-, um nicht zu sagen heimgesucht wurde, unterstreicht eine von der Schreibhilfe des Dichters geführte Statistik, nach der zu Beginn der 1930er Jahre nicht weniger als durchschnittlich acht Besucher pro Tag dem Herren Lippoldsbergs ihre Aufwartung machten. ${ }^{260}$

255 DLA, A:Grimm, Ottokar Lorenz an Hans Grimm, 28. Januar 1933.

256 Vgl. Herbert, Best, bes. S. 42-45; Peukert, Republik, S. 25-31; Wildt, Generation, bes. S. 2329.

257 Wirsching, Generationen, S. 45.

258 Der Grund hierfür ist sicherlich in der Publikation der verbilligten Volksausgabe von Volk ohne Raum (1931) zu suchen. Vgl. Kap. 2.3.3.

259 Vgl. Gümbel, Volk, S. $143 \mathrm{f}$.

260 Vgl. Grimm, Suchen, S. 42: „In einem Jahre, es kann nur das Jahr 1931 oder 1932 gewesen sein, schrieb meine Helferin alle Besucher auf, die im Klosterhaus einen bald größeren bald kleineren Imbiss [...] erhalten hatten, da ergab sich am Ende des Jahres die Zahl Dreitau- 
Zufolge einer - von persönlicher Sympathie gefärbten - Einschätzung Paul Fechters, dem sein erster eigener Besuch in Lippoldsberg stets in lebhafter Erinnerung blieb $^{261}$, leistete Grimm infolge seiner Bereitschaft, das junge, sinn- und orientierungssuchende Deutschland bereitwillig in seinem als „Wallfahrtsstätte“ dienenden Klosterhaus aufzunehmen und ihm zuzusprechen, „mehr an lebendigem, echt politischen Erziehen“ als „alle Lager- und Schulungs- und Bildungskurse“262 zusammen. Die Suggestionskraft Grimms und Lippoldsbergs auf die nationale Jugend ist anekdotenhaft auch in Ernst von Salomons berühmten Roman Der Fragebogen (1951) eingeflossen. „Kaum ein Tag“, so Salomon, der Grimm einst selbst mehrfach in Lippoldsberg aufgesucht hatte, sei vergangen „an welchem nicht Besucher im Klosterhaus erschienen“ seien, „unangemeldete fremde Besucher, wohlverstanden, allerlei junges, begeisterungsfähiges Volk, welches herbeiströmte, den Dichter zu sehen und zu sprechen“263.

Das im Folgenden interessierende Verhältnis zur „Kriegsjugendgeneration“ soll dabei nicht verschleiern, dass mitunter auch etwas ältere, kurz vor der Jahrhundertwende geborene Männer mit ähnlicher Euphorie auf Grimms Werk reagierten. Verwiesen sei auf Gustav Sondermann (1894-1973), der im März 1927 - kurz nach Veröffentlichung einer hymnischen Besprechung von Volk ohne Raum in seiner Zeitschrift Das Dritte Reich. Eckartbrief für Freiheit und Gemeinschaft - voller Pathos die Bedeutung des Werks für ihn sowie für das gesamte junge nationale Deutschland herauszustellen versuchte. ${ }^{264} \mathrm{Zu}$ verweisen ist zudem auf den spä-

send rund. In der Zahl waren freilich die großen Aufmärsche einbegriffen, wie sie sich von 1930 an zu einem gewünschten Vorlesen oder einer gewünschten Ansprache oder zu einem Gruppengespräch einfanden“. Dass sich Grimm nicht um jeden seiner Besucher persönlich kümmerte und auch nicht kümmern konnte, die Pilgerzüge nach Lippoldsberg vielmehr nach ihrem rituellen Charakter als eine dezidiert republikfeindliche, jugendliche Protestkultur zu betrachten sind, versteht sich von selbst.

261 In seinen Memoiren schildert Fechter, dass bei seinem unangekündigten Besuch eine der Damen des Hauses gar „in eine Art verzweifelten Gelächters" ausgebrochen sei, angesichts dessen, dass an diesem Tag vor Fechter bereits „zwischen zwanzig und dreißig“ Andere Grimm aufgesucht hätten. Bei späteren Besuchen, so Fechter, habe er „ähnliche Situationen des öfteren erlebt" (Fechter, Wende, S. 394f.).

262 Fechter, Geschichte, S. 590.

263 Zitiert nach: Gümbel, Volk, S. 140.

${ }^{264}$ Hinsichtlich der über allem schwebenden Frage „Was sollen wir tun?“ kannte Sondermann nur „eine [Antwort]: die deutsche Revolution vorbereiten“. Volk ohne Raum sei ihm bei dieser schicksalshaften Bestimmung ein wesentlicher Orientierungsmaßstab: „Ihr Werk hilft bei dieser Bewegung mit, denn es zerbricht in dem, der wirklich durch die Passion dieses Werkes gegangen ist, die letzten Schranken, die wir eigensüchtig um unser Ich herumgebaut haben und bindet unser Wesen an das Leid der Volksgemeinschaft, entfesselt damit den elementaren Auftrieb zu Volk und Nation; und der kann sich heute, unter den gegebenen Umständen nur revolutionär gestalten“ (DLA, A:Grimm, Gustav Sondermann an Hans Grimm, 24. März 1927). Geburts- und Sterbejahr Sondermanns sind belegt in: Bayerisches Ärzteblatt 28 (1973), S. 928, 930. - Zuvor hatte sich Sondermann bei Grimm gar dafür entschuldigt, dass in seiner Zeitschrift noch keine Rezension des Romans erschienen war. An eine Besprechung von Grimms „Schicksalsbuch der Deutschen“, so Sondermann, habe sich in der Redaktion schlicht lange niemand „so recht herangetraut“. Nebst dem Versprechen einer baldigen Wiedergutmachung, versuchte Sondermann das Wohlwollen Grimms da- 
teren Mitherausgeber des monumentalen Lexikons Geschichtliche Grundbegriffe, Otto Brunner (1898-1982), auf den die erstmalige Lektüre von Volk ohne Raum „wie eine Offenbarung “ 265 wirkte. Insbesondere die von Grimm geschilderte „Geschichte des Leidensweges des deutschen Menschen ohne Raum“ - „heimatlos gemacht $[\ldots]$ durch die Enge der Großstadt“ und daher „Beute der Ideen der Fremdstämmigen“, namentlich der „Lehren von Freiheit und Gleichheit und Völkerverbrüderung"266 - hatte es Brunner angetan. Brunner zählte Grimm zu den wahren Volksrepräsentanten, die, außerhalb aller Parteikämpfe stehend, angesichts der kaum noch zu steigernden Volksnot das Wort erheben und zur Eintracht aufrufen müssten. Jeder, ,in dessen Herzen noch ein Fünkelchen Deutsches Blut" sei, müsse doch „mitschreien: ,Vergesst was euch trennt und denkt nur an das Gemeinsame!" Brunner selbst wollte dies „gerne hinausschreien in die Deutsche Welt", glaubte als „Unbekannte[r]“ jedoch nicht auf öffentliches Interesse hoffen zu dürfen. „Drum komme ich zu Ihnen und bitte Sie aus der Tiefe meines Herzens, aus der Tiefe meiner deutschen Seele heraus, mahnen Sie zur Einigkeit!' 267

Trotz der hohen Suggestionskraft seines literarischen Hauptwerks machte Grimm nach 1933 die bittere Erfahrung, dass sich viele Vertreter der „Kriegsjugendgeneration“, die sich vor der NS-,,Machtergreifung“ als überaus anhänglich und weltanschaulich formbar erwiesen hatten, im „Dritten Reich“ schrittweise von ihm zu entfernen begannen und entfremdeten. Dies schlug sich in sehr unterschiedlicher Weise nieder: Zum Teil lässt sich beobachten, wie zuvor lebhafte und herzliche Korrespondenzen in den ersten Jahren des „Dritten Reichs“ unvermittelt einschliefen, wie im Folgenden das Beispiel von Karl Richard Ganzer (1909-1943) zeigen wird. Zum Teil radikalisierten sich Grimms junge Korrespondenzpartner nach 1933 ideologisch derart rasant und intensiv, dass der weltanschaulich unversehens rechts überholte Dichter bald sämtliche Hoffnungen aufgeben musste, weiterhin Einfluss auf ihr politisches Denken ausüben zu können. Das Beispiel des späteren Bundesverdienstkreuzträgers Karl Paetow (1903-1992) wird dies illustrieren. Zum Teil kam es jedoch auch zu scharfen Konfrontationen

durch zu gewinnen, dass er, demütig seine eigene Bedeutung im Vergleich zu Grimm relativierend, ein Exemplar des aktuellen Heftes seiner Zeitschrift übermittelte: „Im Vergleich zu Volk ohne Raum“, so Sondermann, sei seine Publizistik ,sicherlich winzig“ (DLA, A:Grimm, Gustav Sondermann an Hans Grimm, 13. Februar 1927).

265 DLA, A:Grimm, Otto Brunner an Hans Grimm, 26. Dezember 1929.

266 Ebd.

267 Ebd. Originell war dieser Stoßseufzer über die innere „Zerrissenheit“ der Deutschen freilich nicht - entsprechende Lamentos waren auf Seiten der politischen Rechten seit dem frühen 19. Jahrhundert fester Bestandteil nationaler Selbstperzeption. Nach dem Ersten Weltkrieg vertiefte sich dieses Denken indes deutlich, als der Weimarer Parlamentarismus als neuer, unerreichter Höhepunkt bzw. Abgrund deutscher „Zerrissenheit“ wahrgenommen und entsprechend angegriffen wurde. Die Überwindung des Parteiensystems wurde nach dieser Lesart zur Grundvoraussetzung für das deutsche Volk erklärt, sich wieder - so Max Wundt 1920 in der Broschüre Vom Geist unserer Zeit - „aus dem Zustand der Schmach und Erniedrigung herausarbeiten [zu] können" (Wundt, Geist, S. 94). Vgl. weiterführend auch die Hinweise in: François/Schulze (Hg.), Erinnerungsorte, Bd. 1, S. $469 f$. 
und Auseinandersetzungen, die zu einem jähen Abbruch jeglicher Beziehungen führen konnten. Stellvertretend hierfür soll die Beziehung Grimms zu Ottokar Lorenz $\left({ }^{\star} 1905\right)$, nach 1933 führender Mitarbeiter im Reichsinstitut für Geschichte des neuen Deutschlands, näher betrachtet werden.

Mentorin und EntFremdung Vor und NACH Der NS-„MAChtergreifunG“. DRei FALLbEISPIELE - Der 1909 als Sohn eines Kaufmanns im mittelfränkischen Gunzenhausen geborene Karl Richard Ganzer studierte Geschichte, Geografie und Germanistik an der Universität München. ${ }^{268}$ Ab 1927 war Ganzer im NSDStB sowie als „ständiger Lieferant für nationalsozialistische Zeitungen“269 aktiv. 1929 trat er der SA und NSDAP bei. Ein Jahr später unterbrach Ganzer aufgrund finanzieller Schwierigkeiten sein Studium und arbeitete für kurze Zeit als Hauslehrer, ehe er 1931 im „Braunen Haus“, der Münchner Parteizentrale der NSDAP, angestellt wurde, was ihm auch den Abschluss seines Studiums erlaubte. Ganzers 1934 veröffentlichte Dissertationsschrift widmete sich dem Thema Richard Wagner. Der Revolutionär gegen das 19. Jahrhundert. Für das Wintersemester 1935/36 ist ein Lehrauftrag Ganzers an der Technischen Hochschule München belegt. ${ }^{270}$ Im „Dritten Reich“ trat Ganzer vor allem als Verfasser zahlreicher Propagandaschriften hervor ${ }^{271}$ und zählte zu dem festen Mitarbeiterkreis des 1935 gegründeten Reichsinstituts für Geschichte des neuen Deutschland. 1941 übernahm er nach der Entlassung Walter Franks die kommissarische Leitung des Instituts. Nach seinem Einzug in die Wehrmacht starb Ganzer am 11. Oktober 1943 bei Gomel im heutigen Weißrussland. ${ }^{272}$

Anlass zum Erstkontakt zwischen Ganzer und Grimm bot im Herbst 1931 eine (zuvor bereits im Völkischen Beobachter publizierte ${ }^{273}$ ) huldigende Rezension von Grimms Aufsatzsammlung Der Schriftsteller und die Zeit in den Nordischen Blättern. ${ }^{274}$ Grimm war von ihr überaus angetan und bedankte sich sogleich für die

268 Soweit nicht anders gekennzeichnet sind sämtliche Inhalte des Absatzes dem von Helmut Heiber verfassten ausführlicheren biografischen Abriss zu Ganzer entnommen, vgl. Heiber, Frank, S. 376-384.

269 Faust, Studentenbund, S. 86.

270 Vgl. Pabst/Fuchs/Herrmann, Universität, S. 279.

$271 \mathrm{Zu}$ nennen sind vor allem: Weiter nur weiter! Der Roman des deutschen Aufbruchs 19171933 (1933), 9. November 1923. Tag der ersten Entscheidung (1936) und Das Reich als europäische Ordnungsmacht (1941).

272 Vgl. Hieber, Frank, S. 1180.

273 Information aus: DLA, A:Grimm, Karl Richard Ganzer an Hans Grimm, 19. September 1931.

274 Ganzer begann, Volk ohne Raum vor Augen, seine Rezension mit der Feststellung, dass Grimm „als einziger unter den zeitgenössischen deutschen Dichtern das große Werk“ vollbracht habe, „über die herkömmliche Deutung brüchiger Schicksale irgendwelcher Privatmenschen hinauszugreifen und das Gesamtschicksal seines Volkes [...] einzufangen“. Bei Erscheinen von Volk ohne Raum habe der deutschen Jugend das Herz geschlagen, „weil eine große heimliche Hoffnung sich erfüllte". Grimm habe es vermocht, in dem Einzelschicksal seinen Hauptprotagonisten ,jeder privaten Sphäre“ zu entheben und in ihm das Schicksal des ganzen Volks zu spiegeln: „Der ,Held“ war das Volk selber, und die Hauptgestalt fand weniger des eigenen Wesens halber Interesse [...] als vielmehr dadurch, daß sie 
ihm persönlich übermittelte, „ausgezeichnete Besprechung“275. Aus Sorge, sich durch allzu euphorische Äußerungen womöglich lächerlich zu machen, verzichtete Ganzer in seinem ersten Brief noch darauf, seine persönlichen Ansichten über Grimm und dessen Werk näher auszuführen. ${ }^{276}$ Als Ganzer jedoch drei Monate später, im Dezember 1931, eine Besprechung der Volksausgabe von Volk ohne Raum an Grimm übermittelte ${ }^{277}$, nützte er diese Gelegenheit, um dem Dichter sein Herz auszuschütten: Es sei „keine Phrase“, dass das deutsche Volk Grimm „Unendliches zu danken“ habe und ihm „verpflichtet“278 sei.

Der enorme Verkaufserfolg von Volk ohne Raum galt Ganzer als „das hoffnungsvollste Zeichen für die Zukunft unseres Volkes“. Zugleich entsann er sich seiner „3 oder 4 Jahre“ zurückliegenden Studententage, als er sich mit seinen Münchner Kommilitonen regelmäßig getroffen hatte, um „immer wieder den heillosen Zustand“ Deutschlands zu diskutieren. Die gesamte „öffentliche Meinung“, so Ganzer, habe damals „in vielen Tonarten durcheinander[ge]hall[t]“, nur deutsch sei keine von ihnen gewesen. Alle Zeitungen hätten „eifrig und besessen in Literatur“ gemacht, „die deutsche“ aber, „die wir brauchten, verstaubte in vielen Ecken und Winkeln“. Ihm und seinen Kommilitonen sei es „unmöglich“ erschienen, „gegen das Beharrungsvermögen von Masse und Presse und Intelligenz“ effektiv „anzugehen“, ehe Grimm dann mit seinem Werk die entscheidende „Bresche“ geschlagen habe. Die „wahre Bedeutung dieses Durchbruchs“ sei ihm „damals noch gar nicht so eingehend zum Bewußtsein gekommen“, als „die Schar der Nachkommenden in keiner Weise zu übersehen oder gar als geistige Einheit zu erkennen“ gewesen sei. „Heute aber“ sei „der Endsieg gewiss“279.

Es steht sinnbildlich und stellvertretend für die sich im „Dritten Reich“ immer weiter öffnende Schere zwischen Grimm und der „Kriegsjugendgeneration“, dass sich von Seiten Ganzers an dieses emphatische Schreiben sowie an weitere ausführliche Briefe nach 1933 keine weitere, annähernd vergleichbare Pflege der persönlichen Beziehung anschloss. Stattdessen dünnte der Kontakt rasch aus, um ab 1936 dann völlig zu versiegen. Grimm diente in den Augen Ganzers künftig nicht mehr als maßgebliches, orientierungsstiftendes Leitbild. Diese Funktion füllten fortan die neuen Machthaber aus.

die umfassendsten Probleme einer völkischen Gemeinschaft, die nationale Not und das nationale Schicksal, in sich trug und in sich reifen ließ. [...] Es ist kein leeres, phrasenhaftes Wort, wenn man sagt, daß Hans Grimm mit der Eingebung ,Volk ohne Raum dem deutschen politischen Denken einen neuen Inhalt gegeben hat" (Ganzer, Grimm, S. 127129).

275 DLA, A:Grimm, Hans Grimm an Karl Richard Ganzer, 23. September 1931.

276 „Näheres, Einzelnes über Ihr Buch Ihnen hier persönlich zu sagen, möchte und darf ich wohl vermeiden: es entbehrte der sachlichen wie der inneren Berechtigung, es schiene leere und unwürdige Schmeichelei. Nur eines sei mir zu sagen vergönnt: daß ich nichts inniger wünsche, als daß Ihrem letzten Buche bald ein neues nachfolge. Deutschland bedarf Ihrer Kunst" (DLA, A:Grimm, Karl Richard Ganzer an Hans Grimm, 19. September 1931).

277 Zur Volksausgabe von Volk ohne Raum vgl. Kap. 2.3.2.

278 DLA, A:Grimm, Karl Richard Ganzer an Hans Grimm, 22. Dezember 1931.

279 Ebd. 
Eine zweite Variante der Entfremdung zwischen Grimm und Vertretern der „Kriegsjugendgeneration“ war deren beschleunigte ideologische Radikalisierung, der Grimm weder folgen konnte noch folgen wollte. In den Augen vieler junger Korrespondenzpartner geriet Grimm nach 1933 so gleichsam zum alten Eisen. Das Fallbeispiel Karl Paetows illustriert dies:

Karl Paetow wurde am 19. März 1903 im brandenburgischen Fürstenwalde als Sohn eines Uhrmachermeisters geboren. Bereits 1907 zog die Familie nach Kassel, wo Paetow bis 1922 die Oberrealschule besuchte. Sein Studium der Volkswirtschaftslehre, Germanistik und Kunstgeschichte an den Universitäten Göttingen, Frankfurt am Main, München, Köln, Leipzig und Berlin schloss Paetow 1928 mit einer kunsthistorischen Promotion zum Thema Klassizismus und Romantik auf Wilhelmshöhe ab. ${ }^{280}$ Nach seiner Promotion absolvierte Paetow eine Ausbildung am Landesmuseum Kassel, ehe bereits 1930 die Ernennung zum Leiter des Stadtmuseums Stolp in Pommern (heute pol. Słupsk) erfolgte, wo Paetow bis 1933 arbeitete. Ab 1935 fand er Anstellung bei der Stadt Kassel und war dort unter anderem mit der Erforschung der historischen Altstadt beauftragt. 1938 trat Paetow als Herausgeber einer Bildchronik Kassels hervor. Nach dem Zweiten Weltkrieg, in dem er eine schwere Verwundung erlitt, leitete Paetow von 1951 bis 1968 das Deutsche Tabak- und Kreismuseum in nordrhein-westfälischen Bünde. Während dieser Zeit veröffentlichte er mehrere Nacherzählungen aus der deutschen Märchen- und Sagenwelt, von denen einige bis in die jüngste Vergangenheit zahlreiche Neuauflagen erlebt haben. ${ }^{281}$ Nach seiner Pensionierung leitete Paetow bis 1981 das Deutsche Märchen- und Wesersagenmuseum in Bad Oeynhausen bei Bielefeld. Im selben Jahr wurde ihm das Bundesverdienstkreuz verliehen. Paetow starb am 23. Oktober 1992.

Wie bei vielen seiner Altersgenossen der Fall, übte Grimms Volk ohne Raum auch auf den jungen Paetow eine enorme Faszination aus. Die orientierungsstiftende Bedeutung des Romans geht anschaulich aus einem Brief vom Oktober 1931 hervor, den der damals 28-jährige Paetow unmittelbar im Anschluss an einen Besuch bei Grimm in Lippoldsberg verfasste. Der Brief war nicht zuletzt von dem Bedürfnis motiviert, Grimm in aller Ausführlichkeit auseinanderzusetzen, was er der Lektüre seiner Bücher zu „verdanke[n]“ glaubte. Da ihm bei dem vorangegangenen Treffen in dieser Hinsicht „der Mund wie verklebt“ 282 gewesen war, griff Paetow zur Feder. Grimm, so resümierte Paetow, habe durch seine Werke nicht nur ihm persönlich, sondern dem gesamten deutschen Volk „neue Werte und neue Wege gezeigt“. Vor allem in Volk ohne Raum habe er „in die Klarheit gehoben“, was zuvor nur „verschwommen“, wenngleich „mächtig“ von den Deut-

280 Die biografischen Informationen sind dem knappen Lebenslauf entnommen, den Paetow in seiner Doktorarbeit aufführte. Vgl. Paetow, Klassizismus, S. 103.

281 Vgl. vor allem: Karl Paetow, Rübezahl: Sagen und Legenden, Husum 92012; Ders. Die schönsten Wesersagen an der Märchenstraße von Kassel bis Bremen, Hemmingen ${ }^{6} 2004$; Ders., Die Wittekindsage, Hemmingen ${ }^{4}$ 1994; Ders., Frau Holle: Volksmärchen und Sagen, Husum ${ }^{3} 1986$.

282 DLA, A:Grimm, Karl Paetow an Hans Grimm, 23. August 1931. 
schen verspürt worden sei. Der Roman gehörte in den Augen Paetows zu den wenigen Büchern, die einen „Wendepunkt im Leben des Suchenden“ darstellten. Als hauptsächliche Ursache der enormen Wirkung des Romans auf seine persönliche Entwicklung verwies Paetow auf seine Identität als Grenzlanddeutscher, welche ihn „die Daseinsfragen unseres Volkes“, die er in Grimms Roman angelegt und ausgearbeitet sah, „heftiger “ empfinden lasse ,als die meisten im unbestrittenen Deutschland“283. Grimm, der selbst von 1898 bis 1908 in der britischen Kapkolonie lebte 284 und in seinen zahlreichen autobiografischen Publikationen immerzu bemüht war, die Bedeutung seines jahrelangen „Auslandsdeutschtums“ für seine Persönlichkeitsentwicklung herauszustellen, dürfte diese Deutung eingeleuchtet haben.

Wie stark Paetow die deutsche „Raumfrage“ bereits vor der Lektüre von Volk ohne Raum beschäftigt hatte, lässt sich indes kaum beurteilen. Aufgrund dessen, dass er bis 1930 in Kassel und seinen verschiedenen Studienorten alles andere als das Leben eines Grenzlanddeutschen geführt hatte, ist anzunehmen, dass die Lektüre des Romans für das politische Denken Paetows erst vor dem Hintergrund seiner Neuanstellung in Pommern virulent wurde; der Brief entstand in jenem Zeitraum, in dem Paetow die Leitung des Stadtmuseums Stolp innehatte. Grimm jedenfalls wurde für den frischgebackenen Museumsdirektor zur Identifikationsfigur und Legitimationsinstanz seiner eigenen Tätigkeit. Verweisend auf die maßgebliche Bedeutung der Kunst und Literatur für das Leben eines Volks ${ }^{285}$, glaubte Paetow, aufgrund der Lektüre von Volk ohne Raum seine eigenen „Aufgaben immer mehr erkennen[n]“ zu können. Es seien „die Aufgaben eines schweren Lebens", eine Aussicht, die Paetow allerdings nicht zu betrüben schien: Ein „leichtes Leben und billiges Glück“ habe er „niemals gesucht“. Das „Schicksal“ der Menschen liege in ihrem „Willen“, welchen Paetow schon zum damaligen Zeitpunkt

283 Ebd. Sein Argument erläuterte Paetow folgendermaßen: An der deutschen Ostgrenze vermische sich "das Deutschtum“ schon seit so langer Zeit „mit dem alten Slawentum“, dass deren Vertreter bereits „selber blond und blauäugig geworden“ seien, „oder hatten sie schon das nordische Blut von den Resten der Völkerwanderungsstämme in sich?" Hinzu komme die Doppelbelastung durch eine permanente „Flucht aus dem Osten“ von Seiten der deutschen Bevölkerung bei gleichzeitiger Bereitschaft der Slawen, „in den sich leerenden Raum zu strömen“. Entscheidend aber sei das im Reich weitverbreitete "mangelnde Interesse“ an den Grenzlanddeutschen, dass der Osten generell nicht gelte, „was er wert ist“. Erst wenn er verloren gehen sollte, werde man „spüren, wie lebensnotwendig diese Provinzen sind. Denn hier ist noch der freieste Raum im Reich, hier ist noch Bauernerde, Bauernvolk. Hier kann noch ein volkerneuerndes Geschlecht wachsen. Hier ist unser altes Volk noch so jung wie vor vielen hundert Jahren".

${ }^{284}$ Vgl. Kap. 2.1.

285 „Ich meine, daß eben hier“ - Paetow hatte hier das politisch-gesellschaftliche „System“ vor Augen - „die erneuernden [...] Energien von der Kunst [...] kommen. [Wer] erkennt, wie das Volk in seinem geistigen Teil immer wieder von oben empfängt und wie sehr es abhängig ist von der Art der dargebotenen Gaben, wie sehr es auf Autorität hält, der wird sich bewußt, welche Verantwortung für die Führer einer Nation hier liegen. Ein Volk ist das, was seine Schriftgelehrten aus ihm machen" (DLA, A:Grimm, Karl Paetow an Hans Grimm, 1. September 1931). 
„durch Erbschaft und Rasse“ bestimmt sah. Sein eigenes Schicksal identifizierte Paetow mit jenem des Ostens. Hier warteten „noch Aufgaben“, denen er sich „verpflichtet“ fühlte. Abschließend bat er Grimm zu entschuldigen, dass sein Brief „gar so ins Persönliche gerate[n]“ sei. Paetow fühlte sich jedoch einer „Generation - ein anderer Jahrgang 1902!“ zugehörig, „die von den wenigen Führern[,] an die sie glauben mag[,] eine Stärkung ihres Glaubens erwartet"286. Und zu eben jenen „Führern“ gehörte für den jungen Museumsdirektor im Besonderen der Schöpfer von Volk ohne Raum.

Grimm, der sich die auf diese Weise an ihn herangetragene Verantwortung gerne gefallen ließ, blieb in den kommenden Jahren mit Paetow in unregelmäßigem Kontakt. Die Briefe behandelten dabei allerdings zunächst nur Themen, die im vorliegenden Argumentationszusammenhang ohne Bedeutung sind. Nach 1933 bezeugen die vereinzelten Korrespondenzen zwar die anhaltende Hochachtung Paetows für Grimm, ihre jeweiligen Entstehungsgründe lassen sich jedoch auf bloße monetäre Interessen des nach Kassel zurückgekehrten und nach Geldeinkünften suchenden Paetow zurückführen. So bat er Grimm im Herbst 1933 um eine „Bürgschaft“ für seinen Antrag auf Aufnahme in den Reichsverband deutscher Schriftsteller ${ }^{287}$; rund drei Jahre später wünschte er Grimms Hilfestellung bei der Suche nach einem passenden Verlag für sein Manuskript Die Spiele vom deutschen Jahreslauf. ${ }^{288}$

Bis zum Vorabend des Zweiten Weltkriegs verblasste dann zunehmend die Bedeutung Grimms für Paetows Weltbild. Die wachsende Distanz geht anschaulich aus einem ausführlichen Brief hervor, den Paetow am 2. August 1939 verfasste, unmittelbar im Anschluss an einen neuerlichen Besuch in Lippoldsberg. ${ }^{289}$ Der Bedeutungsverlust Grimms ging indes nicht etwa auf einen Streit mit dem Dichter zurück; Paetows Brief ist vielmehr eine anhaltende und prinzipielle Wertschätzung zu entnehmen. Jedoch ließ Paetow nun, sechs Jahre nach der Etablierung des „Dritten Reichs“, Volk ohne Raum nur noch als eine Leistung der Vergangenheit gelten. Den während des Besuchs in Lippoldsberg unternommenen Versuch Grimms, abermals auf Paetow einzuwirken, wehrte dieser nun nachdrücklich ab. Hintergrund war, wie der Brief bezeugt, dass der Referenzrahmen des politischen Denkens Paetows, der in den Jahren 1931/32 noch so stark von

286 Ebd. (Herv. i. Orig.). Mit der Formulierung „ein anderer Jahrgang 1902“ grenzte sich Paetow von Ernst Glaesers (1902-1963) zeitgenössisch sehr erfolgreichen, heute hingegen weithin vergessenen Antikriegsroman Jahrgang 1902 (Potsdam 1928) ab. Eine knappe Einführung in den Roman bietet: Karpenstein-Eßbach, Krieg, S. 112-120.

287 DLA, A:Grimm, Karl Paetow an Hans Grimm, 27. September 1933.

288 DLA, A:Grimm, Karl Paetow an Hans Grimm, 9. Juni 1936. Die weitere Geschichte dieses Manuskripts ist verworren. Grimm setzte sich auf die Bitte Paetows sogleich mit Reinhold Geheeb vom LMV in Verbindung, der das Buch zwar nicht selbst übernehmen wollte, es jedoch dem Berliner Verleger Junghans empfahl. Am 23. August 1936 meldete Paetow dann an Grimm, mit Junghans verabredet zu haben, dass das Buch zu Weihnachten herauskommen solle; bibliografisch lässt sich eine solche Publikation jedoch nicht belegen.

289 Für die nicht selbstverständliche Zitationserlaubnis aus diesem Brief bin ich Herrn Eckhard Paetow und seiner Familie zu Dank verpflichtet. 
der Lektüre von Volk ohne Raum geprägt gewesen war, mittlerweile von einer tief internalisierter NS-Rassenideologie bestimmt wurde.

Eingangs hob Paetow hervor, dass ihm die vielen bohrenden Fragen, die Grimm bei dem Besuch an ihn gerichtet und aufgeworfen hatte, „schwer auf [die] Seele gefallen“ seien. Nun, nach seiner Rückkehr aus Lippoldsberg, glaubte Paetow jedoch, sie für sich „gelöst und geklärt“ zu haben: Was ihn während des Besuchs an Grimms „Worten so betrübt“ hatte, sei ihm mittlerweile „zu einem Bekenntnis“290 geworden. Im Anschluss an diese Vorbemerkungen entfaltete Paetow ein politisch-ideologisches Glaubensbekenntnis, in dessen Zentrum die vulgärdarwinistische Ordnungsvorstellung stand, dem „Arier“ stehe im Vergleich zu anderen „Menschenrassen“ das höchste Lebens- und Selbstentfaltungsrecht zu. Der „Arier“ stellte in den damaligen Augen Paetows innerhalb der Entwicklungsgeschichte des Menschen den „Hauptspross“ und „Herzkeim“ dar, andere Rassen hingegen lediglich „Seitentriebe“291 minderer biologischer Qualität. Wesen und Aufgabe des „Ariers“ war es nach seiner Ansicht, „in ständiger Selbstüberhöhung die anderen Wesen und Gattungen aus sich heraus[zu]scheide[n]“ und sich dadurch stetig fortzuentwickeln. Auf der Strecke bleibe dabei lediglich, was ohnehin „vermanscht und entedelt" sei, etwa „die dunkelhäutigen Menschenrassen“, über die Paetow die zweifelnde Frage stellte: „Sind die Neger noch Menschen wie wir?“ Bezogen auf seine politische Gegenwart konkretisierte Paetow sein neu gewonnenes Weltverständnis anhand der nationalsozialistischen Rassenpolitik und -ideologie: Um eine „Verpanschung und Vermanschung“ zu unterbinden, so Paetow, habe der „Führer“ jegliche „Rassenmischung“ verboten und insbesondere entschlossen, „die Juden aus unserem Volkskörper aus[zuscheiden]“. Mit diesem „harte[n] Befehle“ habe sich Hitler als „das Gewissen“ in dem „Herzstück arischer, menschlicher Überhöhung“ erwiesen. In Hitlers politischen Entscheidungen kam laut Paetow gar ein „Mensch-gewordene[r] göttliche[r] Wille“292 zum Ausdruck: „Wenn Christus ein Gott war, dann ist es Hitler noch mehr“293.

Auf eine vollständige Zusammenfassung des überaus prekären Briefs, in dem sich Paetow auch über die mutmaßliche „Milde“ des „Führer[s]“ im Umgang mit den Juden als den „Erbfeind[en] des Menschen“ erstaunt und davon überzeugt zeigte, Hitler werde - den Versprechungen „in seinem Buche ,Mein Kampf “ folgend - dem „arische[n] Menschen das ihm zustehende „Siedlungsland [...] im Osten "294 verschaffen, kann an dieser Stelle verzichtet werden. Hier ist lediglich von Interesse, dass das von Paetow umrissene Glaubensbekenntnis ideologisch weit über alles hinausging, was von Grimm jemals vertreten und geschrieben worden war. Anders als während des Treffens in Lippoldsberg brachte Grimm nunmehr jedoch keine Motivation mehr auf, Paetow in seinem Denken weiter

290 DLA, A:Grimm, Karl Paetow an Hans Grimm, 2. August 1939, S. 1.

291 Ebd.

292 Ebd.

293 Ebd., S. 3.

294 Ebd., S. $3 f$. 
beeinflussen zu wollen. Die völlig unreflektierte und bedingungslose, ja schier devote Führergläubigkeit Paetows sowie die ungeheure ideologische Härte des Briefs dürften ihn überrascht und unvorbereitet getroffen haben. ${ }^{295}$ Auch die herausfordernde Andeutung Paetows, dass Grimm dem skizzierten Glaubensbekenntnis insgeheim „näher“ stehe, als er wohl „selber zugeben“ wolle - ganz zu schweigen davon, dass seine Werke für „unzählige Deutsche“ „bei ihrem Weg zum Führer“296, so wie Paetow ihn verstand, Mark- und Meilenstein gewesen seien -, evozierte in Grimm kein Bedürfnis zum Disput. Stattdessen zog er sich auf einen hilflos anmutenden, in den Jahren zuvor völlig untypischen Standpunkt neutraler Unbeteiligtheit zurück. Lapidar hielt Grimm in seinem knappen Antwortschreiben lediglich fest, es sei „schön“ für Paetow, dass er nach seinem individuellen Lebensweg nun zu „diese[m] Glauben gefunden“ habe. Mit den in Paetows Brief angesprochenen „Dingen“ müsse freilich „jeder selbst fertig werden“, je „nach den eigenen Notwendigkeiten und Einsichten“. Dann, so glaubte Grimm, sei „alles in Ordnung" 297 .

Als drittes Beispiel für die im „Dritten Reich“ jäh geschwundene Bedeutung Grimms für das politische Denken der „Kriegsjugendgeneration“ kann der 1905 geborene Ottokar Lorenz gelten. Lorenz, Enkel des ungleich bekannteren gleichnamigen österreichischen Historikers ${ }^{298}$, trat schon während seines Geschichtsstudiums „mit den Interessensschwerpunkten Gesellschaft und Wirtschaft“299 an der Universität München der NSDAP und SA bei und beteiligte sich im November 1923 am Hitler-Putsch. ${ }^{300}$ Nach seiner 1930 fertiggestellten, jedoch erst 1937 publizierten Dissertation zum Thema Karl Marx und der Kapitalismus. Eine Untersuchung über die Grundbegriffe der marxistischen Klassenkampflehre ${ }^{301}$ fand Lorenz infolge einer „Reorganisation des zentralen Münchener [Partei-]Apparats“ eine Anstellung im „Braunen Haus“, der Münchner Parteizentrale der NSDAP. Dort fungierte er in dem von Walter Frank geleiteten Referat für Wirtschaftspolitik als „Presse- und Propagandareferent“302. 1932 erfolgte seine Ernennung zum Gebietsführer der Berliner HJ. Nach seinem Rückzug aus der Jugendarbeit im Jahr 1939 wurde Lorenz als „Alter Kämpfer“ und Träger des „Blutor-

295 Der Sachverhalt, dass sich in den früheren Briefen Paetows trotz aller ideologischen Aufladung keine Anzeichen für eine derart bedingungslose Hingabe an die NS-Ideologie auffinden lassen, weist eine aufschlussreiche Parallele zu dem von Michael Wildt untersuchten Kreis der maßgeblichen Mitarbeiter des Reichssicherheitshauptamts auf. Schließlich fand sich bei „keinem der jungen Männer, die später im RSHA führende Positionen einnahmen, [...] zu Beginn des NS-Regimes irgendwelche Anzeichen auf einen, eliminatorischen Antisemitismus' oder auf eine Bereitschaft zur Vernichtung, die nur auf den Moment des Auslösens" (Wildt, Generation, S. 25f.) gewartet hätte.

296 DLA, A:Grimm, Karl Paetow an Hans Grimm, 2. August 1939, S. 5.

297 DLA, A:Grimm, Hans Grimm an Karl Paetow, 4. August 1939.

298 Vgl. Heiber, Frank, S. 25.

299 Ebd., S. 401.

300 Ebd.

301 Die Dissertation wurde 1937 von Walter Frank in die Schriftenreihe des Reichsinstituts für Geschichte des neuen Deutschlands aufgenommen und damit erstmals publiziert.

302 Pätzold/Weißbecker, Geschichte, S. 203. 
dens“ (1935) mit offenen Armen als Mitarbeiter im Reichsinstitut für Geschichte des neuen Deutschlands aufgenommen. Hier übernahm er zusammen mit Wolfgang Höfler die Leitung des Hauptreferats für Volkswirtschaftslehre und Wirtschaftsgeschichte. Zugleich war er „Geschäftsführer der Münchner Dienststelle“303 des Reichsinstituts.

Zum Zeitpunkt des Erstkontakts mit Grimm war Lorenz als Mitarbeiter des Akademischen Beobachters tätig, dem Hauptorgan des NSDStB. Im Dezember 1929 hatte Lorenz in der Zeitschrift unter dem Pseudonym „Otto Renz" einen Aufsatz zum Thema Der neue Kunstwille in Hans Grimm: „Volk ohne Raum“304 veröffentlicht, von dem Grimm derart angetan war, dass er ihn zum Anlass nahm, den direkten Kontakt mit Lorenz zu suchen. Ähnlich wie in seinem Aufsatz im Akademischen Beobachter ${ }^{305}$ pries Lorenz Grimm in seinem Antwortschreiben als Inkarnation einer volksgerecht gearteten Kunst, deren „göttliches Feuer“ erst durch den Dichter „wieder entzündet“ worden sei. Lorenz sprach zudem von seiner großen Ergriffenheit, wie Grimm in seinen Werken „die nordische Seele“ künde; das „Große“ an Grimms Kunst lag in Lorenz’ Augen besonders darin, wie er jene Seele in seiner Ganzheit dargestellt und also „nicht zerglieder[t] "306 habe.

Darüber hinaus begeisterte sich Lorenz freilich auch deshalb für Volk ohne Raum, da er sich von dem Buch einen unmittelbaren und greifbaren politischen Nutzen für die NSDAP versprach. Die künstlerische Leistung Grimms stellte er in einen engen und direkten Zusammenhang mit den politischen Intentionen der NS-Bewegung. ${ }^{307}$ Dies führte im Umkehrschluss freilich dazu, dass Grimm an Wertschätzung verlieren musste, je fragwürdiger sein Nutzen für die NS-Bewegung wurde bzw. je mehr dieser zu schwinden schien. Wie jäh die zuvor noch zelebrierte Grimm-Verehrung in fundamentale Skepsis umschlagen konnte, zeigte sich, nachdem Lorenz - zusammen mit zahlreichen Altersgenossen aus der HJ in München Grimms Vortrag Von der bürgerlichen Ehre und bürgerlichen Not-

303 Heiber, Frank, S. 401f. Für weitere Informationen zu Wolfgang Höfler vgl. ebd. S. 464, 608.

304 Vgl. Renz, Kunstwille.

305 Vgl. ebd.: Lorenz pries Grimm in seinem Aufsatz als denjenigen Autor, dem es gelungen sei, die zeitgenössische Literatur aus der Sackgasse der sich in atomisierten „Einzelfällen“ ergehenden „psycho-analytische[n] Zergliederung“ herauszuführen, indem er in seinem Roman über die „Darstellung von Einzelschicksalen“ hinausgehend nichts weniger als „das Schicksal des deutschen Volkes“ aufgeschlüsselt habe. In Volk ohne Raum, so Lorenz, sei „unser aller Schicksal [...] dargestellt“. Er kenne kein Buch, „in dem die Bluts- und Schicksalsverbundenheit zwischen dem Einzelnen und der Gemeinschaft" vergleichbar „packend“ und erhellend behandelt worden sei. Grimm achte in seiner Darstellung gewissenhaft auf die Unterscheidung zwischen „Gemeinschaft“ als natürlichem und „lebendige[n] Zusammenhang“ auf der einen und der innerlich zusammenhangslosen „Masse“ auf der anderen Seite.

306 DLA, A:Grimm, Ottokar Lorenz an Hans Grimm, 27. Mai 1930.

307 Grimm hatte demnach „als erster die Verbundenheit zwischen Persönlichkeit und Gemeinschaft künstlerisch dargestellt. Er hat damit ein künstlerisches Problem gelöst, das schon lange dunkel als Aufgabe empfunden wurde [...]. Es ist kein Zufall, daß gleichzeitig in der Politik der verkehrte Sozialismus demokratischer Prägung durch den Nationalsozialismus abgelöst wird, der nicht von der Masse ausgeht, sondern von der Gemeinschaft. [Beide] schöpferischen Leistungen künden das Aufbrechen eines neuen Wollens und einer neuen Zeit" (Renz, Kunstwille, S. 223). 
wendigkeit ${ }^{308}$ beigewohnt hatte. Zwei Tage vor der Übertragung des Reichskanzleramts an Hitler beschrieb Lorenz voller Verbitterung die verheerende Wirkung, die Grimms Rede in seinen „Kameraden der Reichsjugendführung“ und „anderen jungen Parteigenossen" sowie in ihm selbst evoziert hatte. Alle seien von Grimm „grenzenlos enttäuscht“ worden. Durch den Vortrag, so warnte Lorenz, werde „ein Berg von Missverstehen zwischen Ihnen und der nationalsozialistischen Jugend aufgetürmt. “309

Lorenz selbst, dessen persönliche Bekanntschaft mit Grimm offenbar bekannt war, war am Tag nach der Rede von „tief erregt[en]“ HJ-Mitgliedern aufgesucht und ausgefragt worden. Grund der Erregung, so Lorenz, sei dabei weniger gewesen, dass „eine in der Hauptsache unbegründete Kritik“ am Nationalsozialismus geäußert worden sei, sondern dass ausgerechnet der Schöpfer von Volk ohne Raum eine solche Kritik geäußert habe. Keiner der Anwesenden habe begriffen, worauf Grimm mit seiner „Kritik überhaupt hinaus wollte“. Was etwa habe sich Grimm von seiner Ermahnung versprochen, „die nationalsozialistische Bewegung möge nur ja nicht die Wirkungsmöglichkeit der wenigsten einengen, die die besten sind“? Sei es Grimms Aufgabe, „der deutschen Jugend, die vollkommen klar und bewusst ihren Weg“ gehe, „diese Klarheit wieder zu verwirren“ und ihren „nationalsozialistischen Geist [zu] zerreden“? Nichts anderes jedenfalls sei mit seinen „völlig überflüssige[n] und unbegründete[n] Warnungen“ bewerkstelligt worden. Früher oder später - so Lorenz nun auch mit Blick auf die Bitte an den Nationalsozialismus ${ }^{310}$ - werde Grimm auf diesem Weg von der Jugend „zu den ewig nörgelnden und besserwissenden Intellektuellen" gerechnet und verstoßen werden. Harsche Kritik äußerte Lorenz auch daran, dass Grimm in seinem Münchner Vortrag der „deutschen Jugend zu verstehen“ gegeben habe, dass „ihre Existenz nicht von den Parteien“ abhänge, sondern von den Leistungen ganz gewöhnlicher Bürger - etwa der

„Leute, die Brot backen, Erfindungen machen und ihr Geld für irgendwelche wirtschaftlichen Zwecke riskieren. Was soll die deutsche Jugend mit dieser grauenvollen Spießbürgerphilosophie anfangen?! Die Jugend weiß, dass ihr Schicksal von diesen Menschen nicht gestaltet und ganz gewiss nicht gewendet wird. Die deutsche Jugend [...] weiß, dass ihr Schicksal nur von den heroischen Menschen gewendet wird, von denen, die ihr Leben riskieren, von denen die dem Volk einen neuen Willen geben" ${ }^{311}$.

Kurzum: Die nüchtern und bieder anmutenden Überlegungen Grimms zum Nationalsozialismus prallten an Lorenz' Bedürfnis nach Aktionismus, Heldenkult und unbedingter Bekenntnistreue wirkungslos ab. Die entschieden emotio-

308 Vgl. Kap. 5.2.2.

309 DLA, A:Grimm, Ottokar Lorenz an Hans Grimm, 28. Januar 1933.

310 Siehe Kap. 5.2.1.

311 DLA, A:Grimm, Ottokar Lorenz an Hans Grimm, 28. Januar 1933. In seinem Vortrag hatte Grimm, Oswald Spengler zitierend, vor der ungeheuren Gefahr einer potenziellen „Ausschaltung der geschichtlich führenden Kulturschicht" im deutschen Volk (und anderen Kulturvölkern) durch vage umrissene gesellschaftliche Vermassungstendenzen gewarnt. Eben jene Elemente der "Vermassung" nahm er als die großen inneren und äußeren Gefährdungen für die NS-Bewegung wahr. Vgl. Grimm, Ehre [1932], S. 24. 
nal argumentierende Haltung des 28-jährigen Lorenz vermochte der 58-jährige Grimm mit seinen schulmeisterlich wirkenden Ermahnungen nicht zu beeinflussen. ${ }^{312}$

Grimms Enttäuschung über die zunehmende Belehrungs- und Beratungsresistenz der „Kriegsjugendgeneration“ dürfte nach 1933 auch dadurch nicht aufgewogen worden sein, dass mitunter Vertreter dieser Alterskohorte selbst von ähnlichen Erfahrungen berichteten. So beklagte sich etwa der Freikorps-Veteran und Autor des Erfolgsromans Die Geächteten, Ernst von Salomon (19021972), im September 1934 über einen Vortrag vor Göttinger Studenten, die nichts als den „alte[n] Knatsch“ und die längst durchgekauten „Räubergeschichten der Revolution" 313 hätten hören wollen, für weiterführende Themen jedoch völlig unzugänglich gewesen seien. Sämtliche seiner Fragen, so Salomon, stießen seitens der Studenten auf erschreckend banale Antworten, selbst Carl Schmitt sei unreflektiert attackiert und abgelehnt worden. Konsterniert und desillusioniert bilanzierte Salomon seine Bestürzung darüber, die „unzweifelhaft gute Substanz“ der jungen Menschen „in solch unzweifelhaft hoffnungsloser geistiger Resignation versinken“ zu sehen. „Das ist doch die Pest, eine Ideologie, die selbst in diesen unverbrauchten Köpfen solche platten Verheerungen anrichtet“ ${ }^{\text {314 }}$.

Parallelen bei Kolbenheyer - Auch Kolbenheyer war nach 1933 vereinzelt Kritik aus dem Kreis der „Kriegsjugendgeneration“ ausgesetzt. Exemplarisch zeigt dies ein Artikel aus den Jenaer Nachrichten vom 23. Januar 1934 von Rudolf Ortlepp (1909-1942), der im selben Jahr zum Gaustudentenführer Thüringens berufen wurde. Ebenso wie Alfred Rosenberg nur wenige Wochen später auf einer „Kulturwoche“ des Gaus Thüringen in Weimar ${ }^{315}$, griff auch Ortlepp vor allem Kolbenheyers Rede Der Lebensstand der geistig Schaffenden und das neue Deutschland an. Kolbenheyer habe nichts dazu beigetragen, „den augenblicklichen geistigen Lebensstand in Ordnung zu bringen“, seine Ideen könnten für

312 Die diametrale Gegensätzlichkeit der Gemütslagen von Grimm und Lorenz wird besonders evident, führt man sich das kurze Zeit später publizierte, inhaltlich maßgeblich von Lorenz bestimmte Manifest der Jugend vor Augen: „Hunderttausende marschieren im ganzen Reich. Das ist die deutsche Jugend, die sich nicht bange machen läßt, die sich ihren Glauben nicht aus dem Herzen reißen läßt und die stets dort stehen wird, wo um Deutschlands Zukunft gekämpft wird. Es ist kein Zufall, daß diese Jugend sich zu Adolf Hitler bekennt. Denn was sie im Innersten ihrer Seele empfindet, dem hat Adolf Hitler Ausdruck gegeben. Und was die deutsche Jugend aus der schicksalsmäßigen Gestaltung ihres Lebens heraus will und wollen muß, das erkämpft die nationalsozialistische Bewegung Adolf Hitlers" ([Lorenz], Manifest, S. 3). Lorenz ist als Verfasser in eckige Klammern gesetzt, da er zwar ausdrücklich als „verantwortlich für den Gesamtinhalt“ (S.2) des Manifests zeichnete, aber weder auf dem Titelblatt noch in den Verbundkatalogen der deutschen Bibliotheken namentlich erwähnt wird. Zum Teil ist jedoch fälschlicherweise „Reichsjugendführer“ Baldur von Schirach als Verfasser angegeben.

313 DLA, A:Grimm, Ernst von Salomon an Hans Grimm, 20. September 1934.

314 Ebd.

315 Vgl. Kap. 5.2.2. 
die ,junge geistige Generation, niemals richtungsweisend und ausschlaggebend sein"316.

Am stärksten stieß sich Ortlepp an Kolbenheyers Darstellung der nationalsozialistischen Revolution als einer bereits vollendeten Tatsache. In Wirklichkeit befinde sich die von Kolbenheyer „als vollendet bezeichnet[e]“ Entwicklung erst in ihren Anfangsstadium. Noch nicht einmal das „Grundfundament“ der Revolution sei bislang errichtet worden, worin Ortlepp ohne jede Bescheidenheit die Durchsetzung einer „nationalsozialistische[n] Haltung aller Deutschen“317 verstand. Ohne jede Berufung habe Kolbenheyer „von der Vollendung unseres Kampfes“ gesprochen. An ihm, so Ortlepp, lasse sich jene „große Gefahr“ zeigen, „die der Lebensstand der Geistigkeit immer in sich“ berge, namentlich einer „Entwicklung nicht zu helfen, sondern sie zu zerreden, zu zerdiskutieren und durch wissenschaftliche Spekulationen zu verfälschen“. Kurzum: Ortlepp lehnte es auf das „allerschärfste“ ab, dass die „Grundforderungen, die wir von jedem geistig Schaffenden in Zukunft erfüllt wissen müssen“, namentlich die Beteiligung in „SA oder Arbeitsdienst“, von einem Menschen wie Kolbenheyer kritisiert zu sehen, der „niemals [seine] Nase“ in diese Organisationen „gesteckt“318 habe.

Ähnlich wie bei Grimm gingen Vorwürfe dieser Art von Seiten junger Nationalsozialisten spürbar an die Substanz Kolbenheyers, der sich angesichts des Unwesens jener „Frechdächse“ gar zu dem am schlechtesten behandelten Autor der Gegenwart erklärte: „Ich glaube kaum“, so klagte er Ende Januar 1934, unmittelbar nach der Veröffentlichung von Ortlepps Artikel, „daß jemals einem deutschen Dichter solche Rohheiten geboten worden sind“. Dabei treffe dieses schreiende Unrecht mit ihm ausgerechnet jenen Dichter, „der gerade gegen die Internationalen gekämpft“ habe, „fast allein [...] gekämpft“ habe, als diese „noch herrschend“319 gewesen seien. ${ }^{320}$ Nebst solch selbstbeweihräuchernder Weinerlichkeit reagierte Kolbenheyer auf die vereinzelt gegen ihn geäußerte Kritik durch junge Nationalsozialisten auch mit der Trennung der deutschen Jugend in ein wohlwollendes Freund- und ein böswilliges Feindlager. Es herrsche

„heute ein unglaublicher Terror etlicher [...] junger Scharfmacher gegen die andere Jugend. So viel ich weiß u[nd] auch beobachten konnte, ist die Jugend längst nicht mehr innerlich auf Seite der Terrormänner. Nur eine Führung, die der geistigen Notdurft des Volkes gerecht wird, kann heute die Sache im Herzen der Jugend retten. Deshalb kämpfe ich u[nd] werde weiterkämpfen." 321

316 Zitiert aus der maschinenschriftlichen Abschrift des Artikels von Ortlepp in: DLA, A:Stapel, Erwin Guido Kolbenheyer an Wilhelm Stapel, 25. Januar 1934 (Beilage).

317 Ebd.

318 Ebd.

319 DLA, A:Stapel, Erwin Guido Kolbenheyer an Wilhelm Stapel, 29. Januar 1934.

320 Zur Legende von Kolbenheyer als einem „totgeschwiegenen“ Einzelkämpfer im Literaturmarkt der Weimarer Republik vgl. Kap. 3.1.1, 3.1.2 und 3.1.5.

321 DLA, A:Stapel, Erwin Guido Kolbenheyer an Wilhelm Stapel, 5. Februar 1934. 
Der Zweckoptimismus, der aus diesen Zeilen spricht, erwies sich als eine der charakteristischsten Reaktionsweisen, mit denen Kolbenheyer im „Dritten Reich“ auf persönliche Enttäuschungserfahrungen reagierte. Den unterschiedlichen Reaktionsformen, mit denen Kolbenheyer, Grimm und Stapel die Erfahrung verarbeiteten, dass das Antlitz des NS-Staats merklich anders ausfiel als von ihnen vor 1933 imaginiert, wird ein eigenes Kapitel gewidmet werden. Zunächst soll die Aufmerksamkeit aber noch speziell dem Verhältnis zwischen Hans Grimm und Joseph Goebbels gelten, in dem sich die in diesem Kapitel geschilderten Zusammenhänge und Entwicklungslinien wie in einem Brennglas bündeln.

\subsubsection{Von Freundschaft zu Feindschaft: Hans Grimm und Joseph Goebbels}

Der erste Kontakt zwischen Hans Grimm und Joseph Goebbels fand zu einem Zeitpunkt statt, an dem die NSDAP noch eine politisch bedeutungslose Randerscheinung des Weimarer Parteiensystems war. Die Initiative ging dabei von Grimm aus: Ein Schreiben Goebbels' an Grimm vom 17. Februar 1927 belegt, dass sich der Dichter kurz zuvor an den Gauleiter Berlin-Brandenburgs gewandt und sich besorgt nach dem Befinden Hans Husterts erkundigt hatte. Hustert war am 6. Dezember 1922 zu zehn Jahren Festungshaft verurteilt worden, nachdem er sechs Monate zuvor gemeinsam mit seinem Komplizen Karl Oehlschläger als Mitglied der Organisation Consul ${ }^{322}$, die während der Weimarer Republik für mehrere politische Morde verantwortlich zeichnete, ein Blausäure-Attentat auf Philipp Scheidemann ausgeübt hatte, das der damalige Kasseler Oberbürgermeister nur mit großem Glück überlebte. ${ }^{323}$ Hustert genoss seit seiner Inhaftierung in der Weimarer Rechten Märtyrerstatus als vermeintliches Opfer einer mutmaßlich auf dem linken Auge blinden, deutschfeindlichen Justiz. ${ }^{324}$ Goebbels dankte für Grimms Anteilnahme und zeigte sich hocherfreut darüber, den ihm durch die Lektüre von Volk ohne Raum bekannten und „verehr[ten]“ Romancier dem eigenen politischen Lager zurechnen zu dürfen:

„Weder eine sozialdemokratische, noch eine deutsch volksparteiliche, noch eine demokratische, noch eine deutschnationale Regierung hält es für nötig, sich dieses im Zuchthaus verfaulenden jungen Menschen zu erbarmen. Umso tiefer freut es ihn und uns, zu sehen, wie das junge nationalsozialistische Deutschland Anteil an seinem Schicksal nimmt. Dass Sie mit zu dieser stillen, geräuschlosen Gemeinde gehören wollen, gewährt mir vor allem eine tiefe Befriedigung. “325

322 Zur Organisation Consul vgl. Sabrow, Verschwörung, bes. S. 42-65, 169-216.

323 Vgl. Gebhardt, Fall, S. 50f.; Sabrow, Verschwörung, S. 144-146.

324 Die Vorstellung einer tendenziell republikfreundlichen Richterschaft stellt den tatsächlichen Charakter der Weimarer Justiz auf den Kopf. Zur Mentalität der mehrheitlich auf dem rechten Auge blinden Weimarer Richterschaft und zahlreichen Beispiele dezidiert republikfeindlicher Rechtsprechung vgl. Angermund, Richterschaft, S. 19-44; Rasehorn, Rechtspolitik.

325 DLA, A:Grimm/Regierungs- und Parteistellen, Nationalsozialistische Deutsche Arbeiterpartei, Gau Berlin-Brandenburg an Hans Grimm, 17. Februar 1927. 
Goebbels bat Grimm darum, Hustert seine Anteilnahme persönlich mitzuteilen und ihm ein Exemplar seines Romans zukommen zu lassen. Er könne nicht ahnen, „welch eine Freude“ er Hustert damit bereiten würde. ${ }^{326}$ Ansonsten könne für den Gefangenen jedoch nichts weiter unternommen werden, außer „immer bei allen, die in Betracht kommen, zu mahnen, nicht zu vergessen und auf den Tag der Abrechnung zu warten“"327. Nach diesem kurzen Briefwechsel ist bis Ende 1930 kein weiterer Briefkontakt überliefert. Ein Schreiben von Goebbels aus dem Februar 1931 belegt jedoch, dass er damals zu den regelmäßigen Besuchern in Lippoldsberg zählte. ${ }^{328}$

Bis zum Frühling 1932 standen Grimm und Goebbels dann in engem Kontakt. Grimm pflegte diesen Kontakt vor allem deshalb, da ihm die NSDAP spätestens seit Ende 1930 als die einzig verbliebene vielversprechende (partei-)politische Option erschien. ${ }^{329}$ Von der DNVP wandte er sich, trotz seiner engen Freundschaft zu Alfred Hugenberg, entschieden ab. Dabei spekulierte er darauf, den 22 Jahre jüngeren Goebbels politisch formen und gleichsam fortbilden zu können. Aufschlussreich sind hier die Erinnerungen des Schriftstellers Arnolt Bronnen, in denen von einer im Herbst 1931 in Berlin organisierten „VorstandsSitzung“ des „nationalen Schrifttums“ berichtet wird, die von Grimm initiiert worden war. Grimm habe dabei eine gemeinsame „Stellungnahme der deutschen Schriftsteller“ zur NS-Bewegung angestrebt und es als das Ziel des Treffens ausgegeben, zu erörtern, wie die „nun einmal vorhandene elementare Bewegung des Nationalsozialismus in die Hand [zu] bekommen" sei, wie man sie „meistern“ könne, „im Sinne einer deutschen Erneuerung“330. Goebbels hingegen hoffte trotz aller authentischen Sympathie für Grimm vor allem (und nicht ohne Erfolg) darauf, den berühmten Autor als zugkräftige Werbefigur der NSDAP zu gewinnen. Dass Goebbels den Kontakt zu Grimm indes nicht nur aus strategischen Überlegungen heraus suchte, sondern über Aufmerksamkeit und Engagement des berühmten Schriftstellers zunächst aufrichtig erfreut war, belegt schon der erste in den Tagebüchern Goebbels' notierte Kommentar über Grimm. ${ }^{331}$ Am 15. Februar 1931 schrieb Goebbels im Anschluss an ein gemeinsames Mittagessen mit dem Dichter:

326 Ebd. Ob Grimm dieser Aufforderung nachkam, geht aus dem späteren Briefverkehr mit Goebbels nicht hervor, es spricht jedoch nichts dafür, dass Grimm die Bitte ausgeschlagen hätte.

327 DLA, A:Grimm/Regierungs- und Parteistellen, Nationalsozialistische Deutsche Arbeiterpartei, Gau Berlin-Brandenburg an Hans Grimm, 17. Februar 1927. Tatsächlich wurde Hustert noch im Jahr 1927 „im Rahmen einer allgemeinen Amnestie begnadigt“, woraufhin er sich der NSDAP anschloss und bis 1931 „zur SA-Führung in Berlin um Walter Stennes“ gehörte. Vgl. Sauer, Freikorps, S. 24; Sabrow, Verschwörung, S. 192 f.

328 Vgl. DLA, A:Grimm/Regierungs- und Parteistellen, Deutschland, Deutsches Reich, Reichstag an Hans Grimm, 20. Februar 1931.

329 Vgl. Kap. 5.1.

330 Bronnen, Protokoll, S. 332 f.

331 Es ist erheblich plausibler, die Äußerungen der Sympathie zum damaligen Zeitpunkt als authentische Gefühlsäußerungen und nicht als Ausdruck einer hintergründigen, doppelbödigen Propagandaabsicht anzusehen. Die Sympathie Goebbels' für Grimm wird - wenn- 
„Er sieht in der Politik ganz klar. Wir sind ihm die beste deutsche Chance, und deshalb setzt er auf uns. Aber ganz ohne Pathos und Gerede [...], sehr gut und anhänglich zu Hitler. Ich erobere gleich sein Herz. Er ist betroffen, als ich von den Pflichten spreche, die die deutschbewussten Geister uns gegenüber haben. Das geht sichtbarlich an sein Gewissen. Er überantwortet sich dann ganz uns. Zivilkourage! [sic!] Bravo! So sollten wir viele haben. Wir scheiden als Freunde, mit dem Wunsche, uns oft wiederzusehen. Das ist ein Gewinn! Der Dichter des,Volk ohne Raum'steht bei unseren Fahnen." ${ }^{332}$

Dass die persönliche Wertschätzung gegenseitig war, betonte Grimm noch nach dem Zweiten Weltkrieg. Demnach erkannte er bereits bei der ersten SportpalastRede an dem damals noch „unverbrauchte[n] Goebbels“ ein „Stück Genie“, was ihm „Achtung“ abgenötigt habe. ${ }^{333}$ Ein Brief an Stapel vom März 1931 belegt ebenfalls, dass Grimm von der Persönlichkeit Goebbels' merklich beeindruckt war: „Ich habe inzwischen hier [in Berlin] übrigens Dr. Goebbels kennen gelernt und muß sagen, daß diese Bekanntschaft, der eine mehrstündige Aussprache

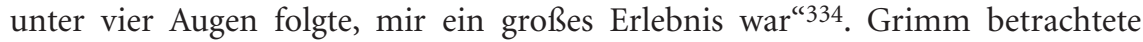
Goebbels damals als den politisch begabtesten und vielversprechendsten Kopf der NSDAP - eine Auffassung, die in seinem persönlichen Umfeld, unter anderem bei Stapel, durchaus Unverständnis hervorrief. ${ }^{335}$

Ein Tagebucheintrag vom 12. März 1931 belegt indes zugleich, dass Goebbels' Meinung über Grimm und andere Rechtsintellektuelle seiner Generation, die sich für den Nationalsozialismus in wohlwollender Weise interessierten, schon zum damaligen Zeitpunkt zwiespältig war. Darüber, wie zielführend die Unterredungen mit jenem Personenkreis für die politischen Zwecke der NSDAP tatsächlich waren, plagten den Gauleiter jedenfalls einige Zweifel: „Aber bei diesen Zirkeln kommt nicht viel heraus. Das ist meist eine Politik der Ästhetik. Eine Massenversammlung ist mehr als zehn Teeabende." 336 Nur zwei Tage später betonte er hingegen, wie „lehrreich“ ein am Vorabend stattgefundenes Treffen mit Grimm und Paul Fechter für ihn gewesen sei. ${ }^{337}$ Eine in die Memoiren Fechters

gleich überspitzt - auch durch Paul Fechters Erinnerungen bestätigt (siehe unten). Außerdem lassen die noch zu schildernden Ereignisse am Königsberger Bahnhof und ihre Folgen eine Zuneigung des „Gauleiters" nahe liegend erscheinen. Bernd Sösemann hat zwar mit Recht auf geschichtsklitternde Selbstinszenierungen hingewiesen, von denen die GoebbelsTagebücher zumal während des „Dritten Reichs“ durchzogen sind; Angela Hermann konnte jedoch für das Zeitfenster 1938/39 an zahlreichen überzeugenden Beispielen nachweisen, dass sich die Tagebücher keineswegs allein in der Lesart Sösemanns erschöpfen. Vgl. Sösemann, Goebbels-Propaganda?; Hermann, Weg.

332 Die Tagebücher von Joseph Goebbels, Teil I, Bd. 2/I, S. 345f. (vgl. auch ebd., S. 362).

333 Vgl. Grimm, Suchen, S. 93.

334 DLA, A:Grimm, Hans Grimm an Deutsches Volkstum, 23. März 1931.

335 Im Anschluss an einen Besuch, den er Grimm im Frühling 1931 gemeinsam mit Albrecht E. Günther in Lippoldsberg abgestattet hatte, berichtete Stapel an Kolbenheyer, Grimm halte „Goebbels im Ernst für einen ,Führer!" Während des Treffens habe Grimm insbesondere mit Günther „immer [...] über den Nationalsozialismus sprechen“ wollen, was diesem schließlich „in Rücksicht auf die anderen Tischgenossen sehr peinlich“ geworden sei (KAG, Wilhelm Stapel an Erwin Guido Kolbenheyer, 19. Mai 1931).

336 Die Tagebücher von Joseph Goebbels, Teil I, Bd. 2/I, S. 362.

337 Goebbels' Kommentar bezog sich hierbei jedoch in erster Linie auf Fechter: „Ganz unser Mann. Sehr klug und angenehm. Warnt uns vor dem Weimarer-Kunstbetrieb Schultze- 
eingeflossene Beschreibung des Verhältnisses zwischen Goebbels und Grimm will gar eine geradezu schülerhafte Haltung des jungen Gauleiters gegenüber dem zum damaligen Zeitpunkt ungleich berühmteren Grimm glaubhaft machen. Fechter blieb unter mehreren „wiederkehrende[n] Nachtgespräche[n] “338 mit Grimm und Goebbels insbesondere eine Abschiedsszene aus dem Januar 1932 in lebhafter Erinnerung, die „etwas von der Haltung eines Schülers zu einem verehrten Lehrer"339 gehabt habe. Obgleich Fechters Darstellung einseitig überzeichnet ist und etwa den Aspekt taktischen Anbiederns im Verhalten Goebbels gänzlich ausklammert, darf doch angenommen werden, dass Grimm bei seiner Absicht, durch zahlreiche Gesprächsabende einen gewissen Einfluss auf Goebbels zu gewinnen, nicht ganz erfolglos gewesen ist. Eine langfristige, tiefgreifende Wirkung auf Goebbels, der seit der Bamberger „Führertagung“ der NSDAP vom 14. Februar 1926 zunehmend auf Hitler fixiert war ${ }^{340}$, blieb Grimm hingegen freilich verwehrt.

Das gute Verhältnis zwischen Grimm und Goebbels bis etwa Mitte 1932 war auch davon bedingt, dass Grimm im März 1931 Augenzeuge geworden war, als mehrere Mitglieder der NSDAP - darunter neben Goebbels auch der vierte Sohn des exilierten Wilhelm II., Prinz August Wilhelm - auf dem Königsberger Bahnhof in eine Schlägerei mit Einheiten der Schutzpolizei verwickelt wurden. ${ }^{341}$ Grimm prangerte diesen Vorfall am 22. März in einem offenen Brief an Paul von Hindenburg ,als ungeheuerlich an und verlangte einen Prozess gegen die Polizisten wegen Körperverletzung “342. Eine Stellungnahme des Reichspräsidenten blieb zwar aus, doch brachte der Brief Grimm in engere Fühlungnahme mit den Nationalsozialisten. Goebbels dankte Grimm sogleich für seinen Artikel und stellte „mit Freude“ fest, dass dieser „in der Öffentlichkeit einen großen Eindruck gemacht" habe. Eilends gab Goebbels den Artikel auch dem Berliner NS-Blatt Der Angriff zum Abdruck. Goebbels war nicht nur erfreut,

Naumburg. Reaktion? Wohl etwas! Aufpassen! Ein lehrreicher Abend für mich. Man bekommt nach allen Windrichtungen Verbindung. Mit Fechter werde ich Tuchfühlung behalten. Grimm ist unser Mann. Er krittelt noch hier und da, aber dafür ist er ja ein Mann der Feder" (Die Tagebücher von Joseph Goebbels, Teil I, Bd. 2/I, S. 364). Zu Fechter und seinem Verhältnis zu Grimm vgl. Kap. 3.1.3.

338 Grimm, Warum [1954], S. 115.

339 Fechter, Wende, S. 404. Fechter sprach von „Dank und Hoffnung auf ein baldiges Wiedersehen, und beides hatte einen Klang von Aufrichtigkeit. Der kleine, schmale Goebbels stand vor dem ihn fast um Haupteslänge überragenden, großen, hageren Grimm, drückte ihm die Hand, sah zu ihm empor und war in diesem Augenblick tatsächlich wie ein Mensch, der in den Stunden dieses Abends etwas empfangen hatte und mit einem Gefühl der Bereicherung davonging" (ebd.).

340 Vgl. Longerich, Goebbels, S. 80-83.

${ }^{341}$ Hintergrund des Vorfalls war eine für Königsberg geplante „politische Versammlung“ der NSDAP gewesen, in der Goebbels und August Wilhelm hätten sprechen sollen, die jedoch durch ein unmittelbar zuvor für Goebbels erlassenes Redeverbot unterbunden wurde, vgl. Franke, Grimm, S. 35.

342 Gümbel, Volk, S. 77. Der Wortlaut des offenen Briefs ist zitiert in: Franke, Grimm, S. 3436. 
sondern überrascht und durchaus beeindruckt von der „aufrechten Haltung“

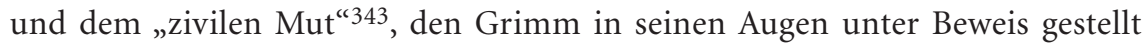
hatte. So schien aus dem Engagement des arrivierten Dichters doch anderes zu sprechen als jene Feigheit und Passivität, die Goebbels und andere führende Nationalsozialisten - anknüpfend an ältere Stereotype ${ }^{344}$ - dem deutschen Bürgertum notorisch vorwarfen. Kurze Zeit später lud Goebbels den damals in Berlin weilenden Grimm auf „dringende Veranlassung“ in den „Schwechtensaal $[\ldots]$ am Magdeburger Platz" ein, um „eine Reihe wichtiger politischer Fragen im Rahmen eines engeren Kreises zu erörtern" 345 . Über die konkreten Inhalte der Zusammenkunft schweigen sich die anschließenden Briefe leider aus.

Seit dem Frühsommer 1932 kühlte sich das Verhältnis zwischen Grimm und Goebbels dann jedoch spürbar ab. Dies war nicht nur durch den triumphalen Erfolg der NSDAP in der Reichstagswahl vom 31. Juli 1932 bedingt $^{346}$, der die Unterstützung durch einzelne, namhafte Autoren der Weimarer Rechten wie Grimm für die Nationalsozialisten zunehmend nebensächlich werden ließ. Mindestens ebenso bedeutsam für die wachsende Entfremdung zwischen beiden Männern war, dass Goebbels aus Grimms öffentlichem Aufruf Bitte an den Nationalsozialismus eine direkte Kritik an seiner Person ableitete - hatte Grimm in ihr doch kritisch auf die Zusammenarbeit der Berliner NSDAP mit der KPD im politischen Protest gegen die Regierung von Papen angespielt. ${ }^{347}$ Zwar übertrieb Grimm, als er im März 1933 gegenüber dem an der Universität Frankfurt lehrenden Rhetorik-Dozenten Friedrich Karl Roedemeyer behauptete, mit dem Berliner Gauleiter „seit etwa dreiviertel Jahren keine Verbindung mehr gehabt“348 zu haben. Ein Brief vom 28. Oktober 1932 belegt jedoch die persönliche Kluft und das gesteigerte Selbstbewusstsein Goebbels', als er nur aufreizend knapp und wie im Vorübergehen über die Bitte an den Nationalsozialismus sprach, so als sei sie eine nicht weiter beachtenswerte und kommentierwürdige Bagatelle,

343 DLA, A:Grimm/Regierungs- und Parteistellen, Deutschland, Deutsches Reich, Reichstag an Hans Grimm, 25. März 1931.

344 Verwiesen sei hier nur auf Heinrich Claß' berühmtes, erstmals 1912 veröffentlichtes Traktat Wenn ich der Kaiser wär', in welchem gleich zu Beginn pauschal die angeblich „völlig ungenügende Abwehr der bürgerlichen Parteien und Gesellschaft" gegenüber dem bedrohlichen „Anwachsen der Sozialdemokratie“ kritisiert wird (Frymann, Kaiser, S. 3).

345 DLA, A:Grimm/Regierungs- und Parteistellen, Deutschland, Deutsches Reich, Reichstag an Hans Grimm, 8. Mai 1931.

346 Die NSDAP konnte ihren Stimmanteil im Vergleich zur Septemberwahl 1930 mit 37,3\% mehr als verdoppeln und gewann 230 von 608 Sitzen im Reichstag.

347 Vgl. Kap. 5.2.1.

348 DLA, A:Grimm, Hans Grimm an Karl Friedrich Roedemeyer, 25. März 1933. Zuvor hatte Roedemeyer, der mit Grimm seit 1930 in Verbindung stand, über seine völkischen Aktivitäten seit dem Ende des Ersten Weltkriegs referiert, namentlich im Baldurbund, im Hochschulring Deutscher Art und in der Luther-Gesellschaft (vgl. DLA, A:Grimm, Friedrich Karl Roedemeyer an Hans Grimm, 23. März 1933). 
deren Haltlosigkeit bereits erwiesen sei. ${ }^{349}$ Eine solche Behandlung seiner Publikation musste Grimm vor den Kopf stoßen.

In der Folgezeit entschwand Grimm immer weiter aus dem Blickfeld Goebbels'. Zwar wurde Grimm im November 1933 von Goebbels in den Präsidialrat der Reichsschrifttumskammer berufen ${ }^{350}$, ein direkter Briefverkehr zwischen beiden Männern ist ab 1933 jedoch nicht mehr nachweisbar. Am 16. Januar 1934 hielt der zum Reichsminister für Volksaufklärung und Propaganda und Leiter der Reichskulturkammer avancierte Goebbels in seinen Tagebüchern dann seine zunehmende Unzufriedenheit mit dem „ewige[n] Literat[en]“ Grimm fest, der politisch „nicht mehr umlernen“351 könne. Anschließend findet Grimm, obgleich er sich ab 1933 als Senator der Deutschen Akademie für Dichtung ${ }^{352}$ und Präsidialrat der Reichsschrifttumskammer ${ }^{353}$ engagierte, in Goebbels' Tagebüchern bis zum Frühsommer 1938 keine Erwähnung mehr. Dass sich der Reichsminister zu diesem Zeitpunkt bereits gänzlich von Grimm distanziert hatte, bezeugt ein Tagebucheintrag vom 26. Mai 1938, in dem Goebbels selbstgefällig und aus einem deutlichen Überlegenheitsgefühl heraus die gesellschaftliche Marginalisierung des Dichters bilanzierte: „Hans Grimm [...] stänkert zwar noch viel, ist aber bedeutend kleiner geworden. So geht das mit den Kritikastern“354.

Nur wenige Tage später nahm sich Goebbels' Tonfall jedoch deutlich schärfer aus. Anlass seiner Empörung waren zwei in den Jahren 1934 und 1936 verfasste Briefe an Wilhelm Frick und den späteren Präsidenten des Volksgerichtshofs Roland Freisler, in denen Grimm auf politisch-gesellschaftliche Missstände in seiner unmittelbaren Umgebung hingewiesen hatte. Konkret kritisierte Grimm zum einen die Verletzung des Wahlgeheimnisses in Lippoldsberg während der Volksabstimmung über das Staatsoberhaupt des Deutschen Reichs vom 19. August 1934, durch die Hitler nachträglich die Vereinigung der Ämter des Reichspräsidenten und des Reichskanzlers in seiner Person bestätigen ließ. Zum anderen beschwerte sich Grimm über die schwere Körperverletzung eines in Lippoldsberg ansässigen sozialdemokratischen Arbeiters namens Friedrich

349 „Vielleicht sind Sie auch heute schon der Ansicht, dass Ihre seinerzeit in der Börsenzeitung ausgesprochene Bitte an den Nationalsozialismus von irrigen Voraussetzungen ausging. Die Entwicklung seit jener Zeit bis heute hat doch wohl unzweideutig Adolf Hitler Recht gegeben. Wir alle hoffen, den Verfasser von ,Volk ohne Raum bald wieder vorbehaltslos bei unseren Reihen zu sehen." (DLA, A:Grimm/Regierungs- und Parteistellen, Deutschland, Deutsches Reich, Reichstag an Hans Grimm, 28. Oktober 1932).

350 Gümbel, Volk, S. 180.

351 Die Tagebücher von Joseph Goebbels, Teil I, Bd. 2/III, S. 358.

352 Neben Grimm und Kolbenheyer wurden Werner Beumelburg, Hans Friedrich Blunck, Hanns Johst, Agnes Miegel, Börries von Münchhausen, Wilhelm Schäfer, Hermann Stehr und Emil Strauß zu Senatoren der Deutschen Akademie der Dichtung bestimmt, vgl. Wulf (Hg.), Kultur, S. 36. Die Geschichte der Akademie der Dichtung im Dritten Reich, die vornehmlich als die Geschichte ihres gescheiterten Bemühens um inhaltliche und organisatorische Selbstständigkeit verstanden werden muss, ist in der Forschung bereits ausführlich beschrieben worden, vgl. Mittenzwei, Untergang.

353 Der Präsidialrat wurde bereits 1935 von Goebbels aufgelöst, vgl. Gümbel, Volk, S. 180, 183.

354 Die Tagebücher von Joseph Goebbels, Teil I, Bd. 5, S. 318. 
Remhof durch den SS-Obersturmführer Hans Merz. ${ }^{355}$ Grimms Annahme, mit Protestschreiben an Frick und Freisler eine Korrektur jener Missständen erreichen zu können, belegt freilich das Unvermögen des Dichters, in der Gewaltausübung gegen „Andersdenkende“ und der Unterwanderung des Wahlgeheimnisses genuine Aktions- und Ausdrucksformen des Nationalsozialismus zu erkennen, die von seinen Adressaten nicht nur gedeckt, sondern befürwortet und aktiv befördert wurden. Trotz dieser Naivität sind die mutigen Briefe jedoch Beleg dafür, dass Grimm sein Rechtsbewusstsein nach 1933 nicht gänzlich preisgab.

Goebbels hingegen betrachtete die Briefe, als er sie im Mai 1938 zu Gesicht bekam, als derart „unverschämt und dreist“, dass er beschloss, sich den Dichter durch den damaligen Staatssekretär im Reichspropagandaministerium Karl Hanke „vorknöpfen“ zu lassen. Anders als noch in den Jahren 1931/32 verkörperte der „Literat“ Grimm für Goebbels nun einen „typische[n] Schwächling“, dem „jedes politische Verständnis“"356 fehle. Hier kam auch die Unzufriedenheit und Enttäuschung des Reichsministers zum Ausdruck, der sich nach der NS-,„Machtergreifung" sichtlich mehr Propagandaleistungen erhofft hatte, als der Dichter zu erbringen bereit war. ${ }^{357}$ Der Konflikt eskalierte im November 1938, als Grimm von Goebbels unter falschen Vorgaben nach Berlin zu einer persönlichen Besprechung einbestellt wurde: Nicht ohne Schadenfreude notierte Goebbels im Vorfeld der Begegnung in seinem Tagebuch, Grimm lebe „in der holden Illusion, ich wollte ihm einen Posten anbieten" 358 . Vor Ort sah sich Grimm jedoch mit einer heftigen Attacke konfrontiert, in der Goebbels das vermeintliche „Sündenregister“359 des Dichters ausbreitete. Den im unmittelbaren Anschluss an diese Konfrontation angefertigten, glaubwürdigen Aufzeichnungen Grimms zufolge kulminierte der anschließende Schlagabtausch beider Männer in der Drohung Goebbels', Grimm im Falle weiterer Verfehlungen in ein Konzentrationslager einsperren zu lassen. ${ }^{360}$ Begreiflicherweise nahm Grimm diesen Einschüchterungsversuch sehr ernst: Seit 1939 trat er nur noch sehr selten an die Öffentlichkeit und setzte auch, den Forderungen von Goebbels entsprechend, die Veranstaltung seiner Lippoldsberger Dichtertage aus. Darüber hinaus zog er sich in der Folgezeit endgültig „aus allen Gremien zurück“361.

Nach der Konfrontation in Berlin kam es zwischen Grimm und Goebbels zu keinen weiteren Begegnungen mehr. In den Tagebüchern des Reichsministers taucht Grimm in der Folgezeit nicht mehr auf - mit einer Ausnahme: Im No-

355 Die Briefe Grimms an Frick und Freisler sind zusammengefasst in: Gümbel, Volk, S. 190193.

356 Die Tagebücher von Joseph Goebbels, Teil I, Bd. 5, S. 329.

$357 \mathrm{Zu}$ diesen Propagandaleistungen Grimms vgl. Kap. 5.3.2.

358 Die Tagebücher von Joseph Goebbels, Teil I, Bd. 6, S. 197.

359 Ebd., S. 208.

360 Für eine detaillierte Darstellung dieser Konfrontation siehe die ausführliche Schilderung in: Franke, Grimm, S. 100-114. Für eine retrospektive Zusammenfassung der Ereignisse aus der Perspektive Grimms siehe: Grimm, Warum [1954], S. 181-184.

361 Lörke, „Schwierig und ablehnend“, S. 159. 
vember 1944 notierte Goebbels seine Verwunderung über die Bereitschaft Grimms, sich an einer von seinem Ministerium ausgehenden Aufforderung „an eine Reihe prominenter Künstler [...], ein öffentliches Bekenntnis zum Führer abzulegen“, zu beteiligen. Eine ganze Reihe von Autoren, so Goebbels, „von denen man das nicht erwartet“ habe, hätte sich „bereitwilligst für diese Aufgabe zur Verfügung“ gestellt und dabei „geradezu dithyrambische Auslassungen“ produziert. Zu ihnen zählte Goebbels auch Hans Grimm, von dem er „das nie erwartet ${ }^{\text {"362 hatte. }}$

Das Verhältnis von Grimm zu Goebbels spiegelt im Kleinen eine Entwicklung wider, die für viele völkisch orientierte Intellektuelle seiner Generation symptomatisch war. In einer ersten Phase der Fühlungnahme und des gegenseitigen Interesses hing Grimm dem letztendlich illusorischen Optimismus an, via Goebbels einen relevanten Einfluss auf die von ihm mit Nachdruck begrüßte und unterstützte NSDAP ausüben zu können. Nachdem er an der NS-Bewegung Wesenszüge wahrzunehmen begann, die er für kritikwürdig hielt, da sie mit seinen politischen Ordnungsvorstellungen kollidierten, beschritt Grimm in einer zweiten Phase den Weg öffentlicher Ermahnungen. Hierdurch wurden die zuvor noch vorhandenen, dünnen Fäden direkter Einwirkung auf Goebbels allerdings unwiderruflich durchtrennt. Dass Grimm 1944, trotz der heftigen Konfrontation mit Goebbels im Jahr 1938, bereit war, sich ohne äußeren Zwang an dem vom Propagandaministerium gewünschten „Bekenntnis zum Führer“ zu beteiligen, ist schwerlich als Ausdruck eines blinden Führerglaubens zu verstehen, ebenso wenig jedoch als Ausdruck der Sorge, bei einer Zurückweisung der Anfrage eine weitere Konfrontation mit Goebbels zu riskieren. Vielmehr kommt hier ein widerspruchsvolles Spannungsverhältnis von grundlegender Bedeutung zum Vorschein: Grimm hegte zwar, ebenso wie Kolbenheyer und Stapel, im „Dritten Reich“ auf privater Ebene eine starke Abneigung gegen einzelne Facetten des NS-Staats, ließ sich davon jedoch nicht von emphatischen öffentlichen Bekenntnissen zum „Dritten Reich“ abbringen. Ohne Zweifel war auch ihm bewusst, dass sein persönliches Schicksal aufgrund des jahrelangen Eintretens für den Nationalsozialismus untrennbar mit jenem des NS-Staats verbunden war. $^{363}$

Beides, die privaten Enttäuschungserfahrungen Grimms, Kolbenheyers und Stapels und ihre gleichzeitige Bereitschaft zur Propaganda für das NS-Regime, sind Gegenstand des folgenden Kapitels.

362 Die Tagebücher von Joseph Goebbels, Teil II, Bd. 14, S. 206. Der Wortlaut dieses Beitrags und die Frage, ob es noch und wenn ja wo zu einer Publikation der „Auslassungen“ Grimms kam, ließ sich leider nicht ermitteln.

363 Siehe hierzu auch das das Kapitel 5.3.1 beschließende Zitat Stapels. 


\title{
5.3 Gefühlte Alternativlosigkeit: Publizistik und Emotion im „Dritten Reich“
}

\subsection{1 „Treue ohne jede Hoffnung"? Enttäuschungserfahrungen nach 1933}

\begin{abstract}
Ich hatte geglaubt, nach der Revolution ein freies Feld für freudige Arbeit zu bekommen. Nun ist es so. Souveräne Gewalttätigkeit unwissender Menschen. Alles geht flüsternd umher. [...] Ich sitze hier auf einem Pulverfaß und muss jeden Augenblick auf den Eingriff manueller Gewalt gefaßt sein. Das ist der Lohn vierzehnjähriger Arbeit für die nationale Sache. Ich bin sehr unglücklich. $^{364}$
\end{abstract}

Ich teile Dein Volksvertrauen nicht. Ein Hauptbestandteil der deutschen Rasse ist das Schweinshündige. ${ }^{365}$

Ungeachtet ihrer tiefen Befriedigung über den Kollaps der republikanischen Staatsordnung sind in den Briefen Grimms, Kolbenheyers und Stapels im Umfeld der nationalsozialistischen "Machtergreifung" euphorische Hochgefühle eine Seltenheit. ${ }^{366}$ Mehrheitlich stehen die Korrespondenzen vielmehr unter dem Zeichen einer großen Anspannung, die sich aus der Ungewissheit darüber speiste, wie sich die Nationalsozialisten in Regierungsverantwortung schlagen würden. Eine vorauseilende Gewissheit, dass der seit langer Zeit erhoffte politische Durchbruch der NSDAP zugleich den endgültigen und dauerhaften Erfolg der „nationalen Revolution" bedeuten würde, spricht aus den Briefen jedenfalls nicht. Nervosität und Zuversicht liefen parallel.

Dass Grimm, Kolbenheyer und Stapel schließlich bereits im Sommer 1933 von intensiver Enttäuschung erfasst wurden, war indes nur zu einem sehr kleinen Teil von der großen politischen Linie der Nationalsozialisten bedingt. Diese entsprach im Kern vielmehr durchaus dem, was die drei Autoren seit 1918/19 erhofft und befürwortet hatten: die sukzessive Zerschlagung des Parteiensystems, die Ausschaltung der liberalen Presse und das systematische Vorgehen gegen jüdische,

364 KAG, Wilhelm Stapel an Erwin Guido Kolbenheyer, 9. Mai 1933 (Herv. i. Orig.).

365 KAG, Wilhelm Stapel an Erwin Guido Kolbenheyer, 26. September 1935.

366 Stapel verfasste im März 1933 vor dem Hintergrund eines für die Zukunft seiner Zeitschrift vielversprechenden Gesprächs mit dem „alte[n] Volkstums-Leser“ und späteren Reichsministers für Wissenschaft, Erziehung und Volksbildung, Bernhard Rust (1883-1945), einen Brief an Kolbenheyer, der von einer ungewöhnlich euphorischen Stimmung zeugt: „Also ich bin Freitag bei Rust gewesen. [...] Ich habe einen sehr guten Eindruck von ihm. Von Dir sprach er mit großer Achtung. [...] [Max] Habermann war Sonnabend bei Hitler. Es ist ein gutes Verhältnis zwischen beiden hergestellt worden. Diese Regierung wird bleiben. Hugenberg sackt von selbst ab, weil er nicht über seine Akten hinauskommt. [...] Ich bin glücklich über den Umschwung in Deutschland. Ich freue mich auf Italien. Ich freue mich, bei Euch zu schein [sic!]. Draußen ist ein sommerlicher Tag. So viel Glück!" (KAG, Wilhelm Stapel an Erwin Guido Kolbenheyer, 13. März 1933, Herv. i. Orig.). 
linksliberale und kommunistische Intellektuelle. Die Enttäuschungserfahrungen Grimms, Kolbenheyers und Stapels gründeten stattdessen primär auf ihrer eigenen, unverhofft randständigen Stellung im NS-Staat. Die tiefen, misstrauischen Vorbehalte, mit der das Regime gerade auch dem Heer der selbsterklärten „Wegbereiter und Vorkämpfer für das neue Deutschland“ 367 begegnete, trafen sie weitgehend unvorbereitet. Mochten die Listen ihrer „nationalen Verdienste“ seit 1918 noch so lange ausfallen: das Gros der „Wegbereiter“ des „Dritten Reichs“ musste sich nach 1933 bald mit der frustrierenden Realität auseinandersetzen und arrangieren, zu den maßgeblichen Machtzentren des NS-Staats nicht vordringen zu können und dort auch kaum Gehör zu finden. Vor diesem Hintergrund malte Kolbenheyer im August 1933 die Lage der „Generation“ der über Fünfzigjährigen in sehr düsteren Farben:

„Wir sind in die bittere Lage versetzt unser Lebenswerk weiterführen zu müssen, um die Literatur u[nd] die Geistigkeit im deutschen Volke zu erhalten - wir sind es fast allein, die das vermögen und... man lebt, organisiert über unsere Köpfe hinweg. [...] Wir werden vor die bitterste Wirklichkeit gestellt: Eine frühere Zeit hat uns totgeschwiegen $\mathrm{u}[\mathrm{nd}]$ verfolgt, weil wir gegen sie kämpften u[nd] die neue Zeit vorbereiteten. Die neue Zeit aber läßt uns liegen (tötet uns also auch vor der Gegenwart), weil sie meint unser Werk u[nd] unsere Gedanken seien von ihr überwunden - sie kennt uns nicht $\mathrm{u}[\mathrm{nd}]$ will uns nicht weiter kennen. “368

So zynisch diese zutiefst einseitige und selbstgerechte Perspektive angesichts der tatsächlichen Opfer des Jahres 1933 auch anmutet, Kolbenheyer rannte mit ihr bei vielen Autoren seiner Alterskohorte offene Türen ein, zumal in der Frühphase des „Dritten Reichs“. Dabei wurden wechselseitig praktisch dieselben larmoyanten Opfer-Narrative bedient, die schon nach 1918 eingeübt und internalisiert worden waren. ${ }^{369}$

Kolbenheyers Pessimismus fiel auch bei Stapel auf fruchtbaren Boden. Dessen ausführliche Replik belegt, dass auch Stapel zum damaligen Zeitpunkt „die Hoffnung, daß wir ,noch einmal an die Reihe kommen“", bereits für eine Illusion hielt: „Wir sind und bleiben erledigt “370. Wohl werde „auch diese Epoche“ einst ihr Antlitz verändern und „sich wandeln“, eine realistische Aussicht darauf, diesen Wandel noch miterleben zu können, sah Stapel für sich und Kolbenheyer jedoch nicht. Die Ziele, die er vor diesem Hintergrund für sich und seine publizistische

367 So der Titel eines 1933 von Wilhelm Freiherr von Müffling herausgegebenen Bandes. Das Buch besteht aus einer Aneinanderreihung der Bildnisse von insgesamt 168 jener „Vorkämpfer", begleitet von zusammenfassenden Bildunterschriften. Über Grimm ist vermerkt: „Schrieb den berühmten Roman ,Volk ohne Raum', der ergreifendste Ausdruck der tiefsten Not des deutschen Volkes, dem die Welt den Raum zum Leben und zur Entwicklung seiner Kräfte versperrt“. Über Kolbenheyer weiß das Büchlein folgendes zu berichten: „Schrieb den dreiteiligen Parazelsusroman [sic!] und völkische Bühnenstücke, in denen er die Einordnung des Menschen in die natürlichen Bindungen von Art und Volkstum betont“. Stapels Bildunterschrift lautet: „Gab den völkisch-konservativen Kräften einen geistigen Sammelpunkt im ,Deutschen Volkstum. Schrieb unter anderem: Antisemitismus und Antigermanismus, Der christliche Staatsmann, Preußen muss sein" (ebd., S. 28f., 38).

368 DLA, A:Stapel, Erwin Guido Kolbenheyer an Wilhelm Stapel, 11. August 1933.

369 Vgl. Kap. 3.1.1.

370 KAG, Wilhelm Stapel an Erwin Guido Kolbenheyer, 13. September 1933. 
Arbeit im NS-Staat noch zu erkennen vermochte, fielen entsprechend dürftig aus. Sie reduzierten sich letztendlich darauf, persönlich Haltung zu bewahren und die eigene „Ehre“ zu schützen: Um seiner „Ehre willen“ stehe er „auch zu diesem Staate“ - und dies mit einer größeren Treue als jene, „die sich mit Erfolg an ihn heran[ge]mach[t] “ hätten, wie Stapel nicht ohne Stolz und Trotz bemerkte. Angesichts der gefühlten persönlichen Perspektivlosigkeit und des als unaufhaltsam empfundenen Siegeszugs junger „Emporkömmlinge“ - vor denen er die NS-Führung anderthalb Jahre zuvor in seinem Aufsatz Forderungen der Kulturpolitik noch so eindringlich gewarnt hatte ${ }^{371}$ - kleidete Stapel seine Haltung zum „Dritten Reich“ in die sprechende Formel: „Treue ohne jede Hoffnung“372.

Für Hans Grimm lässt sich eine ähnliche Befindlichkeit konstatieren. Ihn quälte die bittere Erfahrung, sein in der Tat umfangreiches Engagement für die NSBewegung seit Mitte der 1920er Jahre von den an die Macht gelangten Nationalsozialisten kaum respektiert und gewürdigt zu sehen. Nach seiner Rückkehr von einem Besuch bei Grimm in Lippoldsberg berichtete Gustav Pezold, der Leiter des LMV, im August 1933 an Stapel von einem alarmierenden emotionalen und körperlichen Zustand des Gastgebers: Grimm sei „maßlos erschöpft“, schlafe „nicht mehr“ und werde durch die „kleinen Ungeschicklichkeiten der Zeit [...] aufs höchste“ beunruhigt. Insbesondere sei es ihm unerträglich, dass „nun auf einmal alle Verdienste derjenigen, die die eigentlichen Träger des Krieges waren [...] und die auch nach dem Kriege unter persönlichem Einsatz eine nationale Bewegung in Gang gehalten und vorwärts getrieben haben, nichts mehr gelten sollen“"373.

Mit ihren Enttäuschungserfahrungen standen Grimm, Kolbenheyer und Stapel in einem größeren Zusammenhang jener Vertreter der Weimarer Rechten, die trotz ihrer Unterstützung der Nationalsozialisten außerhalb der NSDAP verblieben waren. An den Trägern jener Segmente der völkischen Bewegung, die sich am Rande der deutschen Gesellschaft abseitigen und esoterischen Welterklärungsmodellen hingaben, ging dieser Kelch ebenso wenig vorüber ${ }^{374}$ wie an „neokonservative[n] Intellektuelle[n]“, die „mit ihren Ideen dazu beigetragen hatten, den Weg für das Dritte Reich zu ebnen“, nach der Machtergreifung jedoch „bald äußerst desillusioniert“375 wurden. Sie alle mussten sich nach 1933 zu dem kons-

371 Vgl. Kap. 5.2.1.

372 KAG, Wilhelm Stapel an Erwin Guido Kolbenheyer, 13. September 1933. Zur Ambivalenz des „Treue“-Begriffs im Nationalsozialismus vgl. Gross, „Treue“.

373 DLA, A:Stapel, Gustav Pezold an Wilhelm Stapel, 11. August 1933.

374 Pars pro toto mag hierfür ein Blick auf die 1933 einige hundert Mitglieder zählende Germanische Glaubens-Gemeinschaft genügen: Mit ihrer Sensorik für die christentumsfeindlichen Elemente der NS-Ideologie war die nationalsozialistische „Machtergreifung“ von ihren Mitgliedern zuvorderst mit der Hoffnung begrüßt worden, dass im Dritten Reich die seit dem späten Kaiserreich vergeblich eingeforderte rechtliche Gleichstellung ihres Verbands erfolgen werde. Angesichts dessen, dass das NS-Regime aus Gründen der Systemstabilisierung den Ausgleich mit den etablierten Kirchen anstrebte, war diese Hoffnung jedoch illusorisch - von der innerhalb der Germanischen Glaubens-Gemeinschaft gehegten Zuversicht auf eine „Anerkennung ihres Glaubens als offizielle Religion des neuen Reiches“ (Schnurbein, Suche, bes. S. 183f.) ganz zu schweigen.

375 Kershaw, Hitler, Bd. 1, S. 610. 
ternierten Eingeständnis durchringen, dass viele ihrer gehegten Wünsche und „zum Ausdruck gebrachten Hoffnungen und Erwartungen“ an den NS-Staat „nicht in Erfüllung gehen würden“376. Gut erforscht sind etwa die „Zwischen Kritik und Affirmation“377 oszillierende Haltung Ernst Jüngers gegenüber dem „Dritten Reich“ sowie die spezifischen Enttäuschungserfahrungen des Soziologen Hans Freyer. ${ }^{378}$ Auch bei Carl Schmitt „trat spätestens 1935 eine Ernüchterung ein, nachdem es offenbar war, wie sehr sich die Wirklichkeit des Nationalsozialismus von den ursprünglichen Visionen einer tatsächlichen Abkehr von Parteienegoismus und Interessenpolitik entfernt hatte" 379 .

Die distanzierte und reservierte Haltung der neuen Machthaber rief bei Grimm, Kolbenheyer und Stapel indes nicht nur Entrüstung darüber hervor, um die verdienten Früchte ihres langen und angeblich so aufopferungsvollen Kampfes gegen die Weimarer Republik gebracht worden zu sein. Verstärkend wirkte die gleichzeitige ernste Sorge, dass sich ein Übergehen der von ihrer Generation angebotenen Ratschläge und Hilfestellungen früher oder später zu einer existenziellen Krise des NS-Staats auswachsen müsse. Diese Gefahr erschien besonders deshalb als eklatant, da die nachrückende Generation in ihren Augen viel zu früh und ohne hinreichende Vorbereitung in einflussreiche politische Ämter gelangt war. Im Februar 1934 geißelte Kolbenheyer die Beratungsresistenz dieser jungen Nationalsozialisten als ein „gänzliche[s] Versagen“ gegenüber ihrer "geistigen $\mathrm{u}[\mathrm{nd}]$ moralischen Verpflichtung "380. Ihre Weigerung, sich an den Ratschlägen ihrer „Vorkämpfer“ zu orientieren oder ihnen zumindest wissbegierig und ehrfurchtsvoll zu lauschen, ließ Kolbenheyer „an dem Bestand der jetzigen Organisation des Staates zweifeln“. Der Nationalsozialismus, so glaubte er, müsse sich schon um seiner selbst willen ,dahin durchfinden, daß er an die Leistungen derer anknüpft, die völkisch gehandelt haben u[nd] gewesen sind, ehe er war“381. Andernfalls stehe früher oder später sein Zusammenbruch zu befürchten.

Der Typ des jungen, bedingungslos strebsamen Aufsteigers mit unzulänglichen Sachkenntnissen wurde in den Korrespondenzen Grimms, Kolbenheyers und Stapels zu einem häufig beschworenen Privatfeindbild. Eine Beschreibung der Charakterzüge jener Aufsteiger durch Stapel im Frühjahr 1934 erinnert dabei unwillkürlich an Heinrich Manns „Untertan“ Diederich Heßling: Stapel störte sich vor allem an dem allgegenwärtigen, selbstüberschätzenden „Führerdünkel“ der jungen Nationalsozialisten, in denen „schamlose Unterwürfigkeit gegen oben“ und ebenso „schamlose Rücksichtslosigkeit gegen unten“382 eine unheilvolle Verbindung eingegangen sei. Die hieraus entstandene Mentalität schien Stapel umso

\footnotetext{
376 Puschner, Strukturmerkmale, S. 466.

377 Kiesel, Kritik.

378 Vgl. Muller, Enttäuschung.

379 Mommsen, Mythos, S. 135.

380 DLA, A:Stapel, Erwin Guido Kolbenheyer an Wilhelm Stapel, 10. Februar 1934.

381 Ebd.

382 KAG, Wilhelm Stapel an Erwin Guido Kolbenheyer, 28. Februar 1934. Zur Figur von Diederich Heßling aus historischer Perspektive vgl. Wirsching, Kronzeuge.
} 
abstoßender, als alle „geistige[n] Werte“ unter dem Gebrauch „banalster Phrasen“ mit Füßen getreten würden. Durch die unreflektierte Erweiterung ihres Feldzugs „gegen den bürgerlichen Intellektualismus [...] auf alles Geistige" hätte die nationalsozialistische „Jugend“ lediglich ihren eklatanten Bildungsmangel unter Beweis gestellt. Angesichts eines solch „unfähige[n] Führertum[s] “ drohe der NS-Staat in „Lebensgefahr“ zu geraten. Hier, so Stapel, „,in dieser Sorte Mensch“, werde „der Totenwurm des Dritten Reiches ausgebrütet ${ }^{\text {“ } 383}$. Trotz aller ausführlichen und eloquenten Kritik blieb bei alledem Stapels grundsätzliche Befürwortung des „Dritten Reichs" gleichwohl unangetastet. Dies galt insbesondere für die Person Hitlers: „Einstweilen nähren sich diese Maden von dem ungeheuren Schatz des Vertrauens, den sich Hitler im Volke erworben hat. Aber sie fressen diese Autorität auf." 384

Dass Stapel keineswegs allen maßgeblichen NS-Funktionseliten denselben Respekt entgegenbrachte wie Hitler, lässt sich einem Brief an Kolbenheyer vom September 1935 entnehmen. Vor dem Hintergrund der rigiden Presselenkung im NS-Staat ${ }^{385}$ warf Stapel vor allem den beiden nationalsozialistischen Chefpropagandisten, Joseph Goebbels und Alfred Rosenberg, vor, dieselbe planmäßige Marginalisierung unliebsamer Autoren zu betreiben, die in der Zeit vor 1933 der liberalen „Judenpresse" angelastet worden war. ${ }^{386}$ Auf die Weisungen von Goebbels und Rosenberg werde alles „systematisch [...] totgeschwiegen“, was „nicht aus dem Parteibuch, der SA und SS hervorgewachsen" sei. Diese Technik hätten Goebbels und Rosenberg „,on den Juden übernommen“: „Man kämpft nicht, sondern man diffamiert durch deutliche Entziehung der Gnade“387.

Obgleich nach der NS-„,Machtergreifung“ zum Präsidialmitglied der Reichsschrifttumskammer, zum Senator der Preußischen Akademie der Dichtkunst sowie zum Senator der Deutschen Akademie in München berufen, empfand sich auch Grimm im August 1934 als ohnmächtiger Statist im nationalsozialistischen Kulturbetrieb. Zum Ausdruck brachte Grimm seine Enttäuschung darüber, dass ihm jener Einfluss verwehrt wurde, der ihm seiner Meinung nach aufgrund seines Lebenswerks zustand, im August 1934 etwa in einem Brief an Hans Friedrich Blunck, den damaligen Präsidenten der Reichsschrifttumskammer. Der Durchorganisation der Politik nach dem „Führerprinzip“ stimmte Grimm zwar zu, die gerechte und ordnungsgemäße Hierarchie sah er im „Dritten Reich“ jedoch geradezu auf den Kopf gestellt:

„Meine Enttäuschung steht auf einem anderen Blatt. Ich erwartete, daß ein Stand entwickelt werden sollte mit Standesbewußtsein und Leistungen. Ich erwartete, daß der großen Idee des ständischen Staates $[\ldots]$ nun die erste Gelegenheit gegeben werden sollte. Ich erwartete ein

383 KAG, Wilhelm Stapel an Erwin Guido Kolbenheyer, 28. Februar 1934 (Herv. i. Orig.).

384 Ebd. (Herv. i. Orig.).

385 Vgl. Abel, Presselenkung; Hagemann, Presselenkung; Kübler, Lenkung. Zugleich wurde jedoch auch auf begrenzte Möglichkeiten von freiem Journalismus nach 1933 hingewiesen: Krüger, Presse.

386 Vgl. Kap. 3.1.1.

387 KAG, Wilhelm Stapel an Erwin Guido Kolbenheyer, 26. September 1935 (Herv. i. Orig.). 
rücksichtsloses Bekenntnis zur Qualität und Leistung. Ich sehe bis jetzt, daß sich eine neue Bürokratie bildet, die gewiß recht fleißig und wohlmeinend ist. Wenn man zum Stand will, kann man nur bei den Meistern und mit den Meistern des Standes und ihrer Leistung anfangen, scheint mir, und muß der Leistung ein Maß Verantwortung und ein Maß Recht vor allem einräumen." ${ }^{388}$

Seine Enttäuschung darüber, dass die völkisch-national orientierten „Meister“ der Kunst nach 1933 nicht an die Spitze der Kulturpolitik gehievt worden waren, verschwieg Grimm auch nicht gegenüber Personen, die ihm nur flüchtig bekannt waren. Dies lässt sich an einem Brief zeigen, den Grimm im Dezember 1934 an den Trierer Chirurgen und Hobbyschriftsteller Herbert Schulzebeer sandte, der ihm zuvor ein Exemplar seines SA-Romans Standarte „X“ (1934) hatte zukommen lassen. Grimm nutzte sein Antwortschreiben nicht nur für eine Danksagung, sondern zugleich für eine Skizze der inneren Unzulänglichkeiten im Herrschaftsgefüge des „Dritten Reichs“. Er betonte zwar auch gegenüber Schulzebeer, die NS-Bewegung „von ihrem frühesten Bestehen an leidenschaftlich gewollt und für sie gearbeitet“ zu haben, das durch die NSDAP errichtete „System“ bezeichnete er jedoch als ein „menschliches und nationales Unglück“. Seine persönlichen Möglichkeiten, auf eine Verbesserung der Zustände hinzuwirken, schätzte der Dichter dabei schon damals überaus pessimistisch ein: „Wir draußen, außerhalb der Partei, wir paar, die noch unabhängig sind, können nur Haltung zeigen; wir können aktiv nichts tun" 389 .

Ähnlich fatalistisch äußerte sich wenige Monate später auch Kolbenheyer gegenüber Grimm. Man dürfe sich „keine Illusionen machen“: Alles sei „am Werke [...], uns womöglich auszuschalten.“ Das „kulturelle Leben“ sei „Leuten in die Hand gegeben“ worden, „die ihre Pöstchen durch 120-Perzentigkeit [sic!] zu halten“ wüssten und „von keinerlei kultureller Leistung angekränkelt“ seien. „Wir sind sozusagen ausgeliefert. "390 Konkreter Anlass und Hintergrund dieser Äußerung war eine gemeinsame Enttäuschung über die Entwicklung der Preußischen Akademie der Dichtkunst. ${ }^{391}$ Die in anderen Bereichen offen befürwortete Gleichschaltungspraxis der Nationalsozialisten sollte in den Augen Grimms und Kolbenheyers vor der Kunst Halt machen. Bereits zum Jahresende 1933 hatte sich Kolbenheyer über die NS-Kulturpolitik, obschon selbst eindeutig einer ihrer Profiteure, ernüchtert geäußert. Gegenüber Stapel bilanzierte er, das „Dritte Reich“ habe „noch durch nichts bewiesen, daß es die deutsche Dichtung wirklich zu schätzen“392 wisse. Vielmehr sei bis dato „eine Gesinnungsblechmusik hochge-

388 Brief von Hans Grimm an Hans Friedrich Blunck vom 31. August 1934, zitiert nach: Gümbel, Volk, S. 181.

389 Hans Grimm an Herbert Schulzebeer vom 20. Dezember 1934, zitiert nach: Grimm, Schriftsteller, S. $180 \mathrm{f}$.

390 DLA, A:Grimm, Erwin Guido Kolbenheyer an Hans Grimm, 7. Mai 1935.

391 Anspruch und Erwartung, innerhalb der Akademie möglichst unabhängig von staatlicher Einflussnahme agieren und Entscheidungen treffen zu können, blieben illusorisch. Vgl. Mittenzwei, Untergang, bes. S. 299-384.

392 DLA, A:Stapel, Erwin Guido Kolbenheyer an Wilhelm Stapel, 31. Dezember 1933 (Herv. i. Orig.). 
lobt“, während etwa das deutsche Theater zusehends der „Verwüstung“ anheimfalle. Ebenso wie Grimm sah auch Kolbenheyer die eigentlichen „Meister“ der deutschen Literatur von den Nationalsozialisten missachtet. Stattdessen würden, so der Dichter, ohne konkrete Namen zu nennen, bloße „Mittelwerte als die ,Dichter ' des Reichs ausposaunt und gefeiert. “393

Wie bereits gezeigt ${ }^{394}$, sah sich Stapel im Vergleich zu Grimm und Kolbenheyer nach 1933 mit der bei Weitem schärfsten öffentlichen Kritik konfrontiert. Diese Erfahrung erfüllte Stapel - nach einer kurzen Phase der Unterschätzung seiner Gegner - alsbald mit einer blinden, hilflos anmutenden Wut, hinter der sich die (subjektiv nachvollziehbare) Angst vor einer Exklusion aus der nationalsozialistischen „Volksgemeinschaft“ verbarg. Gerade die Briefe, die er während eines monatelangen Konflikts mit der SS-Zeitschrift Das Schwarze Korps im Jahr 1935 an Kolbenheyer verfasste, legen hiervon beredtes Zeugnis ab. Die hoffnungslose Unterlegenheit, die Stapel in der direkten Auseinandersetzung mit den zum Teil weit über 20 Jahre jüngeren Angreifern zu spüren bekam, gaben den Anstoß zu einer tiefen inneren Entfremdung vom NS-Staat, die zwar nicht zu einer Beendigung, wohl aber Verminderung seiner Propagandabereitschaft für das Regime führte. ${ }^{395}$ Die Gelassenheit, mit der Stapel - ehe er den Artikel selbst gelesen hatte - noch auf die erste Mitteilung eines „Angriffs“ durch das Schwarze Korps reagiert hatte ${ }^{396}$, verflog sehr rasch. Spätestens als er mit dem Vorwurf konfrontiert wurde, ein verkappter Gegner des Nationalsozialismus zu sein, sah sich Stapel zu einer Reaktion genötigt: „Ich muss darauf antworten, schon ehrenhalber“397. Insbesondere das höhnische Überlegenheitsgefühl, das in den weiteren Artikeln des Schwarzen Korps zum Ausdruck kam, brachte Stapel zunehmend in Rage. „Es gibt nichts Aufreizenderes als Feigheit, die aus geschützter Stellung Gewalt übt", echauffierte er sich im Juli 1935 gegenüber Kolbenheyer. „Schwarzes Korps'? Schwarze Schmach!"398

393 Ebd.

394 Vgl. Kap. 5.2.2.

395 Zu Stapels Propaganda für das „Dritte Reich“vgl. Kap. 5.3.2.

396 Stapel war vom Verlag telefonisch über den ersten gegen ihn gerichteten Artikel im Schwarzen Korps benachrichtigt worden. Der Artikel sei ihm dabei als „der moralisch schwierigste Angriff“ geschildert worden, der seit der Übernahme des Deutschen Volkstums auf ihn unternommen worden sei. „Die SS scheint es fertig gebracht zu haben, die Juden und Zentrumspfaffen, die mich bisher am ärgsten zausten, zu überbieten im Rekord polemischer Gemeinheit. Aber es wird weiterziehen. Wir alle werden von dem Untermenschentum, das mit der Revolution von 1933 auch hochgekommen ist und das sich nicht gezügelt fühlt, noch viel zu leiden haben“ (KAG, Wilhelm Stapel an Erwin Guido Kolbenheyer, 22./23. April 1935).

397 KAG, Wilhelm Stapel an Erwin Guido Kolbenheyer, 21. Juli 1935. Auch in seiner Zeitschrift reagierte Stapel auf die Vorwürfe und belegte anhand seiner Tätigkeiten während der Weimarer Republik die Haltlosigkeit der Vorwürfe, er sei ein Gegner des Nationalsozialismus gewesen. Vgl. Stapel, Stapel [1935].

398 KAG, Wilhelm Stapel an Erwin Guido Kolbenheyer, 25. Juli 1935. Mit „Schwarze Schmach“ griff Stapel ein in der völkischen und nationalkonservativen Publizistik der Weimarer Republik weitverbreitetes, rassistisches Schlagwort auf, das auf den Einsatz farbiger Kolonialsoldaten durch Frankreich während der alliierten Rheinlandbesetzung gemünzt war. Dieser 
Als sich der Konflikt in der Folgezeit zuspitzte und das Schwarze Korps „nicht nur irrig[e], sondern zum Teil mit kalter Bosheit wissentlich gefälscht[e] “399 Vorwürfe erhob, reagierte Stapel zunehmend irrational. Dies war auch maßgeblich dadurch bedingt, dass sich ihm keine Aussicht auf eine Besserung seiner Position und keine wirkungsvolle Möglichkeit der Selbstverteidigung bot. Zunächst erging sich Stapel in Rachefantasien gegen seine Angreifer: Von „verschiedenen Seiten“, so Stapel am 16. August 1935, sei an ihn herangetragen worden, er könne „etwas mit dem Knüppel über den Kopf kriegen oder plötzlich erschossen werden“. „Gerade deshalb“ wollte er jedoch „der Gemeinheit keinen Schritt weichen.“ Er „hänge nicht am Leben. Der einzige Wunsch, den ich hätte, wäre der, den Angreifer mit in den Tod hinüberzunehmen“, um ihn so „im Jenseits noch zu demütigen. “400 Wenige Tage später erklärte er sich in einer Besprechung mit Kollegen der HVA und deren Direktor Benno Ziegler gar dazu bereit, dem Schriftleiter des Schwarzen Korps, Gunter d'Alquen, „eine Pistolenforderung [zu] senden“ 401 .

Diesen ihm schon kurze Zeit später selbst „komisch pathetisch“ anmutenden Gedanken ließ Stapel zwar alsbald wieder fallen, liebäugelte in grauer Theorie jedoch weiterhin mit der Idee eines Duells - schließlich müsse man es „auch dummen Jungens einmal zeigen“. Aus diesem Blickwinkel bekomme „das Komische einen ernsthaften Sinn und das Pathetische eine solide Nüchternheit" ${ }^{\text {"402 }}$. Kurz nachdem Stapel Ende August 1935 schließlich ein Ehrengerichtsverfahren gegen Gunter d'Alquen beantragt hatte, schien ihm wiederum die Verschwörungstheorie plausibel, dass insgeheim ein Mordkomplott gegen ihn geschmiedet worden sei: „Den ganzen Zweck der Angriffe“, so schrieb er an Kolbenheyer, „sehe ich darin, daß man mich auf die schwarze Liste der SS bringen will. Das ist sicher gelungen. Bei der nächsten Gelegenheit... Daran ist nichts zu ändern"403. Auf dem Höhepunkt des Konflikts mit dem Schwarzen Korps weitete sich Stapels Frustration schließlich zu einem prinzipiellen Zweifel an der Qualität des deutschen Volkscharakters aus - eine Reaktion, die auf Befindlichkeiten Stapels nach 1945 vorausdeutet. ${ }^{404}$ Die Person Hitlers blieb zwar nach wie vor über alle Zweifel erhaben, Stapel befürchtete jedoch, dass Hitler sich womöglich gegen die gesammelte Inferiorität und den ,inneren Schweinehund in der deutschen Volkssubstanz" letztendlich nicht werde behaupten können. Wer in Deutschland auf jenen „Schweinehund“ setze, irre nie:

„Ich teile Dein Volksvertrauen nicht. Ein Hauptbestandteil der deutschen Rasse ist das Schweinshündige. Von Anfang an. Schon die alten Römer wußten und benutzten das. [...] Die ganze deutsche Geschichte ist voll von [...] Schofeltaten und [...] Schofelgesinnung. Es sind immer

wurde von breiten Teilen der Öffentlichkeit als bewusster Affront, als Schmach und Entehrung wahrgenommen. Vgl. hierzu: Martin, Kampagne; Wigger, Schmach; Koller, Schmach.

399 KAG, Wilhelm Stapel an Erwin Guido Kolbenheyer, 16. August 1935.

400 Ebd. (Herv. i. Orig.).

401 KAG, Wilhelm Stapel an Erwin Guido Kolbenheyer, 19. August 1935.

402 Vgl. KAG, Wilhelm Stapel an Erwin Guido Kolbenheyer, 22. August 1935.

403 KAG, Wilhelm Stapel an Erwin Guido Kolbenheyer, 4. September 1935.

404 Vgl. Kap. 6.1. 
nur einzelne Männer gewesen, die aus dem Pack für kurze Zeit etwas gemacht haben [...] Wird Hitler, herabgezogen von den Bleigewichten der Nichts-als-Agitatoren, der Weltanschauungsliteraten, der Parteieiferer, der Schulungsbonzen, und schließlich der Denunzianten, Streber, Schmeichler und Arschkriecher aller Art, wird er, der dieses Gesindel auch brauchte, um den ersten und einzigen Versuch einer, deutschen Demokratie in den Mülleimer zu beseitigen, wird er das deutsche Volk und Reich moralisch restituieren?" ${ }^{405}$

Durchaus folgerichtig blieben Stapels Hoffnungen in der Folgezeit hinsichtlich der weiteren Entwicklung des „Dritten Reichs“ ganz auf Hitler konzentriert - ein Phänomen, das durchaus der Intention der NS-Propaganda entsprach. ${ }^{406}$ Stapels Wunsch ging vor allem dahin, Hitler möge ,einmal in diese ganze[n] Kultur- und Bildungskämpfe“ hineinschlagen, damit „das Subalterne “407 verschwinde. Als sein Antrag auf ein Ehrengerichtsverfahren gegen Gunter d'Alquen am 14. Oktober 1935 ohne nähere Begründung abgelehnt wurde, überwog wieder deutlich Stapels ohnmächtige Empörung: „Die Scham ist aus der Welt geschwunden, und die Ehre ist nur ein Wort in Propagandareden “408. Und wenige Tage später: „Es ekelt mich, Volksgemeinschaft mit solchem Lumpengesindel zu haben, wie es hier von Ehre lärmt und Ehre verrät" ${ }^{\text {"409. }}$.

Die auch schon in der politischen Sprache der Weimarer Republik permanent und - mit Ausnahme der Kommunisten - lagerübergreifend beschworene „Volksgemeinschaft" ${ }^{110}$ hatte Stapel schon vor 1933 als eine hohle Phrase wahrgenommen und nicht als gesellschaftliche Leitvorstellung gelten lassen. ${ }^{411}$ Dies änderte sich auch im „Dritten Reich“ nicht. Der Begriff „Volksgemeinschaft“, so Stapel im Mai 1935, schmeichle lediglich dem „breiten Publikum“ und gaukle eine in Wahrheit nicht vorhandene Gleichheit und Gleichwertigkeit vor. Es sei lächerlich, wenn etwa „[Max] Planck, der Mann der Quantentheorie, mit Piefke zusammen Betriebsgemeinschaft" mache. „Tausend Piefkes“ könnten „nicht die Verteilung und Bedeutung des Planktons im Weltmeer oder die sich entwickelnde Idee der Schlacht bei Tannenberg ,erarbeiten'. Es ist ja ein Unsinn; Götzendienst der Masse, die vergottet wird“412. Die „sogenannte, Volksgemeinschaft' von heute“ galt Stapel lediglich als „,euphemistischer Ausdruck für ,Masse.“413

405 KAG, Wilhelm Stapel an Erwin Guido Kolbenheyer, 26. September 1935 (Herv. i. Orig.).

406 Vgl. Kershaw, Hitler-Mythos, bes. S. 46-89. Stapels geradezu dichotomische Gegenüberstellung von Gefolgschaft einerseits und „Führer" andererseits illustriert die hohe Suggestionskraft des nach 1933 propagandistisch forcierten „Hitler-Mythos“. Vgl. dazu auch Sommersberg, Hitler-Mythos.

407 KAG, Wilhelm Stapel an Erwin Guido Kolbenheyer, 26. September 1935 (Herv. i. Orig.).

408 KAG, Wilhelm Stapel an Erwin Guido Kolbenheyer, 16. Oktober 1935.

409 KAG, Wilhelm Stapel an Erwin Guido Kolbenheyer, 18. Oktober 1935.

410 Wie anschlussfähig der schillernde Begriff „Volksgemeinschaft“ auch weit jenseits des rechten Lagers war, zeigt sich nicht zuletzt an dem Sachverhalt, dass Friedrich Ebert den Begriff in seinen Reden als Reichspräsident „[s]chon fast gebetsmühlenartig beschwor" (Mühlhausen, Ebert, S. 816). Weiterführend zur Begriffsverwendung während der Weimarer Republik: Wildt, Volksgemeinschaft.

411 Vgl. Kap. 2.2.1.

412 KAG, Wilhelm Stapel an Erwin Guido Kolbenheyer, 14. Mai 1935.

413 KAG, Wilhelm Stapel an Erwin Guido Kolbenheyer, 22. August 1935. 
Die in diesem Kapitel skizzierten privaten Enttäuschungserfahrungen dürfen indes nicht zu der Annahme verleiten, Grimm, Kolbenheyer und Stapel hätten sich vom NS-Staat ostentativ distanziert oder gar in eine „Innere Emigration“ begeben. Das folgende Kapitel wird zeigen, dass private Enttäuschungserfahrungen und öffentliche Propagandabereitschaft für das Regime vielmehr parallel liefen. Alle drei Autoren sahen es als ihre moralische Pflicht an, das „Dritte Reich“ wo immer möglich zum praktisch Bestmöglichen mitzugestalten, trotz all in ihren Augen evidenter Mängel und Unzulänglichkeiten. Zugleich waren sich Grimm, Kolbenheyer und Stapel angesichts ihrer Rolle als Wegbereiter und Vorkämpfer des Nationalsozialismus aber auch darüber im Klaren, dass ihr persönliches Schicksal irreversibel mit jenem des NS-Staats verbunden war. Der Überzeugung, dass ein Zusammenbruch des Regimes zugleich den eigenen Untergang besiegeln würde, verlieh Stapel im Oktober 1934 am deutlichsten Ausdruck:

„Es ist doch so: Wenn ein Umschwung käme, so würde mein Kopf mit zuerst fallen. Denn wenige sind den Juden und dem Linkszentrum so verhaßt wie ich, infolge meines vierzehnjährigen Kampfes. Mein persönliches Schicksal ist also existenziell mit dem Schicksal des Nationalsozialismus verbunden." ${ }^{114}$

\subsubsection{Bereitschaft zur Propaganda}

Wir erleben also wirklich den Umschwung. Das deutsche Volk ist wieder mal der Bevormundung der Fremden satt geworden $u[n d]$ will selbst führen $u[n d]$ denken. Wie dankbar bin ich dem Geschick einen kleinen Teil beitragen zu dürfen! 415

Trotz aller Enttäuschungserfahrung erachteten Grimm, Kolbenheyer und Stapel die Etablierung des „Dritten Reichs“ grundsätzlich als eine historische Errungenschaft nicht nur der NSDAP, sondern des gesamten deutschen Volks, jedenfalls soweit dieses „nationalen Empfindungen zugänglich“416 war, um eine verbrämende Formulierung Stapels aufzugreifen. Es war ein Basiskonsens der drei Autoren, dass die politischen und gesellschaftlichen Zustände im NS-Staat ungeachtet ihrer Unvollkommenheit jenen der Weimarer Republik unbedingt vorzuziehen waren. Für einen politischen Neubeginn und moralischen Wiederaufbau der Deutschen war ihnen seit jeher die Zerschlagung des Parlamentarismus und die Unterdrückung jedes öffentlichen Einflusses mutmaßlich „undeutscher“, vor allem jüdischer, linksliberaler und kommunistischer Intellektueller, als zwingend notwendig erschienen. Um letzteres zu gewährleisten, drängten alle drei Autoren auf weitreichende Berufsverbote, besonders im Bereich der Publizistik und der Universitäten. Stapel hatte dies schon 1932 in dem Sammelband Was wir vom National-

414 KAG, Wilhelm Stapel an Erwin Guido Kolbenheyer, 9. Oktober 1934 (Herv. i. Orig.).

415 DLA, A:Stapel, Erwin Guido Kolbenheyer an Wilhelm Stapel, 10. Mai 1933.

416 Deutsches Volkstum. Monatsschrift für das deutsche Geistesleben 5 (1923), S. 455. 
sozialismus erwarten hinreichend klargestellt. 417 Grimm äußerte am 18. November 1933 gegenüber Hans Friedrich Blunck seine feste Überzeugung, dass in allen „freien Berufen der Jude in Zukunft und jedenfalls eine Weile ganz ausgeschaltet“ ${ }^{\text {“418 }}$ werden müsse, womit er bereits beschlossenes (Un-)Recht der Nationalsozialisten gleichsam sanktionierte. ${ }^{419}$ Kolbenheyer begrüßte im April 1933 besonders die Entfernung der „Überzahl der Juden aus dem Lehrkörper“420 der deutschen Universitäten. Wenige Wochen zuvor hatte er mit Blick auf die Presse noch ungeduldig moniert, dass alles „noch voll von Leuten“ sei, die „durch die Schule Ullstein, Mosse gegangen“ seien oder „wenigstens die dortigen Urteile u[nd] Meinungen als maßgebend empfunden" 421 hätten. Entsprechend stießen die Gleichschaltungsmaßnahmen des NS-Regimes bei Kolbenheyer ebenso auf Zustimmung wie bei Grimm und Stapel, der das Ende der „liberale[n] Geistesfreiheit und Pressefreiheit" im Deutschen Volkstum als einen hochwillkommenen Ausdruck nationalsozialistischer Staatsräson begrüßte. ${ }^{422}$

Hans Grimms ERKLÄRUNGEN ZUM 12. November 1933 - Am 12. November 1933 fand neben der Reichstagswahl zugleich eine Volksabstimmung über den Austritt Deutschlands aus dem Völkerbund statt. ${ }^{423} \mathrm{Zu}$ diesem Anlass stellte Grimm auf direkte Aufforderung Berlins eine Propagandarede für den Rundfunk zur Verfügung. Dazu aufgefordert hatte ihn Wilhelm Haegert ${ }^{424}$, damals Leiter der Abtei-

417 Stapel hatte seine Forderung nach Berufsverboten unter „Professore[n], Ministerialbeamte[n], Schulräte[n], Direktoren usw." gar auf alle Angehörigen der SPD ausgeweitet (Stapel, Forderungen [1932], S. 154). Die Juden wollte er aus dem gesamten Bereich des „Richten und Erziehens" ausgeschlossen wissen (Stapel, Versuch [1932], S. 189).

418 Zitiert nach: Gümbel, Volk, S. 174. Grimm betonte in demselben Brief weiterhin: „Ich bin aber nicht der Meinung, dass wir die Juden, die geschrieben haben und ordentlich waren, samt und sonders ausschalten und in ihrer Lebensnot etwa nach Osten treiben sollen, wohin sie allein noch können, um dort hinzubringen, was sie bei uns gelernt haben“" (ebd.).

$419 \mathrm{Zu}$ verweisen ist hier vor allem auf das am 4. Oktober 1933 verabschiedete Schriftleitergesetz. Es legte fest, dass an Zeitungen und Zeitschriften nur Personen mitarbeiten durften, die ,arischer Abstammung [...] und nicht mit einer Person von nichtarischer Abstammung verheiratet" waren. Für sämtliche Redakteure und Mitarbeiter war die Mitgliedschaft in der Reichspressekammer künftig obligatorisch. Vgl. Reichsgesetzblatt 1933/I, S. 713-717.

420 DLA, A:Stapel, Erwin Guido Kolbenheyer an Wilhelm Stapel, 28. April 1933.

421 DLA, A:Stapel, Erwin Guido Kolbenheyer an Wilhelm Stapel, 6. März 1933.

422 Vgl. Deutsches Volkstum. Monatsschrift für das deutsche Geistesleben 15 (1933), S. 751: „Die liberale Geistesfreiheit und Pressefreiheit ist freilich unwiderbringlich [sic!] dahin wie wir das seit Jahren gewünscht haben. Man stelle sich Deutschland vor, wenn jetzt ,Pressefreiheit ' in seinen Grenzen herrschte. [...] [E]s würden alle Feinde des neuen Staates aus dem In- und Ausland das Chaos herbeiführen helfen. Es kann und darf jetzt keine Pressefreiheit geben. Und es soll auch künftig keine wieder geben."

423 Für den Austritt aus dem Völkerbund votierten 95,1\% der abgegebenen Stimmen. Die „Wahl“ des Reichstags war freilich eine Farce, da nach gewaltsamen Verboten und aufgenötigten Selbstauflösungen der Weimarer Parteien nur mehr eine nationalsozialistische Einheitsliste zur Wahl stand. Diese erhielt eine Zustimmung von 92,1\%, vgl. Winkler, Weg, Bd. 2, S. 31.

424 Vgl. Brief von Hans Grimm an Joseph Goebbels vom 21. März 1934, zitiert nach: Grimm, Schriftsteller [1980], S. 164. 
lung „Propaganda“ im Reichsministerium für Volksaufklärung und Propaganda. ${ }^{425}$ Grimm betonte in seiner Rede, dass es dem Nationalsozialismus wie keiner politischen Bewegung der deutschen Geschichte vor ihm gelungen sei, „im breiten Volke deutlich zu machen, daß es keinen deutschen Nutzen gebe, es sei denn ein gemeinsamer Nutzen" 426 . Die in dieser Verneinung des Individualismus angelegte „Reformation“ des deutschen Volks galt es in den Augen Grimms am 12. November durch ein klares Votum zugunsten der NSDAP und gegen den Völkerbund zu „bezeug[en]“. Die Weltöffentlichkeit müsse durch die Abstimmungen „über jeden Zweifel“ erkennen, dass „ihr von diesem Tage an der Wille des ganzen Volkes durch den Kanzler Adolf Hitler“ gegenüberstehe. Grimm ließ es sich nicht nehmen, den Austritt aus dem Völkerbund gar zu einem Ausdruck deutschen Friedenswillens zu verklären: Die Welt solle durch ein einstimmiges Votum erfahren, dass „der größte Schritt zu einem Frieden getan“ sei, in welchem „unzweideutiges Aussprechen zu klarem Erkennen“ führe. „Und das heißt: Zu einem echten Frieden durch den Willen statt zu einem falschen Frieden durch Waffen." 427

Ergänzend zu seiner Rundfunkansprache verfasste Grimm auch einen Aufsatz über die Abstimmungen am 12. November 1933. Da Grimm in diesem Fall seine Aufgabe nicht zur vollen Zufriedenheit des Propagandaministeriums erledigte, wurde dort auf eine Verwendung des Texts allerdings verzichtet. In die Öffentlichkeit drangen Grimms Ausführungen jedoch durch eine weitere Rede, die auf dem Aufsatz basierte und die Grimm „vor sehr großer Hörerschaft in Ludwigshafen und großer Hörerschaft in Wetzlar“ 428 hielt. In der mit „Um was es am 12. November 1933 nicht geht“ betitelten Ansprache hob Grimm hervor, dass Voten für die NSDAP und den Völkerbundaustritt dem „gewaltigen geordneten Suchen des ganzen Volkes für die Zukunft und für die ganze Jugend“ zu Gute kämen. Nur durch die nationalsozialistische Partei werde der innere Zusammenhalt „bei dem Aufbruch und Marsche der Millionen“ gewährleistet. „Und was“, so Grimms rhetorisch gemeinte Frage, „wäre dawider [sic!] zu sagen? Das Ziel ist Deutschland und sonst nichts" ${ }^{*} 29$.

Warum aber stieß Grimms Aufsatz trotz dieses klaren Appells im Propagandaministerium auf so wenig Gegenliebe? Ausschlaggebend hierfür war, dass Grimm in seiner Auflistung jener Dinge, die am 12. September für die Stimmabgabe nicht ausschlaggebend sein sollten, Missstände im NS-Staat zur Sprache brachte: Weder, so Grimm, dürfe es bei dem Votum um „persönliche Angelegenheit[en]“ gehen, noch um „die Zustimmung zu irgendeinem Unrecht in eigener Nähe“. Auch stehe nicht „die Zustimmung zu irgendeiner zufälligen Lauheit und Überheblichkeit“

425 Eine Zusammenstellung der einzelnen Abteilungen des Ministeriums und ihrer Leiter bietet: Mühlenfeld, Kommissariat, S. 82f. Weiterführend zum Propagandaministerium: Mühlenfeld, Kommissariat; Dahm, Reichskulturkammer.

426 Zitiert nach: Franke, Grimm, S. 50f.

427 Ebd.

428 Vgl. Brief von Hans Grimm an Joseph Goebbels vom 21. März 1934, zitiert nach: Grimm, Schriftsteller, S. 164.

429 Grimm, November [1933], S. 33. (Herv. i. Orig.). 
oder „dummen Servilität“ zur Debatte. Weiterhin dürften auch nicht einzelne Funktionäre, die man „aus der Nähe etwa als Halunken oder auch als Schwätzer“430 kennengelernt habe, über das Ja oder Nein bei den Wahlen entscheiden. Vielmehr müsse an das Wohl und Wehe der deutschen Jugend gedacht werden, welches Grimm irreversibel an den Erfolg und die Prosperität des NS-Staats geknüpft sah. Diese Gleichzeitigkeit von nationalsozialistischer Bekenntnistreue und Detailkritik ließ sich mit den an unbedingter Gefolgschaft ausgerichteten Leitvorstellungen des Propagandaministeriums freilich nicht vereinbaren. So blieb der Text ungenutzt. ${ }^{431}$

Hans Grimms „Amerikanische Rede“ - Einschlägige Propagandaarbeit für das NS-Regime leistete Grimm auf dem „Deutschen Tag“ in New York im Oktober 1935, zu dem er durch den Deutsch-Amerikanischen Nationalbund eingeladen wurde. ${ }^{432}$ Der Kontakt zwischen Grimm und den Veranstaltern war durch den Volksbund für das Deutschtum im Ausland vermittelt worden, der zugleich die Reisekosten Grimms mitfinanzierte. ${ }^{433}$ Anlass der Feierlichkeiten war das 250. Jubiläum der deutschen Einwanderung in die USA. ${ }^{434}$ Darüber hinaus stand der "Deutsche Tag" jedoch unverkennbar im Zeichen einer emphatischen Bejahung des Nationalsozialismus. Bereits im Vorfeld hatten die Organisatoren gegenüber Grimm herausgestellt, dass der „Deutsche Tag" darauf abziele, auch in den USA „die in der Heimat zur Tat gewordene Volkskameradschaft in die Herzen aller Deutschstämmigen zu tragen " 435 . In diesem Geist wurden in New York zwischen 1934 und 1937 insgesamt vier „Deutsche Tage“ veranstaltet. ${ }^{436}$

1935 stand die Veranstaltung unter dem Motto „Das ganze Deutschtum soll es sein“ - eine Variation der bekannten Losung "Das ganze Deutschland soll es sein!" aus Ernst Moritz Arndts Gedicht Des Deutschen Vaterland (1813). Damit knüpften die Veranstalter an ein weiteres einschlägiges, ideologisch durchtränktes

430 Ebd., S. 32.

431 Vgl. Mittenzwei, Untergang, S. 379.

432 Vgl. Gümbel, Volk, S. 177.

433 Vgl. DLA, A:Grimm, Hans Grimm an Hannoverscher Kurier, 4. September 1935. Grimms Verbindung zu dem Volksbund (bis 1933: Verein) für das Deutschtum im Ausland (VDA) geht mindestens bis auf den April 1927 zurück, als Grimm anlässlich einer Veranstaltung des VDA, zu der „einschließlich unserer Schulgruppenjugend etwa 20000 Menschen“ erwartet wurden, um einen Beitrag für ein Sonderheft der Verbandszeitschrift Deutsche Welt gebeten wurde. Der VDA teilte mit, in seinen „Zeitschriften und dem Rundbrief die Mitglieder und Freunde unseres Vereins nachdrücklich auf ,Volk ohne Raum' hingewiesen“ zu haben und dies auch weiterhin "bei jeder sich bietenden Gelegenheit wieder tun" zu werden (DLA, A:Grimm, Verein für das Deutschtum im Ausland an Hans Grimm, 5. April 1927). Die Geschichte des VDA ist nur für die Zeit des Kaiserreichs gut erforscht, vgl. Weidenfeller, VDA. Die Verbandsgeschichte während der Weimarer Republik ist hingegen ein Desiderat der Forschung. Für die Zeit des „Dritten Reichs“ liegt eine publizierte Magisterarbeit vor (Luther, Volksbund).

434 Die exakte Datierung der Gründung von „Germantown“ wich dabei um zwei Jahre ab, vgl. Ruth, Settlement.

435 DLA, A:Grimm, Hans Grimm an Eugen Kalkschmidt, 20. September 1935.

436 Kipphan, Propaganda, S. 54. 
Jubiläum an: den Todestag Arndts, der sich im Januar 1935 zum 75. Mal jährte. ${ }^{437}$ Grimms Rede kam „ohne irgendeine Weisung oder nur Erklärung eines Amtes von Berlin aus" zustande, wie der Dichter nach seiner Rückkehr aus den USA gegenüber dem Schriftsteller Waldemar Glaser hervorhob. ${ }^{438}$ In der Tat wurde die Rede in der Reichshauptstadt lediglich passiv zur Kenntnis genommen. Eine am Vortag der Veranstaltung ausgegebene NS-Pressemitteilung über den „Deutschen Tag“ in New York bezeugt die weitgehend desinteressierte Haltung des Propagandaministeriums: „Die DNB-Berichte sollen darüber gebracht werden, jedoch keine eigenen Meldungen." 439 Dessen ungeachtet fungierte Grimm durch seinen Auftritt als ein „kulturelle[r] NS-Exportartikel“440, der es als seine Aufgabe empfand, in den Vereinigten Staaten für das „Dritte Reich“ zu werben.

Dem vordergründigen Anlass entsprechend begann Grimm seine New Yorker Rede - die vor etwa 15000 Zuhörern stattfand ${ }^{441}$ - mit einer kurzen Zusammenfassung der Geschichte deutscher Einwanderung in Nordamerika. Sein eigentliches Interesse bestand jedoch darin, weltpolitische Ausblicke „in die Gegenwart“ und ,in die Zukunft“442 zu werfen. Dabei zeichnete er in seiner Darstellung der internationalen Lage des Jahres 1935 ein existenzielles Bedrohungsszenario für das „nordische“ Abendland durch eine von Osten hereinbrechende Vermassung und Kulturlosigkeit: Überall, so mahnte Grimm, seien „die gedankenlosen und ganz kurzsichtigen Massen“ gegen das „schöpferische Führertum“ in Bewegung geraten. „Weit und breit“ werde - zumal in den Großstädten - „der Massenmensch aufgeputscht“ gegen den „mühsam heraufgezüchteten Leistungsmenschen“, dem „Menschen nordischen Wesens“443. Es entbehrt nicht einer gewissen Komik, dass Grimm, der bis dahin stets nur Deutschland und England zu den elitären „Herrenvölkern“ gerechnet hatte, seine erlesene Liste vor dem New Yorker Publikum um die Vereinigten Staaten ergänzte. Als die wesentliche Gemeinsamkeit dieser drei Völker konstruierte Grimm einen sozialdarwinistisch konnotierten „Menschheitsglauben“, der die „nordischen“ Völker vom Rest der Menschheit qualitativ abhebe. Jener Glaube gründe auf der Überzeugung,

„daß die Tüchtigen mehr Recht haben als die Untüchtigen [....], daß die Ordentlichen mehr Recht haben als die Unordentlichen [...], daß die Gesunden mehr Recht haben als die Kranken [...], daß die Begabten mehr Recht haben als die Unbegabten [...], daß die Schöpfer mehr

437 Zur propagandistische Verklärung Arndts im „Dritten Reich“ vgl. Klausnitzer, Leib, S. 73120; Vordermayer, Rezeption.

438 Der Brief ist abgedruckt in: Grimm, Schriftsteller [1980], S. 185-189, Zitat hier S. 186.

439 NS-Presseanweisungen der Vorkriegszeit. Edition und Dokumentation. Bd. 3.2, bearb. v. Gabriele Toepser-Ziegert, hg. v. Hans Bohrmann, München [u. a.] 1987, S. 646. „DNB“ steht für Deutsches Nachrichtenbüro, die zentrale Nachrichten- und Presseagentur des „Dritten Reichs"(Uzulis, DNB).

440 Gümbel, Volk, S. 215.

441 Ebd., S. 177. Vor seiner Abreise nach New York war Grimm nach sogar von 22000 Zuhörern in der Madison Hall ausgegangen, vgl. DLA, A:Grimm, Hans Grimm an Hans Windekilde Jannasch, 3. September 1935.

442 Hans Grimm, Rede [1935], S. 242.

443 Ebd., S. 255f. Zum Komplex der „Großstadtfeindschaft" vgl. Bergmann, Agrarromantik. 
Recht haben als die Nachahmer [...], daß die Besten, daß die Leistungsmenschen [...] ihrer Volksgemeinschaft [und somit] dem gesünderen und glückhafteren Leben jedes einzelnen Erdenmenschen dienen. Aber zu dem Menschheitsglauben der Nordleute gehört noch eines, zu ihm gehört die unerschütterliche Überzeugung und der Wille und der Mut, daß eben wir Nordleute $[\ldots]$ zu Vormännern dieser Erde berufen sind." ${ }^{444}$

Dem NS-Staat erwies der Dichter insbesondere durch die krude Behauptung einen Propagandadienst, der Nationalsozialismus sei mit dem Ziel angetreten, den skizzierten „Menschheitsglauben“ auch zugunsten Englands und der USA zu verwirklichen. Um sich der nach Grimms Darstellung minderwertigen Völker des Ostens erwehren zu können, trete das nationalsozialistische Deutschland „für die Pflicht [...], aber auch das Vorrecht der Leistung“, der „Gesundheit“ und der „Begabung“ ein. In einer „Selbstbesinnung auf das Herrenrecht [...], das mit jedem gesunden Menschen nordischen Wesens geboren“"werde, praktiziere der NS-Staat einen „Sozialismus für den verhemmten Starken und nicht für den hemmungslosen Schwachen“445. Das „Dritte Reich“ führte demnach den Kampf gegen den „aufgewühlten Massenmenschen“ nicht nur um seiner selbst willen, sondern „für alle Menschen nordischen Wesens“. Umso notwendiger sei eine Solidarisierung der USA mit dem Nationalsozialismus, zumal sein mögliches Scheitern verheerende Konsequenzen auch für England und die Vereinigten Staaten nach sich ziehen müsse. Rhetorisch ungelenk wie so häufig in seinen politischen Texten brachte Grimm diesen Gedanken in folgende Formel: „Wenn die Massenmenschen einen von uns überrennen, sind die drei Nordmänner vorbei, und ist die Erwartung aller tüchtigen Kerle auf den endlichen Sieg der eigenen guten Kraft betrogen" 446 . Die Verständigung zwischen Deutschland, England und den USA galt Grimm daher als eine historische Notwendigkeit von kaum zu überschätzender Tragweite und Bedeutung. Seine Propagandabehauptung, dass es dem „Dritten Reich“ im Kern um die gleichsam solidarische Erfüllung eines übergreifenden „Menschheitstraumes“ aller „Nordmänner“ gehe, wiederholte Grimm im Juni 1936 in einem Artikel in Will Vespers Zeitschrift Die neue Literatur. ${ }^{447}$

Grimms Eindrücke aus New York wurden alsbald von seiner Beobachtung überschattet, dass „die amerikanische Presse [...] keine Notiz“448 von dem „Deutschen Tag" genommen habe. Dass seine Rede in den amerikanischen Medien weitestgehend unbeachtet geblieben war und entsprechend die erhoffte außenpolitische Wirkung nicht entfalten konnte, schrieb Grimm im Nachhinein vor allem der politischen Tendenz des „Deutschen Tags“ zu, über die er allerdings bereits im Vorfeld unterrichtet worden war. Nach seiner Rückkehr aus den Vereinigten Staa-

444 Grimm, Rede [1935], S. 259f.; Grimm, Gedanken [1936], S. 376.

445 Ebd., S. 262f. (Herv. i. Orig.)

446 Ebd., S. $265 f$.

447 Grimm, Gedanken [1936], S. 376: „Was aber Deutschland heute versucht, recht und auch schlecht gewiß und wie mit guten so auch mit noch unzureichenden Kräften, das ist, den neuen Glauben an die Menschheit endlich wiederzuholen und ihn aus einer schönen Phrase zu einer Wirklichkeit für alle weißen Menschen zu machen."

448 Gümbel, Volk, S. 177. 
ten monierte Grimm, dass die Veranstaltung „weder amerikanisch noch deutsch“ gewesen sei, sondern versucht habe, „beides zugleich zu sein“. Dabei sei jedoch „das Deutsche“ überbetont worden. Während das Publikum bei der amerikanischen Nationalhymne nicht mitgesungen habe, sei das Horst-Wessel-Lied „laut gesungen“ worden. „Auf diese halbe Weise“, so Grimm, habe „nichts gewonnen“ werden können. Nur wenn die Deutschen in Amerika von ihrem „Amerikanertum“ und nicht von ihrem „halben Deutschtum“ her wirkten, könne „unsere deutsche Not drüben verstanden“ und die „nordische Gemeinsamkeit“ der „bedrohten weißen Herren in der Welt" erkannt werden. ${ }^{449}$ Diese Voraussetzung sei in New York nicht gegeben gewesen.

Einen Achtungserfolg stellte die Amerikareise für Grimm jedoch immerhin finanziell dar: Die Eindrücke seines Amerikaaufenthalts, den er zugleich für Lesungen aus seinen Werken genutzt hatte ${ }^{450}$, publizierte Grimm im Winter 1935 in zahlreichen deutschen Zeitungen unter dem Titel Amerikanische Briefe. Hierbei kamen Grimms exzellente Verbindungen zur deutschen Presse zum Tragen: Bereits vor der Abreise nach Amerika hatte er gegenüber dem Feuilletonleiter des Hannoverschen Kuriers, Kurt Voß, angekündigt, seine Reise als „Gelegenheit für fünf oder sechs Aufsätze“ über die „Auslandsdeutschen“ in den Vereinigten Staaten nutzen zu wollen. Als Voraussetzung dieses Unternehmens nannte Grimm das stattliche Honorar von 2500 Reichsmark $^{451}$ - ein Betrag, der etwas mehr als einem Drittel des Jahresgehalts eines preußischen Studienrats entsprach. ${ }^{452}$ Auf Grimms Frage, ob sich dieses Budget durch die Kooperation mit anderen Zeitungen stemmen ließe, setzte sich Voß mit dem Schriftleiter der Rheinisch-Westfälischen Zeitung, Eugen Mündler, in Verbindung, der sogleich Interesse an einer solchen Zusammenarbeit signalisierte. ${ }^{453}$ Insgesamt, so betonte Voß gegenüber Grimm, sei jedoch die Kooperation von etwa zehn Zeitungen notwendig, um die geforderte Gage finanzieren zu können. ${ }^{454}$ Grimm ließ daraufhin seine Kontakte spielen und konnte bereits nach weniger als drei Wochen an Voß vermelden, Verabredungen mit mehreren Blättern getroffen zu haben: Den Bremer Nachrichten, dem Fränkischer Kurier, den Hamburger Nachrichten, der Königsberger Allgemeinen Zeitung, den Leipziger Neuesten Nachrichten, den Münchner Neuesten Nachrichten und der Rheinisch-Westfälischen Zeitung. ${ }^{455}$ Jeder der insgesamt sechs „Amerikanischen Briefe“ wurde schließlich mit 300 Reichsmark vergütet, wobei sich die beteiligten Zeitungen, die die „Briefe“ parallel veröffentlichten, die Kosten teilten. ${ }^{456}$

449 Grimm, Schriftsteller, S. 187 f.

450 Vgl. Gümbel, Volk, S. 215.

451 Vgl. DLA, A:Grimm, Hans Grimm an Hannoverscher Kurier, 4. September 1935.

452 Vgl. Müller-Benedict, Karrieren, S. 198.

453 Die Rheinisch-Westfälische Zeitung hatte bereits im August 1922 einen „Brief über SüdwestAfrika“ und zwei Jahre später eine Novelle von Grimm veröffentlicht. Vgl. DLA, A:Grimm, Rheinisch-Westfälische Zeitung an Hans Grimm, 7. August 1922 und 13. August 1924.

454 Vgl. DLA, A:Grimm, Hannoverscher Kurier an Hans Grimm, 9. September 1935.

455 Vgl. DLA, A:Grimm, Hans Grimm an Hannoverscher Kurier, 27. September 1935.

456 Gümbel, Volk, S. 215f. informiert knapp über die Inhalte der rassistisch aufgeladenen Briefe. 
Propaganda Stapels für Hitler und die NS-JudenPolitik In DER FrühPHASE des NS-REgIMES - Im Deutschen Volkstum kam zwar vereinzelt zum Ausdruck, dass sich die politische Entwicklung seit dem Januar 1933 nicht gänzlich mit Stapels Wunschvorstellungen deckte ${ }^{457}$, faktisch aber stellte Stapel seine Zeitschrift nach der nationalsozialistischen „Machtergreifung“ sogleich in den Dienst des neuen Staates. Einem Brief an Kolbenheyer vom 7.September 1934 zufolge beabsichtigte Stapel, das Deutsche Volkstum im „Dritten Reich“ als eine Plattform „positive[r] Kritik im höchsten und verantwortungsvollsten Sinne“ zu etablieren. Demzufolge wollte er in erster Linie jenen „bedeutenden Autoren“ eine Bühne bieten, die „von der NSDAP zwar nicht bekämpft, aber bei Seite gehalten“ würden, die „erlaubt, aber nicht geliebt“ seien. Dabei sollten explizit „nur solche Autoren“ als Mitarbeiter herangezogen werden, „die für Hitler und den neuen Staat sind“. Keinesfalls wollte Stapel „Meckerer“ oder gar „getarnte Staatsfeinde“458 zu Wort kommen lassen.

Ebenso wie Grimm äußerte sich auch Stapel im November 1933 zur Reichstagswahl und Abstimmung über den Austritt aus dem Völkerbund. Anders als der Dichter meldete sich Stapel jedoch nicht im Vorfeld, sondern erst nach der Wahl zu Wort, wobei sein Beitrag primär als Propaganda für Hitler persönlich und nicht für den NS-Staat als Ganzes konzipiert war. Dies erklärt sich auch daraus, dass der Artikel zeitlich mit seinem Vortragsverbot an der Universität Kiel zusammenfiel, bei dem sich Stapel zu seinem Ärger erstmals mit feindselig gesinnten Nationalsozialisten jüngeren Alters hatte herumschlagen müssen. ${ }^{459}$ Der Ärger über dieses Scharmützel führte dazu, dass sich Stapels Hoffnungen umso stärker auf Hitler konzentrierten. Entsprechend schrieb er im Anschluss an die Abstimmungen vom 12. November, dass nicht daran zu zweifeln sei, dass die deutsche „Einigkeit“ unmittelbar der „Person Hitlers selbst“ gelte. „Es liegt hier die Bestätigung eines echten Führertums vor" 460 . Stapel argumentierte, dass der in den Wahlen zum Ausdruck gekommene "Gefolgschaftswille“ nichts „Subalternes“ darstelle, wie von „jüdische[n] Schriftsteller[n]“ behauptet worden sei. Vielmehr habe man darin einen „Teil der ewigen deutschen Romantik“ und eine „Urform des deutschen politischen Lebens“ zu erkennen. Die Aufgabe jedes Volksbürgers bestehe nun darin, die neue politische Ordnung durch persönliche Treue gegenüber Hitler zu stabilisieren. ${ }^{461}$

457 Vgl. Deutsches Volkstum. Monatsschrift für das deutsche Geistesleben 15 (1933), S. 311: „Unsere Zeitschrift hat die nationale Revolution gewollt und hat zu ihrem Teile daran mitgewirkt. Es wird sicherlich nicht alles so, wie wir es gedacht und gewünscht hatten. Die Erfüllung gleicht nie dem Wunsch. Wir bekennen uns gleichwohl zu dem aus der nationalen Bewegung neu entstandenen Staat, den wir zu unserem Teile mit herbeigeführt haben" (Herv. i. Orig.). Die Organisationswut der Nationalsozialisten in Angelegenheiten der Kunst ironisierte Stapel in dem Beitrag Planwirtschaftlicher Wiederaufbau der deutschen Lyrik, in: Deutsches Volkstum. Monatsschrift für das deutsches Geistesleben 16 (1934), S. $125 \mathrm{f}$.

458 KAG, Wilhelm Stapel an Erwin Guido Kolbenheyer, 7. September 1934 (Herv. i. Orig.).

459 Vgl. Kap. 5.2.2.

460 Stapel, November [1933], S. 1004.

461 „Der Kaiser war dem romantischen Glauben des deutschen Volkes nicht gewachsen, er sank dahin. Seine Gegenspieler, die Parlamentarier, waren dem romantischen Glauben 
Auch der NS-Judenpolitik diente sich Stapel in der Frühphase des „Dritten Reichs" propagandistisch an. ${ }^{462}$ Dabei stellt der im Februar 1935 veröffentlichte Artikel Besinnungen zur Judenfrage das eklatanteste Beispiel einer apologetischen und desinformierenden Verharmlosung des Nationalsozialismus dar. Dem Artikel stellte Stapel die Feststellung voran, dass die NS-Judenpolitik nicht nach moralischen Maßstäben bewertet werden könne. Angemessen sei vielmehr eine dezidiert kollektivistische Perspektive, bei der das „Glück und Unglück einzelner Juden und jüdische[r] Familien" 463 nicht berücksichtigt werden sollte: Da es sich bei der „Judenfrage um ein Völkerschicksal“ handle, werde die NS-Judenpolitik „nicht dadurch ins Unrecht gesetzt“, dass "hier einem guten Juden Schlimmes widerfuhr“ und dort „eine unschuldige jüdische Familie weichen mußte.“ Man habe mit „geschichtliche[n] Vorgänge[n]“ zu tun, die „nicht mit den Kategorien eines Moralismus begriffen werden“ könnten, „der nur ,gute“ und ,schlechte“ ,Menschen“ und sonst nichts“ kenne. Vielmehr müsse die „Judenfrage“ nach Gesichtspunkten der „Biopolitik“464 betrachtet werden.

Zugleich verglich Stapel das Schicksal der Juden in Deutschland mit jenem der Deutschen in Straßburg, im Memelland und in „östlichen und südöstlichen Ländern" nach dem Ersten Weltkrieg. Er schlussfolgerte dabei, dass niemand, der sich nicht über das Schicksal der Deutschen in den genannten Gebieten entrüste, das Recht zu klagen habe, „wenn wir, um zu einer erträglichen deutschen Lebensordnung zu kommen, das Notwendige vollziehen: uns von den Juden zu trennen“ 465 . Die zynische und perfide Ignoranz einer solchen Argumentation zeigt sich auch daran, dass es Stapel den jüdischen Emigranten moralisch anlastete, nach der Herrschaftsübernahme der NSDAP „in Massen“ Deutschland verlassen zu haben; zu einem solchen Exodus hätte es nie kommen können, hätten die Juden ein "gutes Gewissen“ gehabt. Niemand habe die Juden davon abhalten wollen, sich

ebenfalls nicht gewachsen, sie sanken dahin. Nun kam als Gegenspieler des Parlamentarismus Hitler, der - endlich - sein Reich auf diesen Glauben gründete. [...] Aus Regierung und Volk ist Führer und Gefolgschaft geworden. Darum ist die erträumte Einigkeit wirklich geworden. Jetzt muß die Konsequenz des Glaubens gehalten werden: die Treue“ (ebd., Herv. i. Orig.).

462 Zur antisemitischen Politik in den Frühphase des „Dritten Reichs“ und seiner öffentlichen Aufnahme in Deutschland vgl. Longerich, „Davon haben wir nichts gewusst!“, S. 23-74.

463 Stapel, Besinnungen [1935], S. 71.

464 Ebd. (Herv. i. Orig.). Was Stapel mit dem Begriff „Biopolitik“ konkret meinte, ist an dieser Stelle nicht weiter ausgeführt. In einem einige Monate zuvor veröffentlichten Aufsatz hat sich Stapel indes etwas präziser zu der Thematik geäußert: „Wir Deutschen sind seit dem Weltkriege nicht mehr in der Ausdehnung begriffen, weder durch Handel noch durch geistige und moralische Siege. Selbst unser Volkskörper ist von allen Seiten bedrängt: die deutschen ,Minoritäten` sucht man überall zu entdeutschen. Die gegenwärtige Aufgabe unseres Volkes ist also die Selbstbehauptung. Darum hat der Nationalsozialismus, aus biopolitischer Notwendigkeit, einen ,völkischen' Zug, er neigt dem patrimonialen Denken zu. [...] Die nationalsozialistische Aufgabe besteht wesentlich - darüber lassen Hitlers Reden und seine praktische Politik keinen Zweifel - in einer Verdichtung und Stärkung der völkischen Substanz" (Stapel, Weltvolk [1934], S. 799f., Herv. i. Orig.).

465 Stapel, Besinnungen [1935], S. 71. 
im nationalsozialistischen Deutschland „ein volkhaftes Sonderleben neben den Deutschen aufzubauen"466.

Damit nicht genug, spitzte Stapel seine Vorwürfe gegen die emigrierten Juden dahingehend $\mathrm{zu}$, dass er sie bezichtigte, das Reich insgeheim in der Gewissheit und Absicht verlassen zu haben, dem deutschen Volk vom Ausland aus ihre Interessen aufzwingen zu können, um anschließend wieder „im Triumph“467 nach Deutschland zurückzukehren. Mit dieser Behauptung überging Stapel nicht nur den Sachverhalt, dass der aggressive nationalsozialistische Antisemitismus die Angehörigen jüdischen Glaubens nach der Übernahme der Regierungsverantwortung durch die NSDAP unweigerlich mit Ängsten und Abscheu erfüllen musste; zugleich stellte er sich in die unselige Tradition jenes antisemitischen Weltverschwörungsmythos, welcher - insbesondere nach Veröffentlichung der Protokolle der Weisen von Zion im Jahr 1920 - von völkischen Autoren immer wieder reproduziert wurde und "den“ Juden insbesondere in den Siegerstaaten des Ersten Weltkriegs politische Omnipotenz unterstellte. ${ }^{468}$ Vor dem Hintergrund seiner Ablehnung jüdischer „Assimilation“469 verstieg sich Stapel abschließend gar zu der Prognose, „künftige jüdische Geschlechter“ würden auf „das Jahr 1933 als ein Jahr der Rettung des jüdischen Volkes“ zurückblicken. Diese Deutung versuchte er durch die These plausibel $\mathrm{zu}$ machen, dass die Unterbindung weiterer „Assimilation“ die „Zivilisationsjuden“ und „Zersetzungsjuden“ innerhalb des jüdischen Volks unweigerlich zurückdrängen werde. Auf diese Weise würde Platz geschaffen für die „Volksjuden“ und „Charakterjuden“, wodurch mithin jene jüdischen „Kräfte zur Geltung“ kämen, die konstruktiv „bauen“470 könnten.

Zum Zeitpunkt der Publikation des Artikels stand die nationalsozialistische Judenpolitik zwar noch einige Monate vor ihrem ersten Kulminationspunkt in den „Nürnberger Gesetzen“ vom 15. September 1935, gleichwohl verschwieg Stapel bereits mehrere offene Gewalt- und Einschüchterungsmaßnahmen des NS-Regimes. Dazu gehörte vor allem der „Boykott“ vom 1. April 1933, bei dem Angehörige der SA und SS Passanten unter Androhung von Repressalien und Gewalt vom Einkauf in jüdischen Geschäften abgehalten hatten. ${ }^{471} \mathrm{Hinzu}$ kommen die bereits im Sommer 1933 einsetzenden „Arisierungen“ jüdischer Betriebe, die gerade für Stapels Wahlheimat gut untersucht sind. ${ }^{472}$ Darüber hinaus überging er das am 7.April 1933 erlassene „Gesetz zur Wiederherstellung des Berufsbeamtentums“, durch das jüdische Beamte und Angestellte ihre Anstellungen verloren hatten. ${ }^{473}$

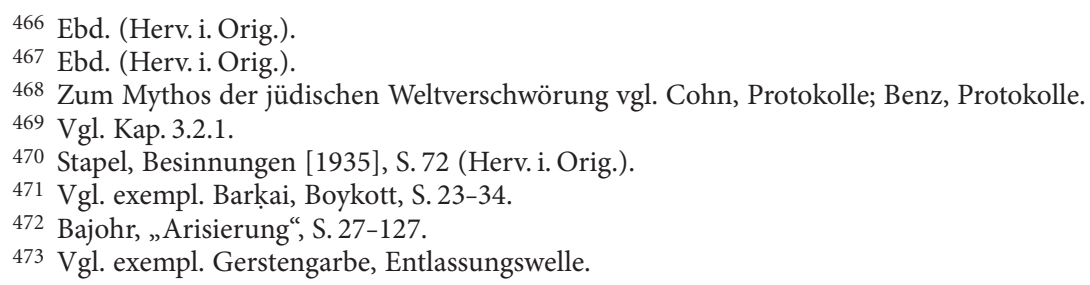


Propaganda und Gefühlsleben bei Kolbenheyer naCh 1938 - Kolbenheyers Werdegang der Jahre 1938 bis 1945 weicht deutlich von jenen Grimms und Stapels ab. Wie gezeigt, zog sich Grimm nach einem heftigen Konflikt mit Joseph Goebbels $^{474}$ seit Ende 1938 weitgehend aus der Öffentlichkeit zurück und vermied es in der Folgezeit, die Reichshauptstadt zu betreten. ${ }^{475}$ Ähnliches ist für Stapel zu konstatieren, der aufgrund der permanenten Kritik an seiner Person und dem kontinuierlichen Bedeutungsverlust seiner Zeitschrift ${ }^{476}$ im Dezember 1938 die Herausgeberschaft des Deutschen Volkstums nach 20 Jahren niederlegte. Stapel, der dem besorgten Kolbenheyer versicherte, dass diese Entscheidung nicht als Abwendung von „Hitlers große[m] Werk“477 missverstanden werden dürfe, wurde nach Eigenaussage mit stattlichen 24000 Reichsmark abgefunden. ${ }^{478}$ Anschließend bezog Stapel für weitere zwei Jahre sein reguläres Gehalt durch die HVA, ohne zur Mitarbeit verpflichtet zu sein. ${ }^{479}$ Während sich Grimm und Stapel also sukzessive ins Privatleben zurückzogen, blieb Kolbenheyer eine sehr viel präsentere Figur im öffentlichen Leben des „Dritten Reichs“. Auch lässt sich bei Kolbenheyer seit den späten 1930er Jahren eine deutlich stärkere emotionale Bindung an den NS-Staat nachweisen als bei Grimm und Stapel. Diese Bindung war maßgeblich von dem Erlebnis der Annexionen Österreichs und des Sudetenlands des im böhmischen Karlsbad aufgewachsenen Dichters bedingt. ${ }^{480}$ Zwar begrüßten auch Grimm und Stapel die Gebietserweiterungen ${ }^{481}$, eine Begeisterung und Hingabe

474 Vgl. Kap. 5.2.4.

475 Gümbel, Volk, S. 173. Grimms Rückzug blieb in Berlin nicht unbeachtet. Im Jahreslagebericht des Reichssicherheitshauptamts von 1938 findet sich die kritische Notiz, Grimm habe sich „nunmehr ganz abseits gestellt“ und nichts publiziert außer „eine kleine Broschüre“, die er zu allem Überfluss auch noch in „einem ausgesprochen konfessionellen Verlag“ publiziert habe (zitiert nach: Franke, Grimm, S. 119). Gemeint war die 1938 im Bertelsmann-Verlag erschienene Englische Rede.

476 Heinrich Keßler geht unter Berufung auf eine persönliche Mitteilung Paul Weinreichs für das Jahr 1938 von einer Auflage von „erheblich unter 3000“ aus (Keßler, Stapel, S. 211). Besonders verheerend wirkte es sich aus, dass nach der Gleichschaltung des DHV die „bisherige Rekrutierungsbasis für neue Leser" wegfiel (Lokatis, Verlagsanstalt, S. 82). Die Zeitschrift wurde in der Folgezeit für die HVA ein immer schwerer zu legitimierendes Zuschussunternehmen.

477 KAG, Wilhelm Stapel an Erwin Guido Kolbenheyer, 31. Oktober 1938.

478 Vgl. DLA, A:Grimm, Wilhelm Stapel an Hans Grimm, 25. Juli 1948.

479 Stapel nutzte die Zeit, um seine lange geplante Studie Die drei Stände. Versuch einer Morphologie des deutschen Volkes zu Papier zu bringen. Anschließend wurde Stapel ab Juli 1941 für die Dauer des Krieges „als literarischer Berater“ im Verlag eingestellt. Es handelte sich dabei um einen rein formellen Titel, tatsächlich genoss Stapel ein freies und offenes Angestelltenverhältnis, das ihm ausdrücklich „reichlich freie Zeit für seine eigenen schriftstellerischen Arbeiten“ lassen sollte (Brief von Benno Ziegler an Erwin Guido Kolbenheyer vom 31. Mai 1945, zitiert nach: Schmalz, Kirchenpolitik, S. 212).

480 „Es ist nicht zu schildern, wie tief mich die Befreiung meiner Heimat bewegt hat. [...] Damals, als wir die Meldung lasen und aus dem Funkgeräte hörten, erlebte ich zum ersten Male die Leidenschaft eines triebhaft politischen Wesens in mir, Erbwuchs, den man mit ,Blut' bezeichnen kann“ (Kolbenheyer, Sebastian Karst, Bd. 3, S. 376).

481 Stapel nahm den „Anschluss“ Österreichs zum Anlass weiterer euphorischer Hitler-Propaganda. In dem ausschließlich dem „Mut“ Hitlers zugeschriebenen Anschluss glaubte Stapel gar „eine Kulmination der Weltgeschichte“ erkennen zu können. Vgl. Stapel, Deutschland [1938], S. 218. 
an den NS-Staat, wie Kolbenheyer sie in der Folgezeit äußerte, ist bei ihnen während des Zweiten Weltkriegs jedoch nicht erkennbar.

Seit 1938 tendierte Kolbenheyer vor dem Hintergrund seiner emphatischen Zustimmung zur Außenpolitik des „Dritten Reichs“ immer stärker dazu, die ihn störenden Elemente des NS-Staats auszublenden und - gemessen an den außenpolitischen Errungenschaften - als nebensächlich zu betrachten. Die Begeisterung Kolbenheyers nahm dabei mitunter unfreiwillig komische Züge an: Als im Vorfeld des Münchner Abkommens im September 1938 die Sudetendeutschen Freikorps ${ }^{482}$ aufgestellt wurden - organisiert durch den späteren Gauleiter Konrad Henlein, mit dem Kolbenheyer seit 1935 persönlich bekannt war ${ }^{483}$-, ließ der bald 60-jährige Dichter in einer enthusiastischen Kurzschlusshandlung per Rundfunk verbreiten, sich dem Freikorps persönlich zur Verfügung zu stellen. ${ }^{484}$ Süffisant wie stets, wenn es um die Person Kolbenheyers ging, beschrieb der damals in dessen Wahlheimat Solln wohnende Schriftsteller Werner Bergengruen in seinen Erinnerungen die belustigte Aufnahme, welche die Rundfunkmeldung im dortigen Gasthaus Zum Hirschen evoziert habe. ${ }^{485}$ Befremdet von der Euphorie, mit der Kolbenheyer dem „Dritten Reich“ gegenüberstand, zeigte sich auch der Lyriker Hans Carossa. In einem Brief vom 6. Januar 1939 beschrieb er Kolbenheyer, dem er kurz zuvor auf einer Zugfahrt nach Berlin begegnet war, wie folgt: „Sein ganzes Wesen ist jubelnde Bewunderung der Gegenwart; in ihm ist nicht ein Blutstropfen von der Kassandra, die uns anderen manchmal unruhige Stunden macht" 486 .

Demonstrativ bezeugte Kolbenheyer seine innere Verbundenheit mit dem Nationalsozialismus schließlich dadurch, dass er noch 1940 in die NSDAP eintrat eine Entscheidung, die Kolbenheyer in seiner Autobiografie als einen Akt der „Dankbarkeit für die Befreiung seiner Heimat vom Tschechenterror“487 begrün-

482 Vgl. zu diesen Formationen: Röhr, Freikorps; Broszat, Freikorps.

${ }^{483}$ In dem ersten Brief an Kolbenheyer vom Juli 1935 spricht Henlein von einer vorhergehenden Begegnung in Eger: „Ich habe die große Hoffnung, ja sogar die Gewissheit, daß unsere Begegnung in Eger der erste Beginn einer engeren Zusammenarbeit zwischen uns werden soll, da gerade auf kulturellem Gebiete das Sudetendeutschtum heute mehr denn je alle Kräfte einsetzen muss, um sich in seinem harten Kampfe ums Dasein zu behaupten" (KAG, Konrad Henlein an Erwin Guido Kolbenheyer, 13. Juli 1935).

484 Vgl. Kolbenheyer, Sebastian Karst, Bd. 1, S. 111.

485 „Eines Abends saßen die Sollner Bürger im Hirschen beisammen und diskutierten die Ereignisse. Plötzlich erscholl aus dem Radio die Stimme des Münchener Rundfunksprechers: ,Soeben erreicht uns folgendes Telegramm aus Solln.' Die politisierenden Biertrinker spitzten erstaunt die Ohren: ein Telegramm aus Solln an den Rundfunk! Der Sprecher verlas den Text: ,Stelle mich in dieser großen Stunde mit Gut und Blut zur Verfügung. Habe mich zum Sudetendeutschen Freikorps gemeldet und erwarte nur noch meine Einberufung. Erwin Guido Kolbenheyer.' Es entstand ein dröhnendes Gelächter, denn soviel wußten diese Männer auch von der Welt, daß es zu den Charakteristika eines Freikorps gehört, daß es eben keine Einberufungsordres ausgehen lässt, sondern daß, wer mittun will, sich von selber einfinden muß. Es versteht sich von selbst, daß er vergeblich auf seinen Gestellungsbefehl gewartet hat" (Bergengruen, Schriftstellerexistenz, S. 128).

486 Carossa, Briefe, Bd. 3, S. 71.

487 Kolbenheyer, Sebastian Karst, Bd. 3, S. 266. 
dete. Auf den nicht unerheblichen zeitlichen Abstand zwischen seinem Parteieintritt und der Annexion des Sudetenlands im Oktober 1938 ging er dabei nicht ein. Dies ist insofern sprechend, als Kolbenheyers Zustimmung zur aggressiven nationalsozialistischen Expansionspolitik keineswegs bei der Annexion des Sudetenlands Halt machte. Als deutsche Truppen im März 1939 die „Rest-Tschechei“ besetzten und Stapel lapidar bilanzierte, Hitler sei damit „vom völkischen auf den imperialen Weg “488 eingeschwenkt, wies Kolbenheyer diese Deutung weit von sich und sprach stattdessen von einer biologisch gerechtfertigten „Lebensraum“-Politik. Stapel reagierte auf die Wortklauberei des Dichters nicht ohne Ironie, wobei er allerdings seine eigene, ungebrochene Bewunderung für Hitler signalisierte. ${ }^{489}$

Wie gezeigt ${ }^{490}$, machte Kolbenheyer eine tragfähige „Bestandsform“ Europas von der freien Entfaltung der jeweiligen biologischen Kräfte der Einzelvölker abhängig. Das biologisch „jüngste“ bzw. „plasmatisch“ anpassungsfähigste Volk besaß in seiner Vorstellungswelt das größte Anrecht auf Selbstentfaltung. Am Vorabend des Zweiten Weltkriegs nahmen für Kolbenheyer das „Dritte Reich“ sowie das faschistische Italien diese Rolle ein. Beide Länder besaßen nach seiner Auffassung „bei höchster Kulturreife“ zugleich das „kräftigste Innenleben des Volkskörpers“ und waren daher allein prädestiniert, „in der Gefolgschaft ihrer genialen Führer“ stabile „völkische Gemeinschaftsformen“ auszubilden und die „natürliche[n] Grundlagen“ für eine „Neubildung der übervölkischen europäischen Lebensgemeinschaft“ zu schaffen. ${ }^{491}$ Den Gedanken einer von dem Nationalsozialismus und dem italienischen Faschismus ausgehenden Kriegsgefahr stritt Kolbenheyer noch 1939 ausdrücklich ab. Die Behauptung, dass es bei der skizzierten Transformation Europas unter nationalsozialistisch-faschistischen Vorzeichen „zu bewaffneten Auseinandersetzungen kommen müsse“, geißelte er als „eine beliebte, aber nicht begründbare These der Kriegshetzer und Defaitisten“. Stattdessen sah Kolbenheyer Europa vor einer „überstaatlichen und völkisch gleichgerichteten Gemeinschaftsbildung stehen“, die das „Leben der weißen, arischen Rasse“ neu gestalten werde. Angesichts dieser Aussichten rief Kolbenheyer seine Leser dazu auf, „das Schicksal [zu] preisen“, dass das deutsche Volk durch „seinen Befreier“ Hitler „an die Führung dieses artumfassenden Neubaus gestellt“492 worden sei.

Auch als das „Dritte Reich“ wenige Monate später Polen überfiel, sah Kolbenheyer keinen Anlass, seine anschaulich widerlegte Deutung zu korrigieren. An seiner Überzeugung, dass das Schicksal Europas von der freien Kraftentfaltung

488 KAG, Wilhelm Stapel an Erwin Guido Kolbenheyer, 21. März 1939 (Herv. i. Orig.).

489 Vgl. KAG, Wilhelm Stapel an Erwin Guido Kolbenheyer, 9. April 1939: „Also ich bin bereit, ,Lebensraum zu sagen. Ich bewundere die Meisterschaft des Führers, Lebensraumpolitik zu treiben, den Weg vom Völkischen zum Imp -, pardon, zum Lebensraumpolitischen zu finden. Das gehört zu den erhabenen Ereignissen der Weltgeschichte. Ich sage: der Weltgeschichte, nicht nur der deutschen Geschichte. Hitler ist aus der deutschen Geschichte in die Weltgeschichte gewachsen" (Herv. i. Orig.).

490 Vgl. Kap. 3.3.1.

491 Kolbenheyer, Weltgestaltung [1939], S. 377f.

492 Ebd. 
des „jungen“ deutschen Volks abhängig sei, hielt er derart dogmatisch fest, dass er sogar den deutschen Angriff auf die Sowjetunion als einen gleichsam naturgemäßen Vorgang zugunsten der ganzen „weißen Kulturrasse“ verteidigte. Diese Überzeugung propagierte er unter anderem in einer Rede vor der HJ auf den „Salzburger Kulturtagen“ im Mai 1942. In ihr mahnte Kolbenheyer an, dass dem „fast übermenschliche[n] Opfer an Leistungsfähigkeit, Standhaftigkeit und äußerster Selbsthingabe“ der deutschen Soldaten an der Ostfront mit weihevoller Achtung begegnet werden müsse. Den Sinn jener Opfer umriss er wie folgt:

„Wir nehmen es hin, als sei die gewaltige Entwicklung eine Selbstverständlichkeit, die unser Volk von einer niedergezwungenen, ausgebeuteten, verachteten Nation zum Stimmführer und Vorkämpfer für die neue Bestandsform Europas gemacht hat, die jetzt gebildet wird. [...] Aber um unseren Führungsanspruch innerhalb der weißen Kulturrasse zu behaupten, muß erreicht sein, daß wir jenseits einer marktläufigen Gesinnungsmache immer wieder und in den entscheidenden Augenblicken innerlichst erleben können, was da wie eine Selbstverständlichkeit hingenommen wird, und wo der Lebenswert dessen zu suchen sei, wodurch unser Volk befreit und wieder erhoben wurde und wodurch es frei und führend bleiben kann. [...] Wir stehen unter Entscheidungskämpfen von weltgeschichtlicher Tragweite für das Leben der Kulturmenschheit. Das künftige Jahrhundert unseres Volkes wird in diesen Monaten das Wegzeichen erhalten, unter dem es eine Entwicklung nehmen soll, die nicht nur für unser Volk selbst, sondern für die gesamte weiße Rasse von Bedeutung sein wird. Eine neue Bestandsform der weißen Menschheit muß gefunden werden, Europa muß seine neue Gestalt erhalten, und das deutsche Volk wird diese Gestalt in erster Linie zu bestimmen haben." ${ }^{493}$

Auch privat verteidigte Kolbenheyer den Überfall auf die Sowjetunion. Im März 1943 teilte er dem ihm bekannten Geschichtsprofessor an der Hochschule für Lehrerbildung im hessischen Weilburg Hjalmar Kutzleb ${ }^{494}$ seine „Überzeugung“ mit, „daß wir in irgendeiner Form dem drohenden Osten begegnen mußten“. Das „Wie der Form“ und manche „üblen Begleiterscheinungen“ waren für Kolbenheyer ausdrücklich sekundär; als entscheidend galt ihm lediglich, dass „noch rechtzeitig der Kampf aufgenommen“ worden sei. Niemals hätte „der Bolschewis-

493 Kolbenheyer, Reden [1942], S. 23f., 30. In Kolbenheyers Gesamtausgabe letzter Hand ist die Rede an zahlreichen Stellen geändert. Aus der hier zitierten Textpassage strich Kolbenheyer unter anderem den verfänglichen Begriff „Stimmführer" und setzte anstelle von „Führungsanspruch“ lediglich „Anspruch“, anstelle von „weißer Rasse“ findet sich die Formel „weiße Menschheit“. Die Formulierung „in erster Linie zu bestimmen haben“ änderte er zu: „in erster Linie mitzubestimmen haben“. Vgl. ders., Gesamtausgabe, Abt. 2, Bd. 7, S. 284 f., $292 \mathrm{f}$. Zum Problem der Textüberarbeitungen Kolbenheyers vgl. Kap. 1.5.

${ }^{494}$ Die Bekanntschaft zwischen Kolbenheyer und Kutzleb (1885-1959) ging auf den Juni 1932 zurück, als Kutzleb sich auf eine Buchzusendung durch Kolbenheyer als Anhänger der Bauhütte zu erkennen gab: „Ich teile Ihre Überzeugung schon lange, daß das Denken des anbrechenden Zeitalters von der Biologie - nicht nur wissenschaftlich, sondern auch weltanschaulich - bestimmt sein wird, daß wir wieder einmal im Begriffe stehen, die kopernikanische Wanderung zu machen, diesmal vom absoluten und absolutistischen Ich zum Leben als dem Totalen mit dem Ich als seiner Funktion. Solange diese Überzeugung das Eigentum der Fachbiologen bliebe, wäre sie eine akademische Angelegenheit. Sie machen den Kampf um die neue Weltanschauung zu einer Angelegenheit des geistigen Lebens überhaupt und erobern dem Dichter sein Recht, in diesem Kampfe der Führer zu sein. Damit reicht Ihr Lebenswerk in die Zukunft, an die zu glauben und der zu dienen - trotz allem - Aufgabe ist. Ich diesem Glauben und Dienst Ihnen verbunden erwidere ich Ihren Kampfgruß" (KAG, Hjalmar Kutzleb an Erwin Guido Kolbenheyer, 13. Juni 1932). 
mus in seiner östlichen, für uns absolut tödlichen Form etwa an der Weichsel Halt gemacht “495. Sein unbedingtes Vertrauen in Hitlers Außen- und Kriegspolitik erklärte Kolbenheyer mit seiner Identität als „Grenzlanddeutscher“. Hitlers „Initiativen“ konnten für ihn seit jeher nur „aus den reinsten Motiven geflossen“ sein. Den „Altreichsdeutschen“, so Kolbenheyer, gehe diese intuitive Gewissheit gemeinhin ab, da sie „niemals das politische Erlebnis einer durch Generationen

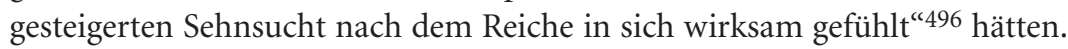

Der Briefwechsel mit Kutzleb ist noch in einer weiten Hinsicht aufschlussreich für Kolbenheyers Mentalität während des Zweiten Weltkriegs. Anschaulich lässt sich an ihm zeigen, wie ihn die vermeintlichen Gewissheiten seiner BauhüttenPhilosophie davon abhielten, den Realitäten des NS-Staats ins Auge zu blicken. So hatte sich Kutzleb im Dezember 1940 über jämmerliche Zustände an den deutschen Hochschulen und einen allgemeinen Niedergang der geistigen Aufnahmeund Leistungsfähigkeit seiner Studenten beklagt. Kutzleb schien es „immer schwieriger“ zu werden, „mit Jüngeren ein Gespräch über was Wesentlicheres als das Wetter [oder] den Krieg“ "497 zu führen. Kolbenheyer reagierte darauf mit der Versicherung, Kutzlebs Sorgen zwar „gut [zu] verstehen“ - auch ihm lasse „die Sorge um das deutsche Geisteswesen keine Ruhe“ -, plädierte jedoch für geduldiges Ausharren. Die Lösung des Problems werde von selbst kommen: Das „in generationenweiter Auslese hochdifferenzierte deutsche Gehirn", so glaubte und behauptete Kolbenheyer, könne unmöglich dauerhaft „unbetätigt“ niedergehalten werden. Das „plasmatische Erbe“ werde sich auch unter widrigen Umständen „durchringen, sobald nur einigermaßen Luft geschaffen wird“. Die „völkische Lebenslage“ sei zunächst „vor Notstandsreaktionen gestellt", die es durchzuhalten gelte. Erst danach könne sich wieder eine „tatsächlich bildnerische Geisteskultur “498 herausbilden. Trösten konnte Kolbenheyers autosuggestiver, biologistischer Zweckoptimismus den mit den Realitäten der NS-Hochschulpolitik unmittelbar konfrontierten Historiker freilich nicht; Kutzlebs nachfolgende Briefe blieben derselben pessimistischen Stimmung verhaftet wie das Schreiben vom Dezember 1940.

Aufschlussreich ist auch die innere Haltung, die Kolbenheyer jenem Personenkreis, der für das „deutsche Geisteswesen verantwortlich“ sei, während jenes Interregnums der Ungeistigkeit anempfahl. Kolbenheyer sprach hier von dem „,plasmatischen Auftrag““, so konsequent wie nur möglich an den eigenen Werken weiterzuarbeiten, das weitere jedoch auszublenden, auf dass der „erreichte Stand des Geistigen so gut als möglich [...] für eine kommende und bessere Gebrauchszeit"499 erhalten bleibe. Eine solche Mentalität duldsam-sturen Aus-

495 KAG, Erwin Guido Kolbenheyer an Hjalmar Kutzleb, 8. März 1943 (Durchschlag). Zur Behauptung eines deutschen „Präventivkriegs“ gegen die Sowjetunion vgl. Wegner, Präventivkrieg, sowie die Aufsätze in: Pietrow-Ennker (Hg.), Präventivkrieg?.

496 KAG, Erwin Guido Kolbenheyer an Hjalmar Kutzleb, 8. März 1943 (Durchschlag).

497 Vgl. KAG, Hjalmar Kutzleb an Erwin Guido Kolbenheyer, 29. Dezember 1940.

498 KAG, Erwin Guido Kolbenheyer an Hjalmar Kutzleb, 6. Januar 1941 (Durchschlag).

499 Ebd. 
harrens fiel Kolbenheyer freilich umso leichter, als er ein staatlich geförderter Autor mit enormen Einkünften war. ${ }^{500} \mathrm{Da}$ ihm zugleich innenpolitische Missstände, wie sie Kutzleb geschildert hatte, vor den Leistungen Hitlers zu verblassen schienen, ermunterte er den Historiker dazu, sich nicht nur auf das Kritikwürdige im NS-Staat zu konzentrieren, sondern auf das zu blicken,

„was politisch erreicht ist und vorerst erreicht werden mußte, wenn je an eine volksentsprechende Entwicklung gedacht werden soll. Ich bin der Überzeugung, daß ohne Hitler das deutsche Volk niemals oder nur nach langen, schmerzvollen Zeiten seine Wiederaufrichtung erlebt hätte. [...] Ist nicht immer und überall in der Weltgeschichte der Befreier dagewesen, wenn die Zeit erfüllt war? Ich glaube nicht an die Zufälle, sowenig ich an eine Vorherbestimmung glaube. “501

Diesen Glauben an Hitler und dessen vermeintlichen biologisch-historischen Auftrag hielt Kolbenheyer bis zuletzt aufrecht. Seine im Vergleich zu Stapel und Grimm deutlich stärkere Verstrickung mit dem „Dritten Reich“ - Stapel sprach nach 1945 privat auch von „weltanschauliche[n] Vorträgen“ Kolbenheyers auf „SS-Ordensburgen“502 - sollte auch Kolbenheyers Leben in der frühen Bundesrepublik maßgeblich bestimmen. Während Grimm und Stapel, deren propagandistischer Einsatz für das „Dritte Reich“ auf die Zeit vor dem Zweiten Weltkrieg konzentriert blieb, nach 1945 weitgehend ungeschoren davon kamen, erwies sich Kolbenheyers später Eintritt in der NSDAP als biografisch verhängnisvoll. Wie Grimm, Kolbenheyer und Stapel ihr jeweiliges Nachkriegsschicksal erlebten, wie sie ihre persönliche NS-Vergangenheit verarbeiteten, welche Möglichkeiten der Publizität ihnen nach 1945 noch offenstanden und wie sie außerhalb ihrer sukzessive schrumpfenden Basisklientel in der Bundesrepublik wahrgenommen wurden, wird Gegenstand der abschließenden Überlegungen sein.

500 Vgl. Wulf (Hg.), Kultur, Bd. 2, S. 108: „Selbstverständlich wurden Kolbenheyers Bücher auch vom Dritten Reich gefördert und deshalb gut abgesetzt. So hat Kolbenheyer beispielsweise für das Jahr 1941 dem Finanzamt hundertzwanzigtausend Mark zahlen müssen - laut Brief Kolbenheyers an das Präsidium der Reichskulturkammer vom 5. 5. 1942, in dem er sich für Steuererleichterungen ,prominenter Künstler' einsetzt“. 1937 hatte Kolbenheyer den Goethepreis der Stadt Frankfurt am Main erhalten, im Dezember 1938 wurde ihm anlässlich seines 60. Geburtstags durch Alfred-Ingemar Berndt, den Leiter der Abteilung „Schrifttum“ im Reichspropagandaministerium, und Hans Hagemeyer, den Leiter des Amts „Schrifttumspflege" im Amt Rosenberg, der Adlerschild des deutschen Reiches verliehen. Vgl. Die neue Literatur 38 (1937), S. 482; Die neue Literatur 40 (1939), S. 107.

501 KAG, Erwin Guido Kolbenheyer an Hjalmar Kutzleb, 6. Januar 1941 (Durchschlag).

502 DLA, A:Grimm, Wilhelm Stapel an Hans Grimm, 4. September 1946. Ein Motiv, warum Stapel diesen Sachverhalt an dieser Stelle hätte erfinden sollen, ist nicht erkennbar. Zwar war es im Zweiten Weltkrieg zu einem Konflikt zwischen Kolbenheyer und Stapel über Fragen der Religion gekommen (vgl. Kap. 6.1), die Annahme einer Art Rachebehauptung wäre jedoch völlig unplausibel. Einerseits versöhnten sich Stapel und Kolbenheyer kurze Zeit nach dem Brief an Grimm wieder, andererseits wiederholte Stapel seine Aussage anderthalb Jahre später. Vgl. DLA, A:Grimm, Wilhelm Stapel an Hans Grimm, 9. Januar 1948. 